\title{
Competencias lectoras y narrativas para el derecho
}

Jorge WITKER

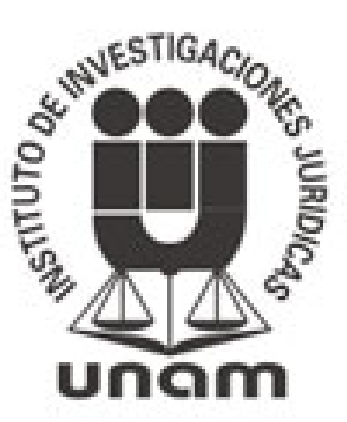

Universidad Nacional Autónoma de México Instituto de Investigaciones Jurídicas 
Licenciado en Ciencias Jurídicas y Sociales por la Universidad de Chile; Diplomado en Derecho Comparado por la Facultad Internacional para la Enseñanza del Derecho Comparado de Strasbur-

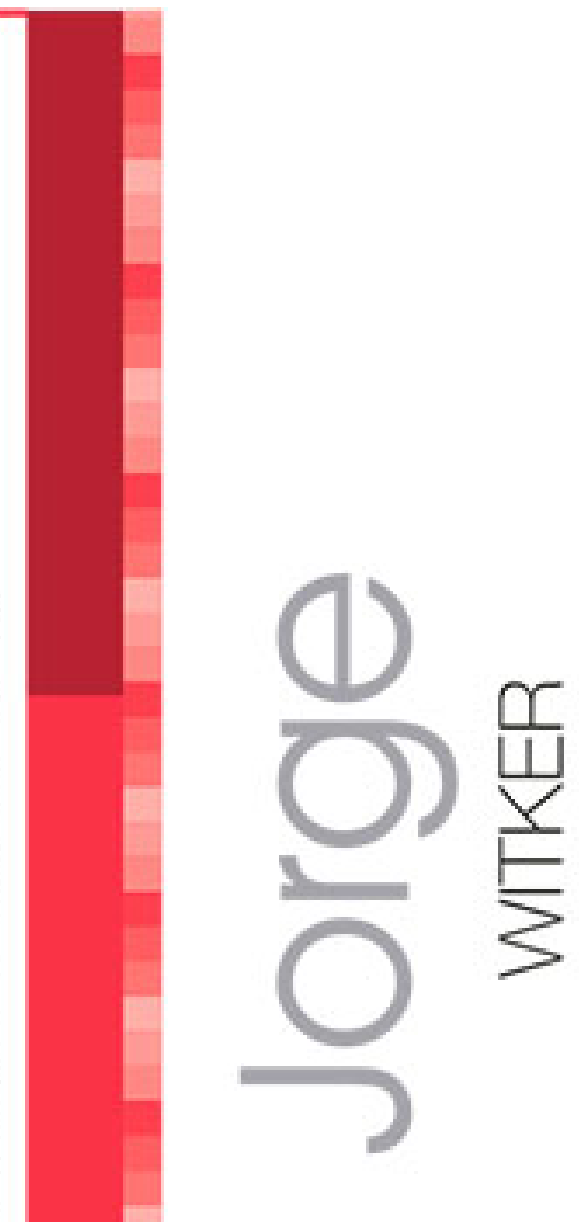

go; Doctorado en Derecho por la Universidad Complutense de Madrid.

Profesor de Derecho Económico y Comercio Exterior en la Facultad de Derecho de la UNAM e investigador en el Instituto de Investigaciones Jurídicas de la UNAM. Investigador Nacional Nivel III desde 1984. Actualmente es director del Seminario de Estudios sobre Comercio Exterior de la Facultad de Derecho de la UNAM.

Ha obtenido el Premio Universidad Nacional en Investigación en Ciencias Sociales 2000 y el Premio Nacional de Comunicación en el Área Jurídica de la Fundación José Pagés Llergo, 2011. Es miembro de la Academia Mexicana de las Ciencias.

Es autor de: La investigación jurídica, Metodología jurídica, Metodología de la enseñanza del derecho, El Tratado de Libre Comercio de América del Norte: diagnóstico y perspectivas jurídicas, Derecho tributario aduanero, Régimen jurídico del comercio exterior en México, Derecho de la competencia en América, Derecho de la competencia económica en el TLCAN, Derecho del comercio exterior, Derecho de la competencia económica en México, además de artículos y ensayos en revistas tanto de divulgación como cientíícas mexicanas y extranjeras.

Árbitro panelista de México en el TLCAN y del Centro Internacional de Arreglo de Diferencias Relativas a Inversiones del Banco Mundial. Consultor en Derecho de la Competencia Económica de la Organización de los Estados Americanos. 
COMPETENCIAS LECTORAS Y NARRATIVAS PARA EL DERECHO 
INSTITUTO DE INVESTIGACIONES JURÍDICAS

Serie DOCTRINA JURÍDICA, núm. 827

\author{
COORDINACIÓN EDITORIAL \\ Lic. Raúl Márquez Romero \\ Secretario técnico \\ Lic. Wendy Vanesa Rocha Cacho \\ Jefa del Departamento de Publicaciones
}

Ricardo Hernández Montes de Oca

Diseño de interiores, cuidado de la edición y formación en computadora 


\section{JORGE WITKER}

\section{COMPETENCIAS LECTORAS $Y$ NARRATIVAS PARA EL DERECHO}
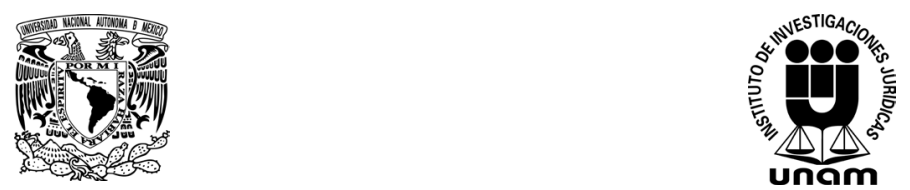

UNIVERSIDAD NACIONAL AUTÓNOMA DE MÉXICO INSTITUTO DE INVESTIGACIONES JURÍDICAS

MÉXICO, 2018 
Primera edición: 25 de abril de 2018

DR @ 2018. Universidad Nacional Autónoma de México

INSTITUTO DE INVESTIGACIONES JURÍDICAS

Circuito Maestro Mario de la Cueva s/n Ciudad de la Investigación en Humanidades

Ciudad Universitaria, 04510 Ciudad de México

Impreso y hecho en México

ISBN: 978-607-30-0260-8 


\section{CONTENIDO}

Introducción ................. XIII

\section{Ejercicios léxicos}

\section{Grupo 1}

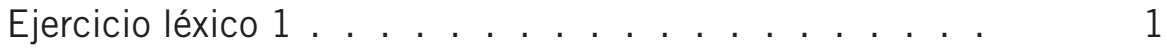

Ejercicio léxico 2 . . . . . . . . . . . . . . . . . . . . 4

Ejercicio léxico 3 . . . . . . . . . . . . . . . 5

Ejercicio léxico 4 . . . . . . . . . . . . . . . . . . . . . . . . . . . 4

Ejercicio léxico 5 . . . . . . . . . . . . . . . . . . . . 8

Ejercicio léxico 6. Crucigrama 1 . . . . . . . . . . . . . 9

Biografía 1. Marco Tulio Cicerón . . . . . . . . . . . . 10

Biografía 2. John Locke . . . . . . . . . . . . . . . . . 12

Grupo 2

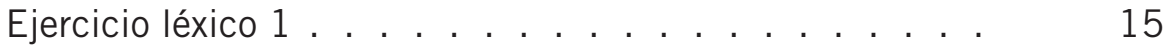

Ejercicio léxico 2 . . . . . . . . . . . . . . . . . . . . 17

Ejercicio léxico 3 . . . . . . . . . . . . . . . 18

Ejercicio léxico 4 . . . . . . . . . . . . . . . . . . . . . . 20

Ejercicio léxico 5 . . . . . . . . . . . . . . . . . . . . 21

Ejercicio léxico 6. Crucigrama 2 . . . . . . . . . . . . . 22

Biografía 3. John Marshall . . . . . . . . . . . . . 23

Biografía 4. Rudolf von Ihering . . . . . . . . . . . . . 25 


\section{Grupo 3}

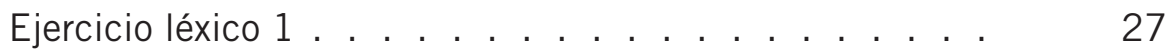

Ejercicio léxico 2 . . . . . . . . . . . . . . . . . . . . . . 29

Ejercicio léxico 3 . . . . . . . . . . . . . 30

Ejercicio léxico 4 . . . . . . . . . . . . . . . . . 32

Ejercicio léxico 5 . . . . . . . . . . . . . . . . . . . . 33

Ejercicio léxico 6. Crucigrama 3 . . . . . . . . . . . . 34

Biografía 5. Hans Kelsen . . . . . . . . . . . . . . . . 35

Biografía 6. Herbert Lionel Adolphus Hart . . . . . . . . 37

\section{Grupo 4}

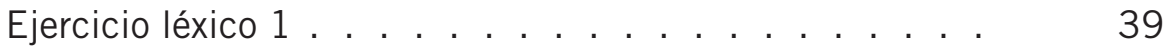

Ejercicio léxico 2 . . . . . . . . . . . . . . . . . . . . 41

Ejercicio léxico 3 . . . . . . . . . . . . . . 42

Ejercicio léxico 4 . . . . . . . . . . . . . . . . . . . . . 44

Ejercicio léxico 5 . . . . . . . . . . . . . . . . . . . 45

Ejercicio léxico 6. Crucigrama 4 . . . . . . . . . . . . 46

Biografía 7. John Rawls . . . . . . . . . . . . . . . . . 47

Biografía 8. Ronald M. Dworkin . . . . . . . . . . . . . 49

\section{Grupo 5}

Ejercicio léxico 1. . . . . . . . . . . . . . . . 51

Ejercicio léxico 2 . . . . . . . . . . . . . . . . . . . . . 53

Ejercicio léxico 3 . . . . . . . . . . . . . . . . . . . 54

Ejercicio léxico 4 . . . . . . . . . . . . . . 56

Ejercicio léxico 5 . . . . . . . . . . . . . . . . . . . . 57

Ejercicio léxico 6. Crucigrama 5 . . . . . . . . . . . . . 58

Bibiografía 9. Richard Allen Posner . . . . . . . . . . . 59

Biografía 10. Carlos Santiago Nino . . . . . . . . . . . 61

\section{Grupo 6}

Ejercicio léxico 1 . . . . . . . . . . . . . . 63

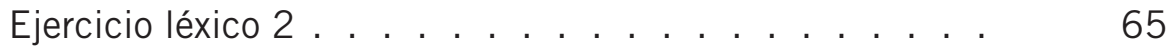


Ejercicio léxico 3 . . . . . . . . . . . . . . . . . . . 66

Ejercicio léxico 4 . . . . . . . . . . . . . . . . . . . . 68

Ejercicio léxico 5 . . . . . . . . . . . . . . . . . . . . 69

Ejercicio léxico 6. Crucigrama 6 . . . . . . . . . . . . 70

Biografía 11. Benito Juárez García . . . . . . . . . . . 71

Biografía 12. Sebastián Lerdo de Tejada . . . . . . . . . 74

\section{Grupo 7}

Ejercicio léxico 1 . . . . . . . . . . . . . . . . . . . . 77

Ejercicio léxico 2 . . . . . . . . . . . . . . . . . . . . 79

Ejercicio léxico 3 . . . . . . . . . . . . . . . 80

Ejercicio léxico 4 . . . . . . . . . . . . . . . . . . . . . . . . 82

Ejercicio léxico 5 . . . . . . . . . . . . . . . . . . . . 83

Ejercicio léxico 6. Crucigrama 7 . . . . . . . . . . . . 84

Biografía 13. Ignacio Luis Vallarta Ogazón . . . . . . . . 85

Biografía 14. Mario de la Cueva y de la Rosa . . . . . . . 88

\section{Grupo 8}

Ejercicio léxico 1 . . . . . . . . . . . . . . . . . . . . 91

Ejercicio léxico 2 . . . . . . . . . . . . . . . . . . . . . . . 93

Ejercicio léxico 3 . . . . . . . . . . . . . . . . . . . 94

Ejercicio léxico 4 . . . . . . . . . . . . . . . . . 96

Ejercicio léxico 5 . . . . . . . . . . . . . . . . . . . . . . . . 99

Ejercicio léxico 6. Crucigrama 8 . . . . . . . . . . . . . . 98

Biografía 15. Eduardo García Máynez . . . . . . . . . . 99

Biografía 16. Alfonso García Robles . . . . . . . . . . . 101

\section{Grupo 9}

Ejercicio léxico 1 . . . . . . . . . . . 103

Ejercicio léxico 2 . . . . . . . . . . . . . . . . . . . . 105

Ejercicio léxico 3 . . . . . . . . . . . . . . . . . 106

Ejercicio léxico 4 . . . . . . . . . . . . . . . . 108

Ejercicio léxico 5 . . . . . . . . . . . . . . . . . 109 
Ejercicio léxico 6. Crucigrama 9 . . . . . . . . . . . . . 110

Biografía 17. Héctor Fix-Zamudio . . . . . . . . . . . . 111

Biografía 18. Sergio García Ramírez . . . . . . . . . . . 113

Grupo 10

Ejercicio léxico 1. . . . . . . . . . . . . . 115

Ejercicio léxico 2 . . . . . . . . . . . . . . . . . . . 117

Ejercicio léxico 3 . . . . . . . . . . . . . . . 118

Ejercicio léxico 4 . . . . . . . . . . . . . . . . . . . . . 120

Ejercicio léxico 5 . . . . . . . . . . . . . . . . . . . 121

Ejercicio léxico 6. Crucigrama 10 . . . . . . . . . . 122

Biografía 19. Jorge Carpizo McGregor . . . . . . . . . . 123

Biografía 20. Eduardo Ferrer Mac-Gregor Poisot . . . . . 125

Ejercicios léxico-sintácticos. . . . . . . . . . . . . . . . 127

I. Adjetivos . . . . . . . . . . . . . . . . . . . . . . . 128

II. Frases. . . . . . . . . . . . . . . . . . . . . . . . 131

III. Adverbios y adjetivos . . . . . . . . . . . . . . . . . . 134

IV. Verbos y adverbios . . . . . . . . . . . . . . . . . . 137

V. Oraciones sustantivas . . . . . . . . . . . . . . . . . 140

\section{Lecturas}

Fragmentos de los textos base para la elaboración de los ejercicios

El derecho en el ámbito de las ciencias sociales. . . . . . 151

¿Es el derecho una ciencia? . . . . . . . . . . . . . . . 159

Jurisdicción . . . . . . . . . . . . . . . . . . . . . . 161

Del Estado liberal al Estado social y democrático de derecho 165

El control de convencionalidad. . . . . . . . . . . . . . 169

El acto administrativo . . . . . . . . . . . . . . . . . . 175 
Los pueblos indígenas en el constitucionalismo latinoamericano contemporáneo. . . . . . . . . . . . . . . . . .

Recursos genéticos y biopiratería . . . . . . . . . . . . 183

Derechos económicos, sociales y culturales. . . . . . . . 187

Cárdenas y el inicio de la economía mixta (Plan Sexenal) 191

La investigación jurídica. Elementos preliminares . . . . . 193

Problemas de transferencia de tecnología e inversión extranjera.

\section{Soluciones}

\section{Ejercicios léxicos}

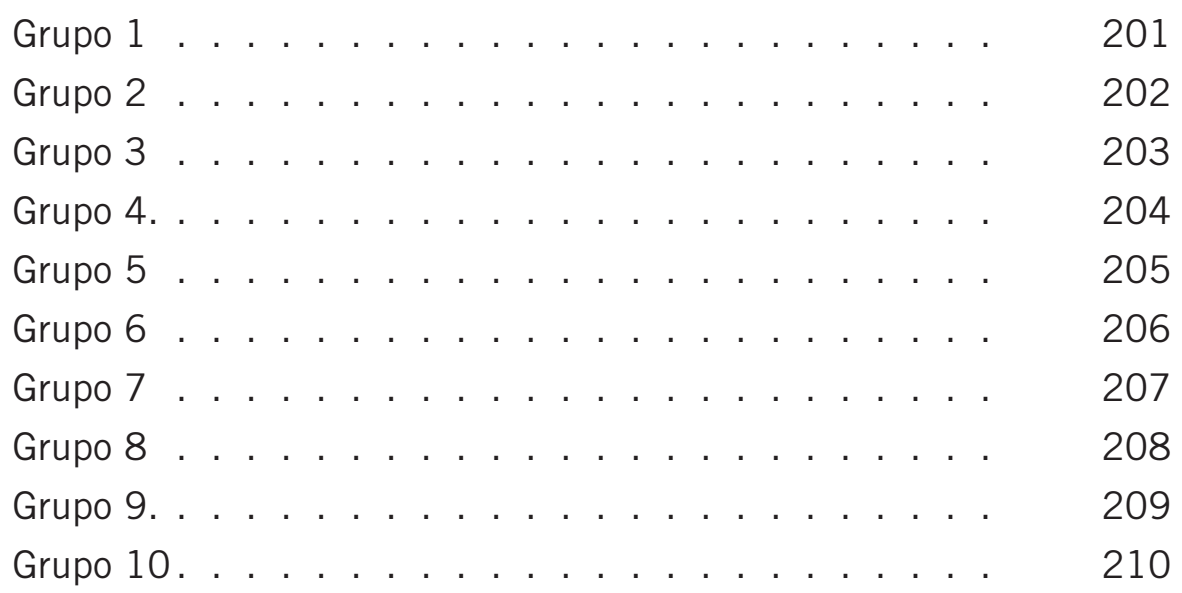

Ejercicios léxico-sintácticos

I. Adjetivos . . . . . . . . . . . . . . . . . . . . . . . 211

II. Frases. . . . . . . . . . . . . . . . . . . . . . . . 212

III. Adverbios y adjetivos. . . . . . . . . . . . . . . 213

IV. Verbos y adverbios.. . . . . . . . . . . . . . . . . . . . . . 214

V. Oraciones sustantivas . . . . . . . . . . . . . . . . . 216

Bibliografía. . . . . . . . . . . . . . . . . 219 


\section{INTRODUCCIÓN}

Una de las características centrales de la sociedad contemporánea es que nos encontramos en la llamada sociedad de la información que, a través de distintos procesos, transita hacia la sociedad del conocimiento.

Estos dos aspectos (información y conocimiento) plantean a la educación contemporánea desafíos no fáciles de procesar, y que impactan el contenido y temática del universo de las ciencias sociales.

En este escenario, que algunos autores califican de alta complejidad, las distintas disciplinas de las llamadas ciencias culturales, o ciencias humanas, deben construir distintos métodos y técnicas, para que el estudiante esté en condiciones y desarrolle competencias que puedan registrar, compendiar y asimilar contenidos que deben enfocarse desde la interdisciplinariedad, para dar cuenta de una realidad cambiante y en permanente mutación.

Uno de los dilemas de la educación contemporánea, en estos contextos, es equilibrar, por una parte, contenidos disciplinarios, con habilidades y destrezas capaces de identificar y detectar determinados léxicos conceptuales o herramientas, para unir, en lo posible, la teoría y la práctica como actividad cotidiana de los llamados procesos de aprendizaje.

En esta tesitura, el manejo del lenguaje, escrito y oral, conforma una materia prima esencial para capacitar y enseñar contenidos sociojurídicos en todo lo ancho que implica dicha expresión.

Una actividad básica para la asimilación y comprensión del lenguaje sociojurídico es la lectura, como proceso cognitivo, que coadyuva a transitar de simples vocablos o palabras, pasando a la construcción de frases y oraciones, culminando con la elaboración de discursos conceptuales y narrativas jurídicas.

Esta habilidad expositiva, que va de lo simple a lo complejo, conforma un estadio fundamental para introducir, ya en la elaboración de los discursos más acabados, la utilización de la argumentación jurídica como la vertiente fundamental para el discurso jurídico; es decir, sin registrar con propiedad el ejercicio de los vocablos individuales, 
Este libro forma parte del acervo de la Biblioteca Jurídica Virtual del Instituto de Investigaciones Jurídicas de la UNAM

vinculados o relacionados con las construcciones sintácticas de frases, y que culminen en párrafos de discursos construidos lógica y sintácticamente, es imposible utilizar la argumentación como una herramienta persuasiva que ayude a razonar y motivar la verdad jurídica en sus distintas manifestaciones (procesal, judicial, penal, así como en la investigación, etcétera).

A lo anterior, que sirve de base —además - a las comunicaciones científicas de las investigaciones sociojurídicas, estas habilidades y aprendizajes de construcción de discursos se vuelven elementos sustanciales para la expresión oral de los planteamientos jurídicos, en los distintos foros y escenarios en que se desenvuelve la actividad de los abogados, jueces, magistrados y juristas. Esta oralidad, como característica de las nuevas reformas procesales, en todas las ramas del derecho, no puede desarrollarse sin este tipo de ejercicios, que vienen a superar largamente las tradicionales inercias memorísticas con que, por largos años, se han desenvuelto las diversas profesiones jurídicas.

Este ensayo recoge la experiencia del libro Comprensión y redacción de textos de economía del profesor Ricardo Arriaga Campos, publicado por la Facultad de Economía de la UNAM en ediciones del 2013 y 2015, y derivado de un proyecto PAPIME de la UNAM, que aplicamos al campo jurídico.

En efecto, el texto que presentamos abarca tres secciones: 1) ejercicio de vocablos socio-jurídicos; 2) frases, oraciones y enunciados que utilizan los vocablos y coadyuvan a construir ideas relacionadas, y 3) comprensión de narrativas y discursos que permiten a los estudiantes comprenderlos para practicar razonamientos y argumentación jurídica que representa la actividad que suministra razones, a favor o en contra, de una tesis o fundamento que se sostiene o refuta.

Las tres secciones mencionadas, además de los ejercicios y crucigramas que contienen, se presentan con veinte biografías, al final de cada grupo, de juristas nacionales e internacionales, que han hecho significativos aportes a la ciencia del derecho.

Como material adicional a lo anterior, incorporamos fragmentos de textos, de donde derivan el vocabulario y las oraciones utilizadas en los ejercicios. Se trata de que los leas, pausadamente, y te familiarices con el lenguaje, las ideas, el estilo y recursos en la redacción, que se presentan en los autores mencionados, con la idea de que gradualmente adquieras las competencias para comprender y redactar discursos y narrativas jurídico-sociales. 
El libro culmina con las soluciones de los ejercicios que, lógicamente, debes consultar después que los hayas resuelto previamente, con el objetivo de que tu propio ensayo-error sea un estímulo para identificar palabras, elaborar frases y oraciones, y construir narrativas que, progresivamente, asimilarás.

El presente texto, de comprensión y adaptación a la ciencia jurídica, contó con el apoyo técnico-bibliográfico del licenciado Bernardo Toro Vera, a quien expreso mi gratitud y respeto.

Ciudad Universitaria, octubre de 2017 


\section{EJERCICIOS LÉXICOS}

\section{GRUPO 1}

Objetivos: Incrementar el vocabulario básico, y ampliarlo en la mente del estudiante, de manera que pueda entregarle competencias para desenvolverse de mejor forma en la aproximación y comprensión de textos.

Las soluciones respectivas, para mayor comprensión, que te permitirán comprobar tu avance, las podrás encontrar en el apartado correspondiente al final de este libro.

\section{Ejercicio léxico 1}

I. Observa bien las siguientes palabras:

1. Técnica

2. Listo

3. Métodos

4. Certeza

5. Conocimiento

6. Afinidad

7. Consecuencia

8. Lectura

9. Argumentos

10. Bondad

11. Jurisprudencia

12. Interés

13. Desarrollo

14. Conjunto

15. Enfoques

16. Escuela

17. Progreso
18. Abandonar

19. Durar

20. Convivencia

21. Perspectiva

22. Conferencia

23. Oración

24. Razón

25. Filosofía

26. Cultura

27. Dogmática

28. Literatura

29. Plausible

30. Confianza

31. Circunscribir

32. Facilidad

33. Científico

34. Variabilidad

II. Consulta en tu diccionario qué significan las palabras anteriores que ya observaste. 
Este libro forma parte del acervo de la Biblioteca Jurídica Virtual del Instituto de Investigaciones Jurídicas de la UNAM

III. De las palabras anteriores, selecciona la palabra o frase acorde al texto o al sentido expresado en el enunciado. ${ }^{1}$

Ejemplo: Los objetivos no eran nada de sencillos de considerando la dinámica seguida hasta entonces.

Solución: Los objetivos no eran nada de sencillos de alcanzar, considerando la dinámica seguida hasta entonces.

\section{Ejercicios}

1. En cuanto a la afirmación sobre el escaso progreso del derecho, ésta se puede desmentir fácilmente a la luz del dogmático en el derecho de las últimas décadas.

2. El debate sobre si el derecho es o no proviene del siglo XIX.

3. No se plantea en los del common law (ni se planteó tampoco, al menos como un problema importante, en la donde los juristas gozan de un prestigio indiscutido. romana),

4. No se pueden aplicar similares a los de las ciencias naturales, tales como la observación, la verificación y la experimentación.

5. Es un que no progresa en la misma medida que las ciencias naturales, y los resultados del derecho también carecen de utilidad porque son variables y poco certeros.

6. Von Kirchmann tenía razón -y la sigue teniendo- al sostener que la jurisprudencia no es una ciencia... la jurisprudencia es una

7. La variabilidad del objeto, la ausencia de la falta de certeza y de utilidad, impiden que el derecho sea ciencia.

8. "Tres palabras rectificadoras del legislador convierten bibliotecas enteras en basura"; a de ello es imposible aprehender el objeto.

1 Lo anterior, asumiendo que puedes adecuar la mejor conjugación verbal y la relación entre género y número, para dar a la frase un sentido coherente. 
Este libro forma parte del acervo de la Biblioteca Jurídica Virtual del Instituto de Investigaciones Jurídicas de la UNAM

9. La aparición de nuevas ramas del derecho, nuevos modelos de aproximación al estudio del derecho, nuevos y variados metodológicos y epistemológicos, etcétera.

10. Sobre la falta de certeza, se puede indicar que la indeterminación que pueda existir en la jurídica no siempre conduce a la duda absoluta ni tampoco puede calificarse de inútil.

11. Los de Kirchmann son los siguientes: es imposible que se pueda construir ciencia respecto de un objeto que carece de fijeza y permanencia.

12. El derecho no es un conocimiento inútil porque permite perfeccionar su objeto de estudio, el que cumple en la sociedad múltiples funciones sociales: estructurar la social, premiar o castigar conductas, promover el cambio social, etcétera.

13. Von Kirchmann pronunció una que llevaba el titulo de "La falta de valor de la jurisprudencia como ciencia", en la que negó rotundamente que lo que hacen los juristas pueda ser llamado ciencia.

14. El profesor Atienza, sin embargo, le da la a Von Kirchmann en un punto y considera que el asunto está mal planteado.

15. La auténtica raíz del problema es la falta de prestigio social de los juristas y de la labor teórica que desarrollan, carencia que se pretende superar usufructuando el rótulo de

16. La deliberación y discusión de argumentos entre los dogmáticos pueden encontrarse soluciones, si no sólidas al menos aceptables para los prácticos del derecho.

17. Nos encontramos, pues, con un nuevo caso de "definición persuasiva", como lo prueba el hecho de que la polémica ha quedado a los juristas de países de derecho continental.

18. Así sobre el problema de la del objeto, se puede decir que el carácter de científico de un conocimiento no reside exclusivamente en el objeto sino en el conocimiento mismo. 
Este libro forma parte del acervo de la Biblioteca Jurídica Virtual del Instituto de Investigaciones Jurídicas de la UNAM www.juridicas.unam.mx

\section{Ejercicio léxico 2}

Marca con una "X" la palabra que mejor consideres para la definición dada.

\section{Ejemplo:}

Modificar la apariencia, condición o comportamiento.

\begin{tabular}{|l|l|l|}
\hline Cambiar $(X)$ & Deber ( ) & Asumir ( ) \\
\hline
\end{tabular}

\section{Ejercicios}

1. Diligente, pronto, expedito.

\begin{tabular}{|l|l|l|}
\hline Efectivo ( ) & Prudente ( ) & Listo ( ) \\
\hline
\end{tabular}

2. Perteneciente o relativo a las aplicaciones de las ciencias y las artes.

\begin{tabular}{|c|c|c|}
\hline Técnica ( ) & Virtud ( ) & Carencia ( ) \\
\hline
\end{tabular}

3. Entendimiento, inteligencia, razón natural.

\begin{tabular}{|l|l|l|}
\hline Sentido ( ) & Razón ( ) & Conocimiento ( ) \\
\hline
\end{tabular}

4. Interpretación del sentido de un texto.

\begin{tabular}{|l|l|l|}
\hline Entendimiento ( ) & Lectura ( ) & Visión ( ) \\
\hline
\end{tabular}

5. Proximidad, analogía o semejanza de una cosa con otra.

\begin{tabular}{|l|l|l|}
\hline Afinidad ( ) & Empatía ( ) & Cercanía ( ) \\
\hline
\end{tabular}

6. Conjunto de las sentencias de los tribunales, y doctrina que contienen.

\begin{tabular}{|l|l|l|}
\hline Equidad ( ) & Jurisprudencia ( ) & Competencia ( )
\end{tabular}


Este libro forma parte del acervo de la Biblioteca Jurídica Virtual del Instituto de Investigaciones Jurídicas de la UNAM www.juridicas.unam.mx

7. Provecho, utilidad, ganancia.

\begin{tabular}{|c|c|c|}
\hline Bondad ( ) & Interés ( ) & Lucro ( ) \\
\hline
\end{tabular}

8. Hecho o acontecimiento que se sigue o resulta de otro.

\begin{tabular}{|l|l|l|}
\hline Consecuencia ( ) & Resultado ( ) & Finalidad ( ) \\
\hline
\end{tabular}

9. Exposición oral ante un público sobre un determinado tema de carácter didáctico o doctrinal.

\begin{tabular}{|l|l|l|}
\hline Oratoria ( ) & Reunión ( ) & Conferencia ( ) \\
\hline
\end{tabular}

10. Avance, adelanto, perfeccionamiento.

\section{Ejercicio léxico 3}

Anota la opción que consideres como mejor definición de las siguientes palabras:

\section{Ejemplo:}

Enfoque ( c )

a. Forma de considerar un asunto.

b. Contingencia o proximidad de un daño.

c. Acción o efecto de enfocar.

1. Bondad ( )
a. Pretensión de justicia.
b. Natural inclinación a hacer el bien.
c. Cualidad de amigable.

2. Convivir ( )

a. Ocupar espacio con amistades.

b. Entablar conversación con extraños.

c. Vivir en compañía de otro u otros. 
Este libro forma parte del acervo de la Biblioteca Jurídica Virtual del Instituto de Investigaciones Jurídicas de la UNAM

3. Escuela ( )

a. Lugar en donde se forman las personas.

b. Establecimiento público donde se da a los niños la instrucción primaria.

c. Sitio de acceso a los libros.

4. Dogmático ( )

a. Inflexible, que mantiene sus opiniones como verdades inconcusas.

b. Duro de la cabeza.

c. Permanente en sus logros.

5. Cultura ( )

a. Conocimientos que permite a alguien desarrollar su juicio crítico

b. Facultad de discernir sobre un respectivo tema.

c. Crítica de un pensamiento determinado.

6. Oración（ )

a. Relación de una frase respectiva.

b. Unión de palabras en un párrafo determinado.

c. Estructura gramatical formada por la unión de un sujeto y un predicado.

7. Conferencia ( )

a. Información otorgada ante un periodista.

b. Relación abreviada de un punto de vista.

c. Exposición oral ante un público sobre un determinado tema de carácter didáctico o doctrinal.

8. Confianza ( )

a. Posibilidad de pedir lo que se va a dar.

$b$. Esperanza firme que se tiene de alguien o algo.

c. Actitud de asombro ante un hecho posible. 
Este libro forma parte del acervo de la Biblioteca Jurídica Virtual del Instituto de Investigaciones Jurídicas de la UNAM

\section{Ejercicio léxico 4}

Haz una relación entre ambas columnas, trazando una línea entre el vocablo de la columna del lado izquierdo con la definición del lado derecho, que a tu juicio establezcan una relación correcta.

\begin{tabular}{|l|l|}
\hline \multicolumn{1}{|c|}{ Vocablo } & \multicolumn{1}{c|}{ Definición } \\
\hline Razón & 1. Dejar solo a alguien, dejando de cuidarle. \\
\hline Perspectiva & 2. Arte de la expresión verbal. \\
\hline Argumento & 3. Subsistir, permanecer. \\
\hline Literatura & $\begin{array}{l}\text { 4. Evolución de una economía hacia mejores } \\
\text { niveles de vida. }\end{array}$ \\
\hline Filosofía & 5. Acto de discurrir el entendimiento. \\
\hline Durar & $\begin{array}{l}\text { 6. Panorama de un objeto desde la posición } \\
\text { del espectador. }\end{array}$ \\
\hline Certeza & $\begin{array}{l}\text { 7. Conjunto de saberes que busca estable- } \\
\text { cer, racionalmente, los principios más gene- } \\
\text { rales sobre el conocimiento de la realidad, y } \\
\text { del sentido del obrar humano. }\end{array}$ \\
\hline Desarrollo & $\begin{array}{l}\text { 8. Razonamiento para probar o demostrar } \\
\text { una proposición, o para convencer de lo que } \\
\text { se afirma o se niega. }\end{array}$ \\
\hline Abandonar & \begin{tabular}{l} 
9. Conocimiento seguro y claro de algo. \\
\hline
\end{tabular}
\end{tabular}


Este libro forma parte del acervo de la Biblioteca Jurídica Virtual del Instituto de Investigaciones Jurídicas de la UNAM www.juridicas.unam.mx

\section{Ejercicio léxico 5}

En las columnas siguientes anota, en el casillero correspondiente, el sinónimo (es decir, la palabra más parecida), así como el correspondiente antónimo (es decir, la palabra que signifique lo contrario), que más te parezca, del vocablo de la columna izquierda, a partir del ejemplo que se muestra a continuación.

\begin{tabular}{|c|c|c|}
\hline Vocablo & Sinónimo & Antónimo \\
\hline Desmesurado & Excesivo & Insignificante \\
\hline Conjunto & & \\
\hline Circunscribir & & \\
\hline Listo & & \\
\hline Usar & & \\
\hline Conferencia & & \\
\hline Tomar & & \\
\hline Bondad & & \\
\hline Facilidad & & \\
\hline Duda & & \\
\hline Válido & & \\
\hline Tiene & & \\
\hline Complejo & & \\
\hline Neutro & & \\
\hline Directo & & \\
\hline Vinculado & & \\
\hline Activo & & \\
\hline Detener & & \\
\hline Prioridad & & \\
\hline Evolución & & \\
\hline Etéreo & & \\
\hline Acceso & & \\
\hline Comparar & & \\
\hline Reserva & & \\
\hline & & \\
\hline & & \\
\hline & & \\
\hline & & \\
\hline & & \\
\hline & & \\
\hline & & \\
\hline & & \\
\hline & & \\
\hline & & \\
\hline & & \\
\hline & & \\
\hline & & \\
\hline & & \\
\hline & & \\
\hline
\end{tabular}


Este libro forma parte del acervo de la Biblioteca Jurídica Virtual del Instituto de Investigaciones Jurídicas de la UNAM www.juridicas.unam.mx

\section{Ejercicio léxico 6}

Crucigrama 1

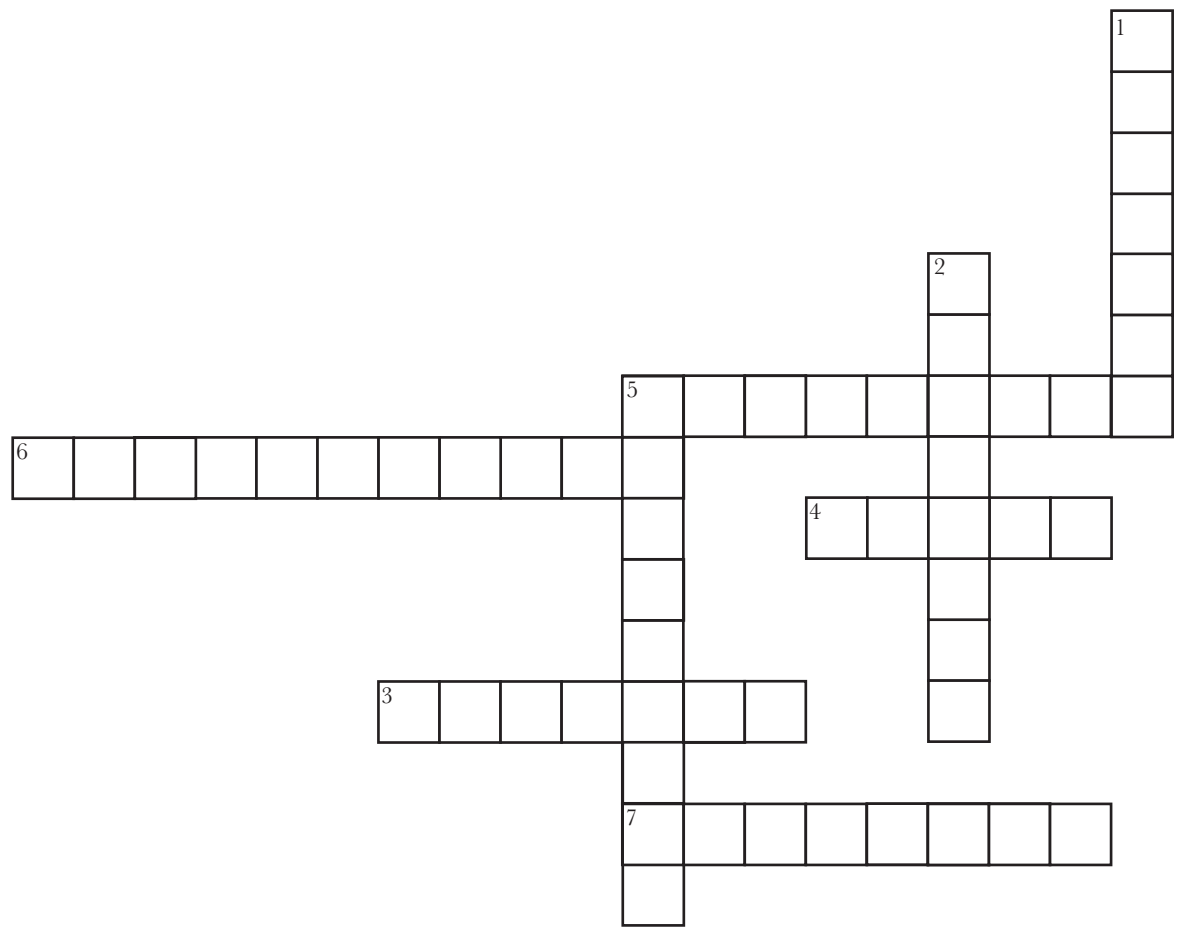

\section{Vertical}

1. Establecimiento o institución donde se dan o se reciben ciertos tipos de instrucción.

2. Acción de ir hacia delante.

5. Disposición para hacer algo sin gran trabajo.

\section{Horizontal}

3. Estructura gramatical formada por la unión de un sujeto y un predicado.

4. Subsistir, permanecer.

5. Manera de pensar o de ver las cosas.

6. Exposición oral ante un público sobre un determinado tema de carácter didáctico o doctrinal.

7. Proximidad, analogía o semejanza de una cosa con otra. 
Este libro forma parte del acervo de la Biblioteca Jurídica Virtual del Instituto de Investigaciones Jurídicas de la UNAM

\section{Biografía 1 Marco Tulio Cicerón}

Arpino, actual Italia, 3 de enero de 106 a.C.-Formia, 7 de diciembre del 43 a.C.

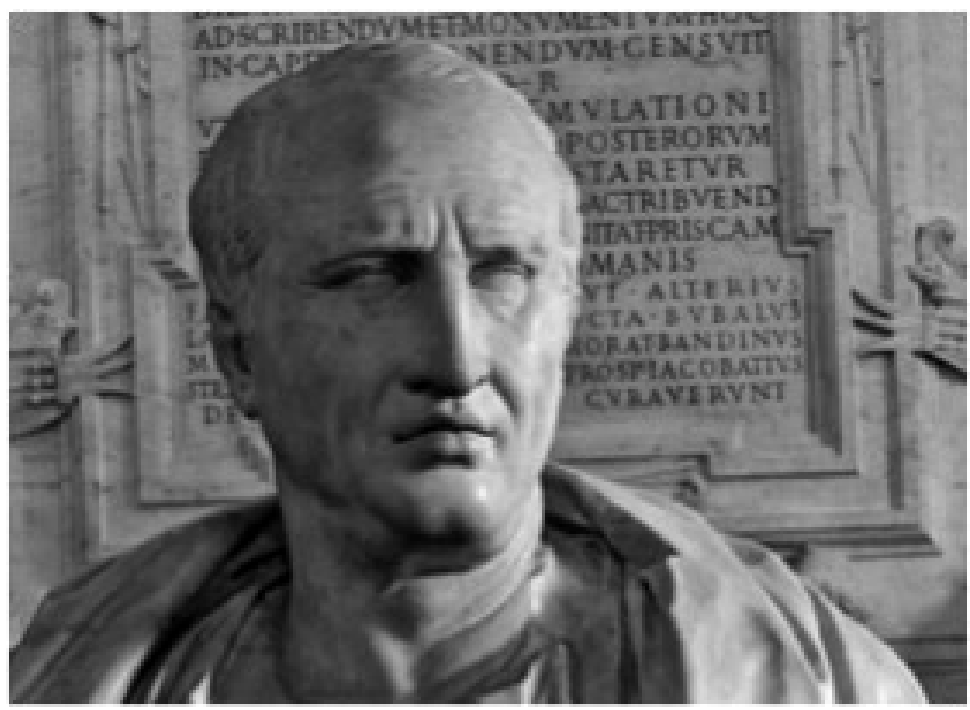

Escritor, político y orador romano. Cursó estudios de derecho, oratoria, literatura y filosofía en Roma. Después de una breve carrera militar y tres años de experiencia como abogado viajó a Grecia y Asia, donde continuó sus estudios. Regresó a Roma en el 77 a.C. y comenzó su carrera política.

En el 74 a.C. fue elegido miembro del Senado. Apoyado por los patricios en su candidatura al consulado en el 64 a.C. ante el otro candidato, Lucio Sergio Catilina. Elegido Cicerón, Catilina volvió a intentarlo al año siguiente con los mismos resultados. Entonces, organizó una conspiración para derribar el gobierno. Cicerón controló la situación, detuvo y ejecutó a varios de los partidarios de Catilina y a éste lo expulsó del Senado con una ardiente soflama conocida como Catilinarias. Fue criticado por Julio César y por otros senadores romanos que opinaban que había obrado con excesiva dureza, sin proporcionar las debidas garantías legales a los conspiradores. Por esto tuvo que partir como exiliado en el 58 a.C. 
Este libro forma parte del acervo de la Biblioteca Jurídica Virtual del Instituto de Investigaciones Jurídicas de la UNAM

Vivió un año en Macedonia, tras el que fue perdonado por el general romano Pompeyo el Grande. Hasta el 51 a.C. se dedicó a la literatura, pero aceptó el encargo de gobernar la provincia romana de Cilicia como procónsul. Un año después volvió a Roma, en el 50 a.C., y se unió a Pompeyo, que se había convertido en el mayor enemigo de Julio César. Cuando César derrotó a Pompeyo, en el 48 a.C., aceptó su amistad, aunque vivió apartado de la vida política mientras César fue dictador de Roma.

Tras el asesinato de César, ya en el 44 a.C., retornó a la política. Esperando ver la restauración de la República, apoyó a Octavio, más tarde el emperador Augusto, en sus luchas contra el cónsul romano Marco Antonio. A pesar de todo, Octavio y Marco Antonio se reconciliaron, y Cicerón fue ejecutado como enemigo del Estado el 7 de diciembre del 43 a.C. en Formia.

Entre sus obras destacan sus tratados De Legibus (Sobre las leyes), De Officiis (Sobre el deber), y De Natura Deorum (Sobre la naturaleza de los dioses). La más famosas de sus piezas de oratoria son las cuatro contra Catilina, conocidas por Catilinarias, y las catorce contra Marco Antonio conocidas por Filípicas. Entre las obras menores de Cicerón se encuentran los tratados De Senectute (Sobre la vejez) y De Amicitia (Sobre la amistad). 
Este libro forma parte del acervo de la Biblioteca Jurídica Virtual del Instituto de Investigaciones Jurídicas de la UNAM

\section{Biografía 2} JOHN LOCKE

Wrington, Somerset, 1632-Oaks, Essex, 1704

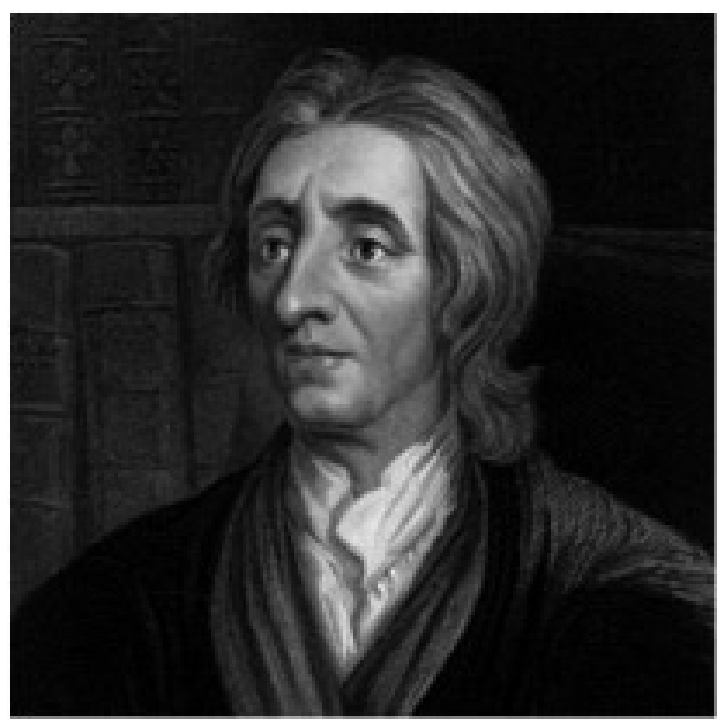

Pensador británico, uno de los máximos representantes del empirismo inglés, que destacó especialmente por sus estudios de filosofía política.

Polifacético, estudió en la Universidad de Oxford, en donde se doctoró en 1658. Aunque su especialidad era la medicina y mantuvo relaciones con reputados científicos de la época (como Isaac Newton), John Locke fue también diplomático, teólogo, economista, profesor de griego antiguo y de retórica, y alcanzó renombre por sus escritos filosóficos, en los que sentó las bases del pensamiento político liberal.

Locke fue uno de los grandes ideólogos de las elites protestantes inglesas que, agrupadas en torno a los whigs, llegaron a controlar el Estado en virtud de aquella revolución, y, en consecuencia, su pensamiento ha ejercido una influencia decisiva sobre la constitución política del Reino Unido hasta la actualidad. Defendió la tolerancia religiosa hacia todas las sectas protestantes e incluso a las religiones no cristianas; pero el carácter interesado y parcial de su liberalismo quedó de manifiesto al excluir del derecho a la tolerancia tanto a los ateos como a los católicos (siendo el enfrentamiento de estos últimos con los protes- 
Este libro forma parte del acervo de la Biblioteca Jurídica Virtual del Instituto de Investigaciones Jurídicas de la UNAM

tantes la clave de los conflictos religiosos que venían desangrando a las islas Británicas y a Europa entera).

En su obra más trascendente, Dos ensayos sobre el gobierno civil (1690), sentó los principios básicos del constitucionalismo liberal, al postular que todo hombre nace dotado de unos derechos naturales que el Estado tiene como misión proteger: fundamentalmente, la vida, la libertad y la propiedad. Partiendo del pensamiento de Thomas Hobbes, Locke apoyó la idea de que el Estado nace de un "contrato social" originario, rechazando la doctrina tradicional del origen divino del poder; pero, a diferencia de Hobbes, argumentó que dicho pacto no conducía a la monarquía absoluta, sino que era revocable y sólo podía conducir a un gobierno limitado.

Defendió la separación de poderes como forma de equilibrarlos entre sí e impedir que ninguno degenerara hacia el despotismo; pero, por inclinarse por la supremacía de un poder legislativo representativo de la mayoría, se puede también considerar a John Locke como un teórico de la democracia, hacia la que acabarían evolucionando los regímenes liberales. Por legítimo que fuera, sin embargo, ningún poder debería sobrepasar determinados límites (de ahí la idea de ponerlos por escrito en una Constitución). Este tipo de ideas inspirarían al liberalismo anglosajón (reflejándose puntualmente en las Constituciones de Gran Bretaña y Estados Unidos) y también, indirectamente, al del resto del mundo (a través de ilustrados franceses, como Montesquieu o Voltaire). 


\section{GRUPO 2}

Objetivos: Incrementar el vocabulario básico, y ampliarlo en la mente del estudiante, de manera que pueda entregarle competencias para desenvolverse de mejor forma en la aproximación y comprensión de textos.

Las soluciones respectivas, para mayor comprensión, que te permitirán comprobar tu avance, las podrás encontrar en el apartado correspondiente al final de este libro.

\section{Ejercicio léxico 1}

I. Observa bien las siguientes palabras:
1. Plenitud
15. Progresividad
2. Vaivén
16. Imperio
3. Estructura
17. Garantía
4. Complicidad
18. Perenne
5. Poder
19. Condición
6. Fundamental
20. Jurista
7. Democratización
21. Designación
8. Persuasión
22. Monarca
9. Potestad
23. Revolución
10. Sujeción
24. Sociedad
11. Estado
25. Ética
12. Unívoco
26. Primigenio
13. Idea
27. Elegir
14. Inflexivo

II. Consulta en tu diccionario qué significan las palabras anteriores que ya observaste. 
Este libro forma parte del acervo de la Biblioteca Jurídica Virtual del Instituto de Investigaciones Jurídicas de la UNAM

III. De las palabras anteriores, selecciona la palabra o frase acorde al texto o al sentido expresado en el enunciado.2

\section{Ejercicios}

1. El Estado moderno nace durante la llamada Baja Edad Media, bajo la premisa de los elementos esenciales que, con los respectivos blación". , se mantienen hasta hoy: "territorio", "soberanía", "po-

2. El concepto de Estado de derecho — como ya he mencionado- supone básicamente que el Estado se somete a la ley que él mismo impone a través de su ; ley que es obligatoria para todos, gobernantes y gobernados, en igualdad de condiciones, contrariamente a lo que ocurría en la monarquía absoluta.

3. Toda en que no esté establecida la garantía de los derechos, ni determinada la separación de poderes, carece de Constitución.

4. El concepto de Estado de derecho no significa que éste reglamente, mediante preceptos, la vida que en él se desarrolla, ni que limite sus fines a la realización del derecho, sino que tal Estado eleva el derecho a fundamental de su existencia.

5. Esta noción de concentración del poder en manos del rey, respecto de la población ubicada en un territorio determinado, se da como reacción a la atomización del político que había supuesto el carácter socioeconómico del feudalismo, así como beneficiado por la circunstancia histórica del fin de las Cruzadas.

6. Estado de derecho es la de la actividad estatal a la Constitución y a las normas aprobadas conforme a los procedimientos que ella establezca, que garantizan el cumplimiento responsable y controlado de los órganos del poder; el ejercicio de la autoridad conforme a disposiciones reconocidas y no retroactivas en términos perjudiciales, y la observancia de los derechos individuales, sociales, culturales y políticos.

7. El Estado (liberal) de derecho sólo permitía entregar y respetar, por parte del derechos y libertades civiles y políticas, sin

2 Lo anterior, asumiendo que puedes adecuar la mejor conjugación verbal y la relación entre género y número, para dar a la frase un sentido coherente. 
Este libro forma parte del acervo de la Biblioteca Jurídica Virtual del Instituto de Investigaciones Jurídicas de la UNAM

respetar necesariamente las condiciones de vida de los habitantes/ ciudadanos de cada país.

8. El Estado democrático y social de derecho es un Estado (sobre todo) democrático, en el que la democracia es entendida en dos sentidos armónicamente interrelacionados: democracia política como método de de los gobernantes y participación activa de los gobernados; y democracia social como la realización del principio de igualdad en la sociedad.

\section{Ejercicio léxico 2}

Marca con una "X" la palabra que mejor consideres para la definición dada.

1. Entendimiento, inteligencia, razón natural.

\begin{tabular}{l|l|l} 
Educación ( ) & Conocimiento ( ) & Asumir ( )
\end{tabular}

2. Índole, naturaleza o propiedad de las cosas.

\begin{tabular}{l|l|l} 
Raíz ( ) & Certeza ( ) & Condición ( )
\end{tabular}

3. Que tiene igual naturaleza o valor que otra cosa.

\begin{tabular}{|l|l|l|}
\hline Unívoco ( ) & Parecido ( ) & Específico ( ) \\
\hline
\end{tabular}

4. Persona que ejerce una profesión jurídica.

\begin{tabular}{|l|l|l} 
Profesionista ( ) & Jurista ( ) & Dirigente ( )
\end{tabular}

5. Que sirve de fundamento o es lo principal en algo.

\begin{tabular}{|l|l|l|}
\hline Real ( ) & Preciso ( ) & Fundamental ( ) \\
\hline
\end{tabular}

6. Variedad inestable de las cosas en su duración o logro.

\begin{tabular}{|l|l|l|}
\hline Vaivén ( ) & Duda ( ) & Precisión ( ) \\
\hline
\end{tabular}


Este libro forma parte del acervo de la Biblioteca Jurídica Virtual del Instituto de Investigaciones Jurídicas de la UNAM

7. Disposición o modo de estar relacionadas las distintas partes de un conjunto.

\begin{tabular}{|c|c|c|}
\hline Sistema ( ) & Estructura ( ) & Orden ( ) \\
\hline
\end{tabular}

8. Tener expedita la facultad o potencia de hacer algo.

\begin{tabular}{|c|c|c|}
\hline Razón ( ) & Facultado ( ) & Poder ( ) \\
\hline
\end{tabular}

9. Dominio, poder, jurisdicción o facultad que se tiene sobre algo.

\begin{tabular}{|c|c|c|}
\hline Virtud ( ) & Potestad ( ) & Cualidad ( ) \\
\hline
\end{tabular}

10. Forma de organización política, dotada de poder soberano e independiente, que integra la población de un territorio.

\begin{tabular}{|l|l|l|}
\hline Pueblo ( ) & Nación ( ) & Estado ( ) \\
\hline
\end{tabular}

\section{Ejercicio léxico 3}

Anota la opción que consideres como mejor definición de las siguientes palabras:

1. Elegir ( )
a. Asumir un cargo.
b. Escoger o preferir a alguien o algo para un fin.
c. Ser popular.

2. Sociedad ( )

a. Grupo de personas pertenecientes al ámbito civil.

b. Persona jurídica dedicada a asuntos mercantiles.

c. Agrupación natural o pactada de personas, organizada para cooperar en la consecución de determinados fines. 
Este libro forma parte del acervo de la Biblioteca Jurídica Virtual del Instituto de Investigaciones Jurídicas de la UNAM

3. Monarca ( )

a. Jefe del Estado de un reino, que ejerce normalmente la más alta representación de éste y que arbitra y modera el funcionamiento de sus instituciones, recibiendo y transmitiendo su cargo por sucesión hereditaria.

b. Club de fútbol mexicano.

c. Líder de una colonia.

4. Imperio ( )

a. Estructura internacional dedicada a la guerra.

b. Organización política del Estado regido por un emperador.

c. Conjunto de países agrupados para fines comunes.

5. Plenitud ( )

a. Gracia íntegra del alma.

b. Totalidad, integridad o cualidad de pleno.

c. Que no está incompleto.

6. Designación（ ）

a. Acto de señalar o destinar a alguien o algo para determinado fin.

b. Entrega de las credenciales de autoridad.

c. Posibilidad de mandar.

7. Sujeción（ ）

a. Sostener los pantalones.

b. Unión con que algo está sujeto de modo que no puede separarse, dividirse o inclinarse.

c. Apretar una cosa. 
Este libro forma parte del acervo de la Biblioteca Jurídica Virtual del Instituto de Investigaciones Jurídicas de la UNAM

\section{Ejercicio léxico 4}

Haz una relación entre ambas columnas, trazando una línea entre el vocablo de la columna del lado izquierdo con la definición del lado derecho, que a tu juicio establezcan una relación correcta.

\begin{tabular}{|c|c|}
\hline Vocablo & Definición \\
\hline Cómplice & $\begin{array}{l}\text { 1. Aprehensión o juicio que se forma en vir- } \\
\text { tud de un fundamento. }\end{array}$ \\
\hline Poder & $\begin{array}{l}\text { 2. Que sirve de fundamento o es lo principal } \\
\text { en algo. }\end{array}$ \\
\hline Persuasión & 3. Primitivo, originario. \\
\hline Fundamental & $\begin{array}{l}\text { 4. Tener expedita la facultad o potencia de } \\
\text { hacer algo. }\end{array}$ \\
\hline Democracia & 5. Recto, conforme a la moral. \\
\hline Ética & $\begin{array}{l}\text { 6. Variedad inestable o inconstancia de las } \\
\text { cosas en su duración o logro. }\end{array}$ \\
\hline Primigenio & $\begin{array}{l}\text { 7. Participante o asociado en crimen o culpa } \\
\text { imputable a dos o más personas. }\end{array}$ \\
\hline Vaivén & 8. Que avanza o aumenta gradualmente. \\
\hline Progresivo & $\begin{array}{l}\text { 9. Forma de gobierno en la que el poder polí- } \\
\text { tico es ejercido por los ciudadanos. }\end{array}$ \\
\hline
\end{tabular}




\section{Ejercicio léxico 5}

En las columnas siguientes anota, en el casillero correspondiente, el sinónimo (es decir, la palabra más parecida), así como el correspondiente antónimo (es decir, la palabra que signifique lo contrario), que más te parezca, del vocablo de la columna izquierda.

\begin{tabular}{|c|c|c|}
\hline Vocablo & Sinónimo & Antónimo \\
\hline Elegir & & \\
\hline Inflexivo & & \\
\hline Primigenio & & \\
\hline Monarca & & \\
\hline Unívoco & & \\
\hline Garantía & & \\
\hline Sujeción & & \\
\hline Progresivo & & \\
\hline Persuasión & & \\
\hline Vaivén & & \\
\hline Plenitud & & \\
\hline Poder & & \\
\hline Revolución & & \\
\hline
\end{tabular}


Este libro forma parte del acervo de la Biblioteca Jurídica Virtual del Instituto de Investigaciones Jurídicas de la UNAM www.juridicas.unam.mx

Ejercicio léxico 6

Crucigrama 2

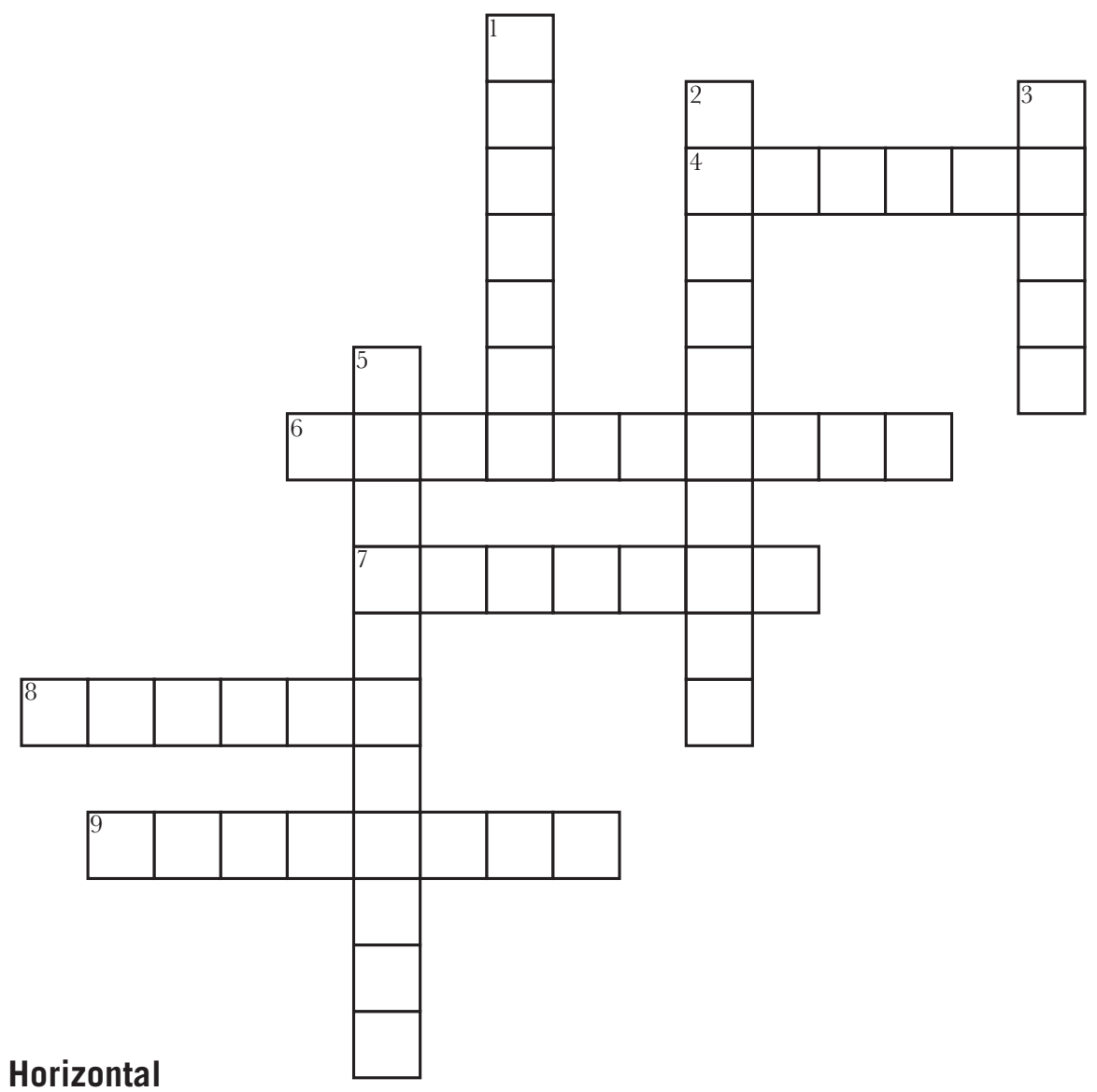

4. Organización jurídica de determinada sociedad.

6. Sistema de gobierno en donde se eligen las autoridades por votación popular.

7. Organización política del Estado regido por un emperador.

8. Variedad inestable o inconstancia de las cosas en su duración o logro.

9. Unión con que algo está sujeto de modo que no puede separarse, dividirse o inclinarse.

\section{Vertical}

1. Que tiene igual naturaleza o valor que otra cosa.

2. Acción y efecto de persuadir.

3. Tener expedita la facultad o potencia de hacer algo.

5. Proceso de elección de determinadas autoridades. 
Este libro forma parte del acervo de la Biblioteca Jurídica Virtual del Instituto de Investigaciones Jurídicas de la UNAM

\section{Biografía 3 \\ JOHN MARSHALL}

Germantown, Virginia, Estados Unidos, 24 de septiembre de 1755-Filadelfia, Pensylvania, Estados Unidos, 6 de julio de 1835

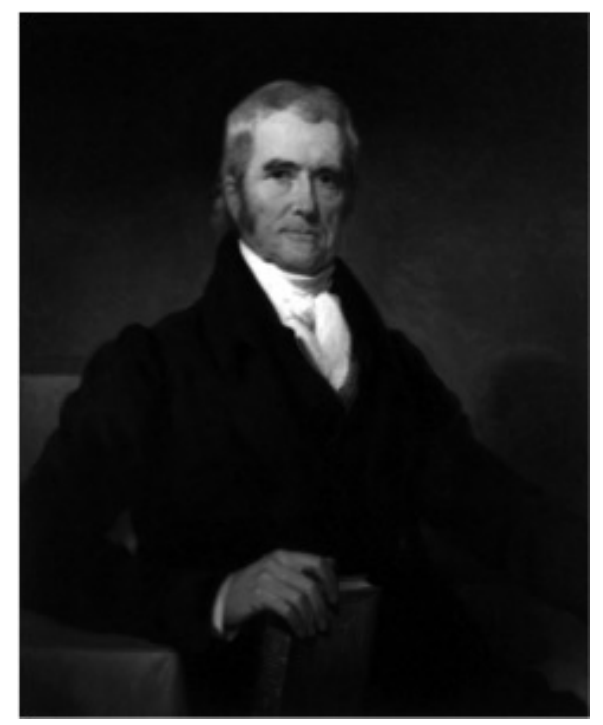

Fue un abogado, juez, político, diplomático, legislador, estadista, jurista y militar estadounidense; era originario de la Commonwealth de Virginia y líder del partido federalista.

En 1780, Marshall estudió derecho, asistiendo a una serie de conferencias del juez George Wythe en el College of William \& Mary en Williamsburg, Virginia, la única educación formal legal que recibiría Marshall, y pronto obtuvo una buena formación sobre el common law. Ese mismo año fue admitido a la barra de Virginia y comenzó su propia práctica legal. Construyó el éxito de su profesión de abogado por defender a los clientes contra los acreedores británicos que trataron de cobrar las deudas contraídas durante el dominio colonial británico, antes de la Revolución estadounidense de 1776.

Comenzó su carrera pública mediante la representación del condado de Fauquier en la Asamblea General por un solo término. En 1782, se incorporó a la Cámara de Delegados de Virginia, representando al condado de Henrico. Sería reelecto en 1787, y de nuevo en 1795. 
Este libro forma parte del acervo de la Biblioteca Jurídica Virtual del Instituto de Investigaciones Jurídicas de la UNAM

Compitió para el Ayuntamiento en 1785, quedando en segundo lugar, haciéndose registrador de la ciudad. Una de sus funciones de registrador de la ciudad era actuar como juez en la Corte de Hustings Richmond, donde conoció pequeños casos penales y civiles. A través de esta posición, Marshall estableció una reputación de ser un hombre justo y modesto que comunica con claridad y basa sus decisiones en el bien común.

En 1788, Marshall se convirtió en delegado a la Convención Estatal que se había formado para ratificar la Constitución de los Estados Unidos.

En 1801, se convirtió en juez presidente (Chief Justice) de la Corte Suprema de Estados Unidos, cargo que ocupó hasta su muerte, el 6 de julio de 1835, en Filadelfia, Pensilvania.

En dicho cargo le tocó conocer uno de los casos más trascendentales del constitucionalismo: Marbury vs. Madison, que estableció las bases de la revisión judicial. El caso llegó a la Suprema Corte estadounidense en 1803, a raíz de una historia hostil: hacia el final del mandato del presidente John Adams, mientras se desempeñaba como secretario de Estado, había nominado a William Marbury como juez de paz para el Distrito de Columbia; en lugar de decidir personalmente la comisión de Marbury, dado que el nombramiento había sido hecho a última hora, John Marshall abandonó el documento para su sucesor como secretario de Estado, James Madison; sin embargo, una vez que Thomas Jefferson (adversario político de Adams) asumió el cargo de presidente de los Estados Unidos, prohibió a Madison para entregar la comisión, ya que había sido redactado por los partidarios de Adams. Marbury respondió presentando una demanda, solicitando que el Tribunal Supremo emitiera una orden judicial que obligara a Madison para dar el encargo a Marbury.

Ante esto, y en su calidad de Chief Justice, dictaminó que el Tribunal Supremo carecía de poder para hacer que la mano de Madison sobre la comisión, aunque él pensaba que Marbury tenía derecho a tenerlo. En el proceso, Marshall determinó que el artículo 13 de la Ley de la Judicatura de 1789 (que autorizaba a la Corte Suprema para dictar órdenes a los funcionarios del gobierno) era inconstitucional. Además, llegó a la conclusión de que todas las leyes en conflicto con la Constitución deben ser, a partir de entonces, "nulas y sin valor". De este modo, Marshall instituyó el proceso de revisión judicial y, posteriormente, colocó a la rama judicial como igual ante sus pares del Legislativo y del Ejecutivo; además, sentó las bases de lo que conocemos como principio de supremacía constitucional. 
Este libro forma parte del acervo de la Biblioteca Jurídica Virtual del Instituto de Investigaciones Jurídicas de la UNAM

\section{Biografía 4 RUDOLF VON IHERING}

Aurich, actual Alemania, 22 de agosto de 1818-Gotinga, actual Alemania, 17 de septiembre de 1892

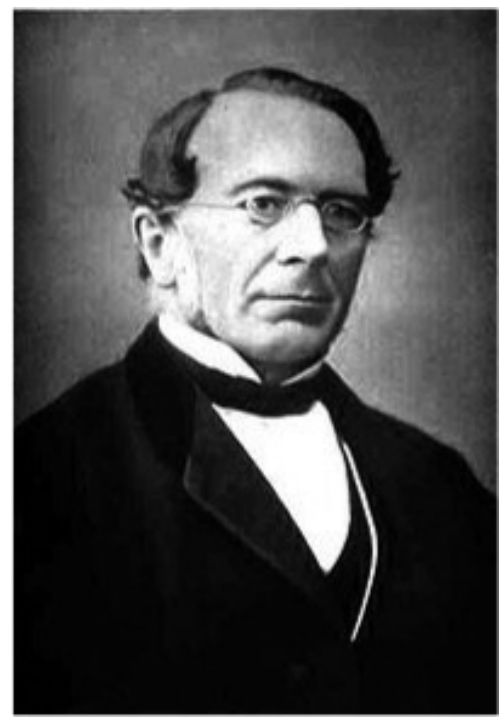

Ilustre jurista alemán, uno de los mayores filósofos del derecho de Europa y de la historia jurídica continental. Identificado inicialmente con la dogmática pandectística, fue después fundador y autor eminente de la sociología del derecho.

Sus teorías tuvieron gran trascendencia e influencia en el desarrollo de la doctrina jurídica moderna, especialmente en los campos del derecho civil, penal y constitucional.

Estudió jurisprudencia en las universidades de Heidelberg, Múnich, Gotinga y Berlín, donde se doctoró en 1842 con una Dissertatio de hereditate possidente, y en 1843 consiguió la habilitación como profesor de derecho romano. Su gran obra Disertaciones de derecho romano (1844) le valió la cátedra de la materia de la Universidad de Basilea, de la cual pasó a las de Rostock (1846), Kiel (1849), Giessen (1852) y, finalmente, Viena (1868); ello significó el mayor reconocimiento de su fama. 
Este libro forma parte del acervo de la Biblioteca Jurídica Virtual del Instituto de Investigaciones Jurídicas de la UNAM

Ejerció una gran influencia en el desarrollo de las doctrinas jurídicas modernas, al considerar el derecho más como un producto social que como una elaboración doctrinal.

En su libro El espíritu del derecho romano (1852) introduce la definición del derecho subjetivo como un interés jurídicamente protegido; posteriormente, en La lucha por el derecho (1872), y El fin en el derecho (1877), remarca que la finalidad es el elemento configurador de los institutos jurídicos y que el derecho se impone a través de la lucha.

Otras de sus obras son Broma y veras en la jurisprudencia (1884); a las cuales cabe añadir dos sobre la propiedad: Der Besitzwille (Jena, 1889) y Der Besitz (en Handwörterbuch der Staatswissenschaft, 1891), y algunos textos póstumos histórico-sociológicos que alcanzaron un éxito amplio y duradero. 


\section{GRUPO 3}

Objetivos: Incrementar el vocabulario básico, y ampliarlo en la mente del estudiante, de manera que pueda entregarle competencias para desenvolverse de mejor forma en la aproximación y comprensión de textos.

Las soluciones respectivas, para mayor comprensión, que te permitirán comprobar tu avance, las podrás encontrar en el apartado correspondiente al final de este libro.

\section{Ejercicio léxico 1}

I. Observa bien las siguientes palabras:
1. Palabra
16. Atención
2. Término
17. Controversia
3. Jurisdicción
18. Resolver
4. Último
19. Tribunales
5. Arbitraje
20. Delegada
6. Gobernados
21. Federación
7. Cúmulo
22. Militar
8. Precedente
23. Entidad
9. Decisión
24. Laudos
10. Materia
25. Improcedencia
11. Posibilidad
26. Concurrencia
12. Acuerdo
27. Local
13. Voluntaria
28. Trascender
14. Coactivamente
29. Instalar
15. Solución
30. Emitir

II. Consulta en tu diccionario qué significan las palabras anteriores que ya observaste. 
Este libro forma parte del acervo de la Biblioteca Jurídica Virtual del Instituto de Investigaciones Jurídicas de la UNAM

III. De las palabras anteriores, selecciona la palabra o frase acorde al texto o al sentido expresado en el enunciado. ${ }^{3}$

1. es la facultad que tiene el Estado para dirimir litigios de trascendencia jurídica, a través de alguno de sus órganos o por medio de árbitros, mediante la aplicación de normas jurídicas e individualizadas.

2. El arbitraje constituye un medio no judicial de de conflictos en virtud del cual, las partes, de común acuerdo, se someten a la decisión de un árbitro, el cual emite un laudo, no una sentencia.

3. Jurisdicción federal es la que corresponde a los juzgados y de la Federación, la local es la que ejercen los juzgados y tribunales estatales, así como de la Ciudad de México, y la concurrente supone la intervención, en la misma especie de asuntos, de órganos del Poder Judicial de la Federación y de la entidad federativa del territorio de que se trate.

4. El Estado cuenta, entre su cúmulo de atribuciones, con la de instalar órganos - precisamente llamados jurisdiccionales_ que se encargan de impartir justicia entre los

5. Existe la posibilidad de dirimir controversias a través del

6. Los arbitrajes en laboral constituyen un caso especial, ya que las Juntas de Conciliación y Arbitraje, aun cuando formalmente no son tribunales, cuentan con plena jurisdicción para emitir sus laudos y para hacerlos cumplir incluso coactivamente.

7. Esos órganos, por regla general, son públicos y pertenecen al Poder Judicial de la a los poderes judiciales locales, o bien, al Poder Ejecutivo, como en el caso del Tribunal Federal de Justicia Fiscal y Administrativa.

8. La jurisdicción tiene lugar cuando no hay una controversia a resolver.

3 Lo anterior, asumiendo que puedes adecuar la mejor conjugación verbal y la relación entre género y número, para dar a la frase un sentido coherente. 
Este libro forma parte del acervo de la Biblioteca Jurídica Virtual del Instituto de Investigaciones Jurídicas de la UNAM

\section{Ejercicio léxico 2}

Marca con una "X" la palabra que mejor consideres para la definición dada.

1. Determinación, resolución que se toma o se da en una cosa dudosa. Puntualidad ( ) Decisión ( ) Clasificación ( )

2. Poder que tienen los jueces y tribunales para juzgar y hacer ejecutar lo juzgado.

\begin{tabular}{|l|l|l|}
\hline Sentencia ( ) & Autoridad ( ) & Jurisdicción ( ) \\
\hline
\end{tabular}

3. Procedimiento extrajudicial para resolver conflictos de intereses mediante sometimiento de las partes, por mutuo acuerdo, a la decisión de uno o varios árbitros.

\begin{tabular}{l|l|l} 
Arbitraje ( ) & Convenio ( ) & Amistad ( )
\end{tabular}

4. Último momento de la duración o existencia de algo.

\begin{tabular}{|l|l|l|}
\hline Horario ( ) & Tiempo ( ) & Término ( ) \\
\hline
\end{tabular}

5. Aplicación de una resolución anterior en un caso igual o semejante al que se presenta.

\begin{tabular}{|l|l|l|}
\hline Ejecución ( ) & Precedente ( ) & Sentencia ( ) \\
\hline
\end{tabular}

6. Resolución que se toma en los tribunales, sociedades, comunidades u otros órganos.

\begin{tabular}{|l|l|l|}
\hline Acuerdo ( ) & Precisión ( ) & Razón ( ) \\
\hline
\end{tabular}

7. Poder legítimo del derecho para imponer su cumplimiento o prevalecer sobre su infracción.

\begin{tabular}{|l|l|l} 
Fuerza ( ) & Coacción（ ) & Intimidación ( )
\end{tabular}


Este libro forma parte del acervo de la Biblioteca Jurídica Virtual del Instituto de Investigaciones Jurídicas de la UNAM

\section{Ejercicio léxico 3}

Anota la opción que consideres como mejor definición de las siguientes palabras:

1. Voluntario ( )

a. Que tiene mucha voluntad.

b. Que pide siempre a cambio.

c. Que se hace por espontánea voluntad y no por obligación o debe.

2. Atención ( )

a. Acción de acoger favorablemente, o satisfacer un deseo, ruego o mandato.

b. Acción de tomar en cuenta cierta opinión.

c. Acción de efectuar cierta actividad.

3. Solución（ ）

a. Respuesta determinada.

b. Posibilidad llevada a la práctica.

c. Acción y efecto de resolver una duda, dificultad o problema.

4. Delegada ( )

a. Persona que tiene ciertas aptitudes.

$b$. Dicho de una persona: en quien se delega una facultad o jurisdicción.

c. Sujeto que es nominado a un cargo político.

5. Acuerdo ( )

a. Resolución que se toma en los tribunales, sociedades, comunidades u otros órganos.

$b$. Unión de decisiones dirigidas a un determinado fin.

c. Percepción que llega a la memoria de una persona. 
6. Tribunales ( )

a. Sede donde laboran los licenciados de derecho.

b. Espacio donde se dirige el tribuno a la gente.

c. Lugar destinado a los jueces para administrar justicia y dictar sentencias.

7. Federación（ ）

a. Reunión de grupos de personas con un objetivo en común.

b. Unión estable de Estados en la que la relación entre los miembros se ordena bajo los principios de unidad, autonomía, jerarquía y participación.

c. Acuerdo de autoridades en busca de soluciones determinadas. 
Este libro forma parte del acervo de la Biblioteca Jurídica Virtual del Instituto de Investigaciones Jurídicas de la UNAM

\section{Ejercicio léxico 4}

Haz una relación entre ambas columnas, trazando una línea entre el vocablo de la columna del lado izquierdo con la definición del lado derecho, que a tu juicio establezcan una relación correcta.

\begin{tabular}{|c|c|}
\hline Vocablo & Definición \\
\hline Instalar & $\begin{array}{l}\text { 1. Discusión de opiniones contrapuestas en- } \\
\text { tre dos o más personas. }\end{array}$ \\
\hline Cúmulo & $\begin{array}{l}\text { 2. Perteneciente o relativo a un territorio, a } \\
\text { una comarca o a un país. }\end{array}$ \\
\hline Militar & $\begin{array}{l}\text { 3. Poner en posesión de un empleo, cargo o } \\
\text { beneficio. }\end{array}$ \\
\hline Laudo & $\begin{array}{l}\text { 4. Colectividad considerada como unidad, y, } \\
\text { en especial, cualquier corporación, compa- } \\
\text { ñía, institución, etcétera, tomada como per- } \\
\text { sona jurídica. }\end{array}$ \\
\hline Materia & $\begin{array}{l}\text { 5. Solucionar un problema, una duda, una } \\
\text { dificultad o algo que los entraña. }\end{array}$ \\
\hline Controversia & $\begin{array}{l}\text { 6. Junta, unión o suma de muchas cosas no } \\
\text { materiales, como negocios, trabajos, razo- } \\
\text { nes, etcétera. }\end{array}$ \\
\hline Entidad & $\begin{array}{l}\text { 7. Conjunto de conocimientos que constitu- } \\
\text { yen un campo del saber, una disciplina cien- } \\
\text { tífica o una asignatura académica. }\end{array}$ \\
\hline Local & $\begin{array}{l}\text { 8. Decisión o fallo dictado por los árbitros o } \\
\text { amigables componedores, que pone fin al } \\
\text { procedimiento arbitral. }\end{array}$ \\
\hline Resolver & $\begin{array}{l}\text { 9. Perteneciente o relativo a la milicia o a la } \\
\text { guerra, por contraposición a lo civil. }\end{array}$ \\
\hline
\end{tabular}




\section{Ejercicio léxico 5}

En las columnas siguientes anota, en el casillero correspondiente, el sinónimo (es decir, la palabra más parecida), así como el correspondiente antónimo (es decir, la palabra que signifique lo contrario), que más te parezca, del vocablo de la columna izquierda.

\begin{tabular}{|c|c|c|}
\hline Vocablo & Sinónimo & Antónimo \\
\hline Acuerdo & & \\
\hline Voluntario & & \\
\hline Término & & \\
\hline Emitir & & \\
\hline Instalar & & \\
\hline Solución & & \\
\hline Posibilidad & & \\
\hline Improcedencia & & \\
\hline Controversia & & \\
\hline Trascender & & \\
\hline Precedente & & \\
\hline Último & & \\
\hline
\end{tabular}


Este libro forma parte del acervo de la Biblioteca Jurídica Virtual del Instituto de Investigaciones Jurídicas de la UNAM www.juridicas.unam.mx

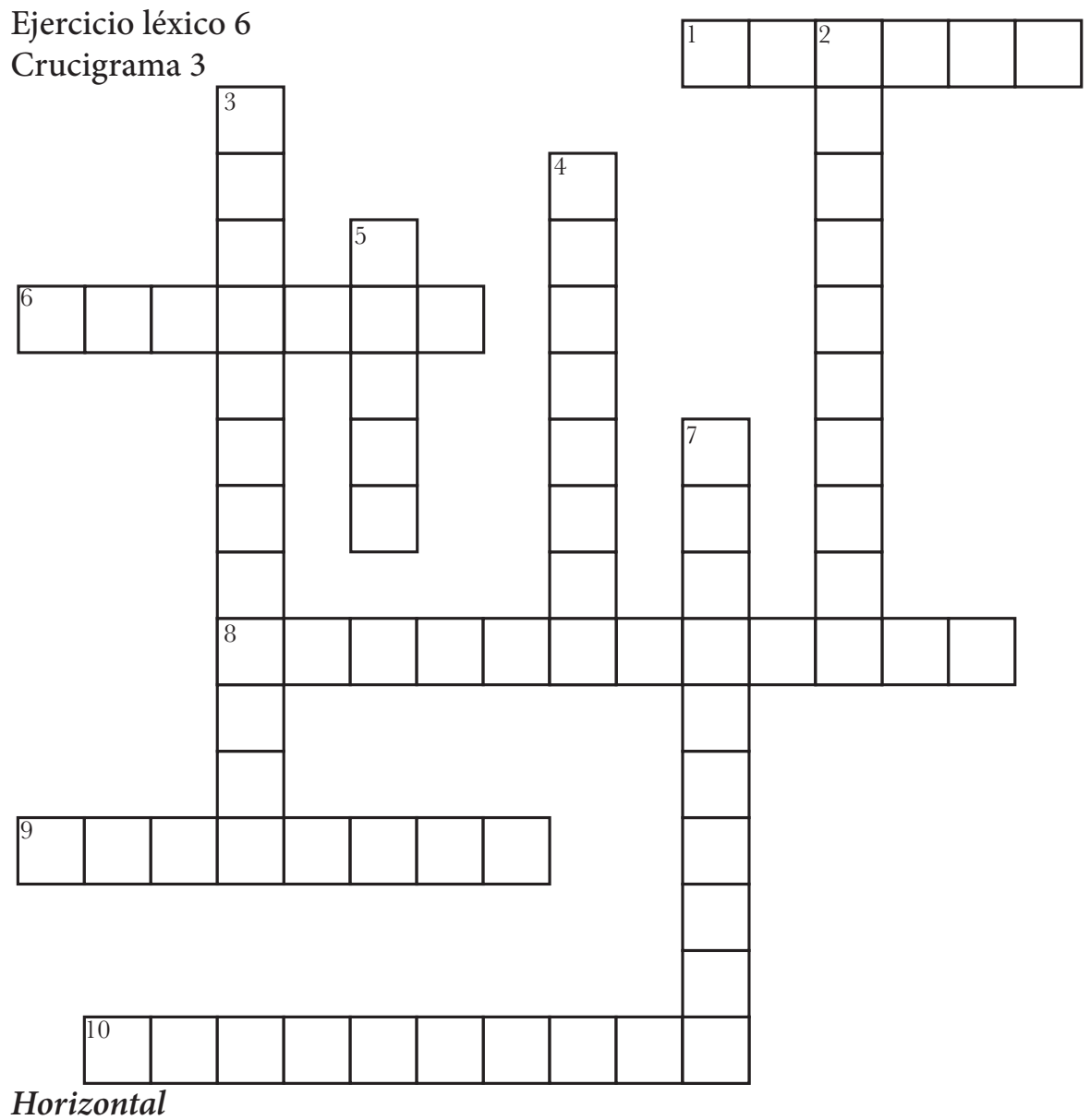

1. Que está al final de una línea, de una serie o de una sucesión.

6. Que profesa o ejerce la milicia.

8. Discusión de opiniones contrapuestas entre dos o más personas.

9. Cortesía, urbanidad, demostración de respeto u obsequio.

10. Acción y efecto de resolver una duda, dificultad o problema.

\section{Vertical}

2. Lugar destinado a los jueces para administrar justicia y dictar sentencias.

3. Poder que tienen los jueces y tribunales para juzgar y hacer ejecutar lo juzgado.

4. Que ejerce coacción o resulta de ella.

5. Decisión o fallo dictado por árbitros que pone fin al procedimiento arbitral.

7. Poder central de un Estado federal. 
Este libro forma parte del acervo de la Biblioteca Jurídica Virtual del Instituto de Investigaciones Jurídicas de la UNAM

\section{BIOgRAFÍA 5 \\ Hans Kelsen}

Praga, 11 de octubre de 1881-Berkeley, California, 19 de abril de 1973

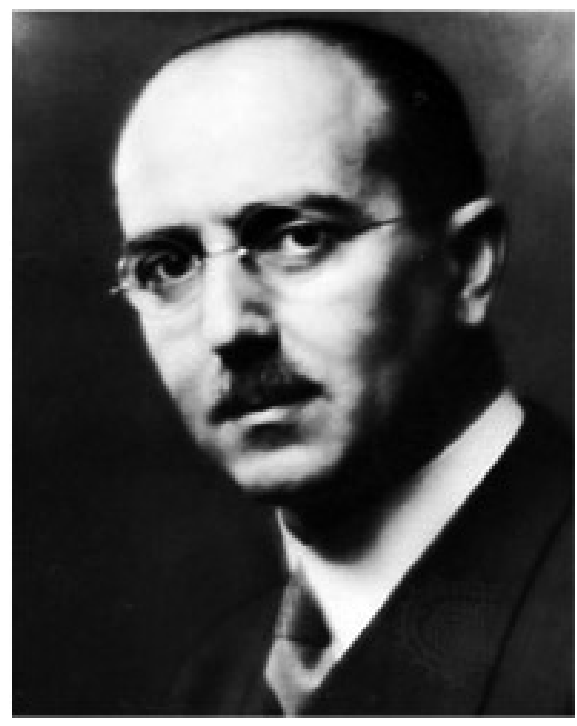

Jurista y filósofo austríaco, quizás el más influyente del siglo XX. Estudió derecho en la Universidad de Viena en 1911, ahí mismo completó su habilitación en derecho constitucional y filosofía del derecho. Cursó un seminario complementario en la Universidad de Heidelberg, bajo la dirección de Georg Jellinek.

Profesor de Filosofía del Derecho de la Universidad de Viena (desde 1917), Kelsen fue uno de los principales autores de la Constitución republicana y democrática que se dio Austria en 1920, tras su derrota en la Primera Guerra Mundial (1914-18) y la consiguiente disgregación del Imperio Austro-Húngaro. En 1929 pasó a la Universidad de Colonia, pero la ascensión de Hitler al poder le llevó a dejar Alemania (1933).

Tras unos años enseñando en la Universidad de Ginebra, pasó a la de Praga (1936). Finalmente, con el estallido de la Segunda Guerra Mundial (1939-45) decidió abandonar Europa, refugiándose en los Estados Unidos (1940). Allí ejerció la docencia en la Universidad de Harvard, de donde pasó a enseñar ciencia política en la de Berkeley (1942). 
Este libro forma parte del acervo de la Biblioteca Jurídica Virtual del Instituto de Investigaciones Jurídicas de la UNAM

Kelsen defendió una visión positivista que él llamó teoría pura del derecho: un análisis formalista del derecho como un fenómeno autónomo de consideraciones ideológicas o morales, del cual excluyó cualquier idea de «derecho natural». Analizando la estructura de los sistemas jurídicos llegó a la conclusión de que toda norma emana de una legalidad anterior, remitiendo su origen último a una norma hipotética fundamental que situó en el derecho internacional, aunque las opiniones más sesgadas aún la sitúan en la norma constitucional; de ahí que defendiera la primacía del derecho internacional sobre los ordenamientos nacionales.

Su concepción del derecho como técnica para resolver los conflictos sociales le convierte en uno de los principales teóricos de la democracia del siglo XX.

Entre sus obras destacan De la esencia y valor de la democracia (1920); Teoría general del Estado (1925) y Teoría pura del derecho, quizá la obra jurídica más influyente del siglo XX (1935). 
Este libro forma parte del acervo de la Biblioteca Jurídica Virtual del Instituto de Investigaciones Jurídicas de la UNAM

\section{Biografía 6}

Herbert Lionel Adolphus Hart

Harrogate, Reino Unido, 18 de julio de 1907-Oxford, Reino Unido, 19 de diciembre de 1992

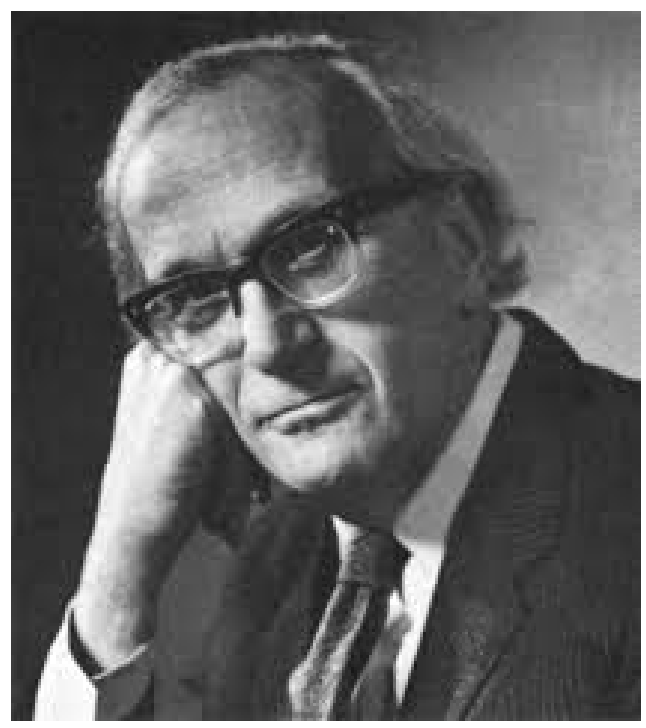

Uno de los filósofos del derecho más importantes del siglo XX. Estudió derecho en el New College (Universidad de Oxford) del cual se graduó en 1932.

En un principio se dedicó a ejercer la profesión en forma privada. La mayoría de los más prestigiosos abogados y jueces ingleses habían hecho eso y, como consecuencia, no habían obtenido grado de licenciatura en derecho o educación jurídica universitaria. De este modo, Hart fue llamado a The Bar en 1932 y se dedicó por ocho años a la práctica de la profesión como Chancery Barrister, en Londres.

Con el comienzo de la Segunda Guerra Mundial, ingresa a trabajar en el Servicio de Inteligencia Británico (MI5), en donde compartió labores con otros filósofos oxonienses como Gilbert Ryle y Stuart Newton Hampshire. Con el fin de la contienda, Hart pasa a desempeñarse como académico en Oxford, donde ocupó la cátedra de jurisprudencia. Además, fue profesor visitante en varias universidades estadounidenses, y principal de Brasenose College. 
Este libro forma parte del acervo de la Biblioteca Jurídica Virtual del Instituto de Investigaciones Jurídicas de la UNAM

En 1959 publica, junto con A. M. Honoré, Causation in Law; en 1961 publica su trabajo más importante: The Concept of Law (El concepto del derecho).

Hart se inscribe en la corriente de pensamiento positivista, llamada jurisprudencia analítica, para la cual el análisis del lenguaje resulta un elemento fundamental, a fin de una mejor comprensión del derecho.

La obra de Hart es sin duda una de la más influyente en la filosofía analítica jurídica del siglo XX, sobre todo si la comparamos, en el ámbito del derecho anglosajón, con Ronald Dworkin, su contradictor más famoso, sobre todo en lo que se refiere a incluir nuevos elementos en el ejercicio jurídico, como es el papel activo del Estado para la operatividad de los derechos individuales.

Hart dio un nuevo impulso a los estudios analíticos. Su formación universitaria no jurídica y su conocimiento de la filosofía analítica cultivada en Oxford desde principios de siglo constituirán una de las claves de su éxito. A esto se añade que Hart tenía un conocimiento práctico del derecho por su trabajo como abogado, lo cual le permitió también llevar a cabo con conocimiento de causa una crítica de las explicaciones usuales en jurisprudencia analítica. La característica distintiva de este impulso a los estudios analíticos estriba en que Hart aportó al campo de la filosofía jurídica nuevas herramientas de análisis, que ofrecieron la posibilidad de una mejor comprensión del papel múltiple que en la vida social cumplen los términos y expresiones del derecho, y de una inteligencia más clara de las relaciones que exhiben los fenómenos a que se alude con las palabras "derecho", "coacción" y "moral". Al mismo tiempo, clarificó el significado preciso de las objeciones formuladas contra el enfoque analítico y de los debates suscitados en torno a esas objeciones.

Otros textos destacados de Hart son: Law, Liberty and Morality (1963); Punishment and Responsibility. Essays in the Philosophy of Law (1968); Essays on Bentham. Jurisprudence and Political Theory (1982), Essays on Jurisprudence and Philosophy (1983) y Poscript (1994, agregado en la segunda edición de The Concept of Law). 


\section{GRUPO 4}

Objetivos: Incrementar el vocabulario básico, y ampliarlo en la mente del estudiante, de manera que pueda entregarle competencias para desenvolverse de mejor forma en la aproximación y comprensión de textos.

Las soluciones respectivas, para mayor comprensión, que te permitirán comprobar tu avance, las podrás encontrar en el apartado correspondiente al final de este libro.

\section{Ejercicio léxico 1}

I. Observa bien las siguientes palabras:
1. Definición
2. Implica
3. Oficina
4. Prohibición
5. Naciones Unidas
6. Acierto
7. Trabajo
8. Acceso
9. Comisionado
10. Vida
11. Legislación
12. Investigaciones
13. Reproductiva
14. Superior
15. Codificación

16. Organizaciones

17. Acceso

18. Sociales

19. Beneficios

20. Condiciones

21. Vestido

22. Vivienda

23. Individuos

24. Enseñanza

25. Compartir

26. Relacionar

27. Participar

28. Mencionar

29. Comunicar

30. Convenio

II. Consulta en tu diccionario qué significan las palabras anteriores que ya observaste. 
Este libro forma parte del acervo de la Biblioteca Jurídica Virtual del Instituto de Investigaciones Jurídicas de la UNAM

III. De las palabras anteriores, selecciona la palabra o frase acorde al texto o al sentido expresado en el enunciado. ${ }^{4}$

1. El Comité de la ONU hace las necesarias y emite un dictamen, junto con recomendaciones.

2. Los derechos económicos, y culturales son los derechos humanos relacionados con el lugar de trabajo, la seguridad social, la vida en familia, la participación en la vida cultural y el acceso a la vivienda, la alimentación, el agua, la atención de la salud y la educación.

3. El fundamento de la supranacional de los derechos económicos, sociales y culturales (DESC) es la Declaración Universal de los Derechos Humanos de 1948.

4. Protección de la salud sexual y

5. No hay una definición única de lo que cada uno de los derechos mencionados , ya que depende de la legislación nacional de cada país, y/o de los convenios y otros instrumentos internacionales vigentes.

6. En materia de derechos humanos, existe la Oficina del Alto Comisionado de las para los Derechos Humanos.

7. Los , grupos de personas u organizaciones que los representan pueden presentar "comunicaciones" al Comité por violaciones de los derechos económicos, sociales y culturales enunciados en el Pacto DESC.

4 Lo anterior, asumiendo que puedes adecuar la mejor conjugación verbal y la relación entre género y número, para dar a la frase un sentido coherente. 
Este libro forma parte del acervo de la Biblioteca Jurídica Virtual del Instituto de Investigaciones Jurídicas de la UNAM www.juridicas.unam.mx

\section{Ejercicio léxico 2}

Marca con una "X" la palabra que mejor consideres para la definición dada.

1. Conjunto de conocimientos, principios, ideas, etcétera, que se enseñan a alguien.

\begin{tabular}{|l|l|l} 
Enseñanza ( ) & Método ( ) & Disciplina ( )
\end{tabular}

2. Encontrar la solución o la respuesta correcta a un problema o a una incógnita.

\begin{tabular}{|l|l|l|}
\hline Resolver ( ) & Acertar ( ) & Encontrar ( ) \\
\hline
\end{tabular}

3. Organización mundial de los países para la promoción de la paz, la seguridad y la cooperación internacional

\begin{tabular}{|c|c|c|}
\hline ONU ( ) & OMS ( ) & OIT ( ) \\
\hline
\end{tabular}

4. Departamento donde trabajan los empleados públicos o particulares.

\begin{tabular}{|c|c|c|}
\hline Sede $($ ) & Casa matriz ( ) & Oficina ( ) \\
\hline
\end{tabular}

5. Energía de los seres orgánicos.

\begin{tabular}{|l|l|l} 
Fotosíntesis ( ) & Vida ( ) & Capacidad ( )
\end{tabular}

6. Consentir en lo que alguien solicita o quiere.

\begin{tabular}{|l|l|l|}
\hline Acceder ( ) & Posibilitar ( ) & Permitir ( ) \\
\hline
\end{tabular}

7. Encargado de una comisión

\begin{tabular}{|l|l|l} 
Comisionado ( ) & Designado ( ) & Mandatado ( )
\end{tabular}

8. Que es más que algo o alguien en cualidad o cantidad.

\begin{tabular}{|l|l|l|}
\hline Monarca ( ) & Autoridad ( ) & Superior ( ) \\
\hline
\end{tabular}


9. Cosa que es resultado de la actividad humana.

\begin{tabular}{|l|l|l|}
\hline Efecto ( ) & Trabajo ( ) & Potencia ( ) \\
\hline
\end{tabular}

10. Prenda o conjunto de prendas exteriores con que se cubre el cuerpo.

\begin{tabular}{|l|l|l|}
\hline Vestido ( ) & Pantalón ( ) & Tela ( ) \\
\hline
\end{tabular}

\section{Ejercicio léxico 3}

Anota la opción que consideres como mejor definición de las siguientes palabras:

\section{Definir ( )}

a. Dar cierta idea de un problema.

b. Decidir, determinar, resolver algo dudoso.

c. Establecer una solución difícil.

2. Beneficios ( )
a. Gratificación por la ayuda brindada.
b. Resultado de cualquier acción.
c. Bien que se hace o se recibe.

3. Individuo ( )
a. Cada ser organizado, sea animal o vegetal, respecto de la espe- cie a que pertenece.
b. Miembro de la naturaleza humana.
c. Todos los vertebrados vivientes.

4. Compartir ( )
a. Entregar lo de cada uno.
b. Permitir acceso a bienes.
c. Repartir, dividir, distribuir algo en partes. 
5. Organización ( )
a. Asociación de personas regulada por un conjunto de normas en función de determinados fines.
b. Estructura de cualquier cuerpo social, sin finalidad alguna.
c. Conjunción de fines comunes.

6. Vivienda ( )
a. Espacio de encuentro de personas.
b. Punto de reunión de una comunidad.
c. Lugar cerrado y cubierto construido para ser habitado por per- sonas.

7. Condición ( )
a. Posición en una sociedad determinada.
b. Índole, naturaleza o propiedad de las cosas.
c. Estado en que se encuentra una cosa. 
Este libro forma parte del acervo de la Biblioteca Jurídica Virtual del Instituto de Investigaciones Jurídicas de la UNAM

\section{Ejercicio léxico 4}

Haz una relación entre ambas columnas, trazando una línea entre el vocablo de la columna del lado izquierdo con la definición del lado derecho, que a tu juicio establezcan una relación correcta.

\begin{tabular}{|c|c|}
\hline Vocablo & Definición \\
\hline Implicar & $\begin{array}{l}\text { 1. Descubrir, manifestar o hacer saber a al- } \\
\text { guien algo. }\end{array}$ \\
\hline Comunicar & $\begin{array}{l}\text { 2. Índole, naturaleza o propiedad de las co- } \\
\text { sas. }\end{array}$ \\
\hline Investigación & $\begin{array}{l}\text { 3. Establecer relación entre personas, cosas, } \\
\text { ideas o hechos. }\end{array}$ \\
\hline Codificación & $\begin{array}{l}\text { 4. Hacer que alguien o algo participe o se } \\
\text { interese en un asunto. }\end{array}$ \\
\hline Convenio & $\begin{array}{l}\text { 5. Volver a hacer presente lo que antes se } \\
\text { dijo y alegó. }\end{array}$ \\
\hline Reproducir & 6. Hacer mención de alguien o algo. \\
\hline Condición & 7. Acuerdo o pacto. \\
\hline Mencionar & $\begin{array}{l}\text { 8. Acción de realizar actividades intelectuales } \\
\text { y experimentales de modo sistemático con el } \\
\text { propósito de aumentar los conocimientos so- } \\
\text { bre una determinada materia. }\end{array}$ \\
\hline Relacionar & $\begin{array}{l}\text { 9. Acción de hacer o formar un cuerpo de } \\
\text { leyes metódico y sistemático. }\end{array}$ \\
\hline
\end{tabular}


Este libro forma parte del acervo de la Biblioteca Jurídica Virtual del Instituto de Investigaciones Jurídicas de la UNAM www.juridicas.unam.mx

\section{Ejercicio léxico 5}

En las columnas siguientes anota, en el casillero correspondiente, el sinónimo (es decir, la palabra más parecida), así como el correspondiente antónimo (es decir, la palabra que signifique lo contrario), que más te parezca, del vocablo de la columna izquierda.

\begin{tabular}{|c|c|c|}
\hline Vocablo & Sinónimo & Antónimo \\
\hline Mencionar & & \\
\hline Vida & & \\
\hline Vestir & & \\
\hline Individuo & & \\
\hline Participar & & \\
\hline Acceder & & \\
\hline Organizar & & \\
\hline Definir & & \\
\hline Comunicar & & \\
\hline Superior & & \\
\hline Enseñar & & \\
\hline Acertar & & \\
\hline Trabajar & & \\
\hline Beneficiar & & \\
\hline Prohibir & & \\
\hline
\end{tabular}


Este libro forma parte del acervo de la Biblioteca Jurídica Virtual del Instituto de Investigaciones Jurídicas de la UNAM

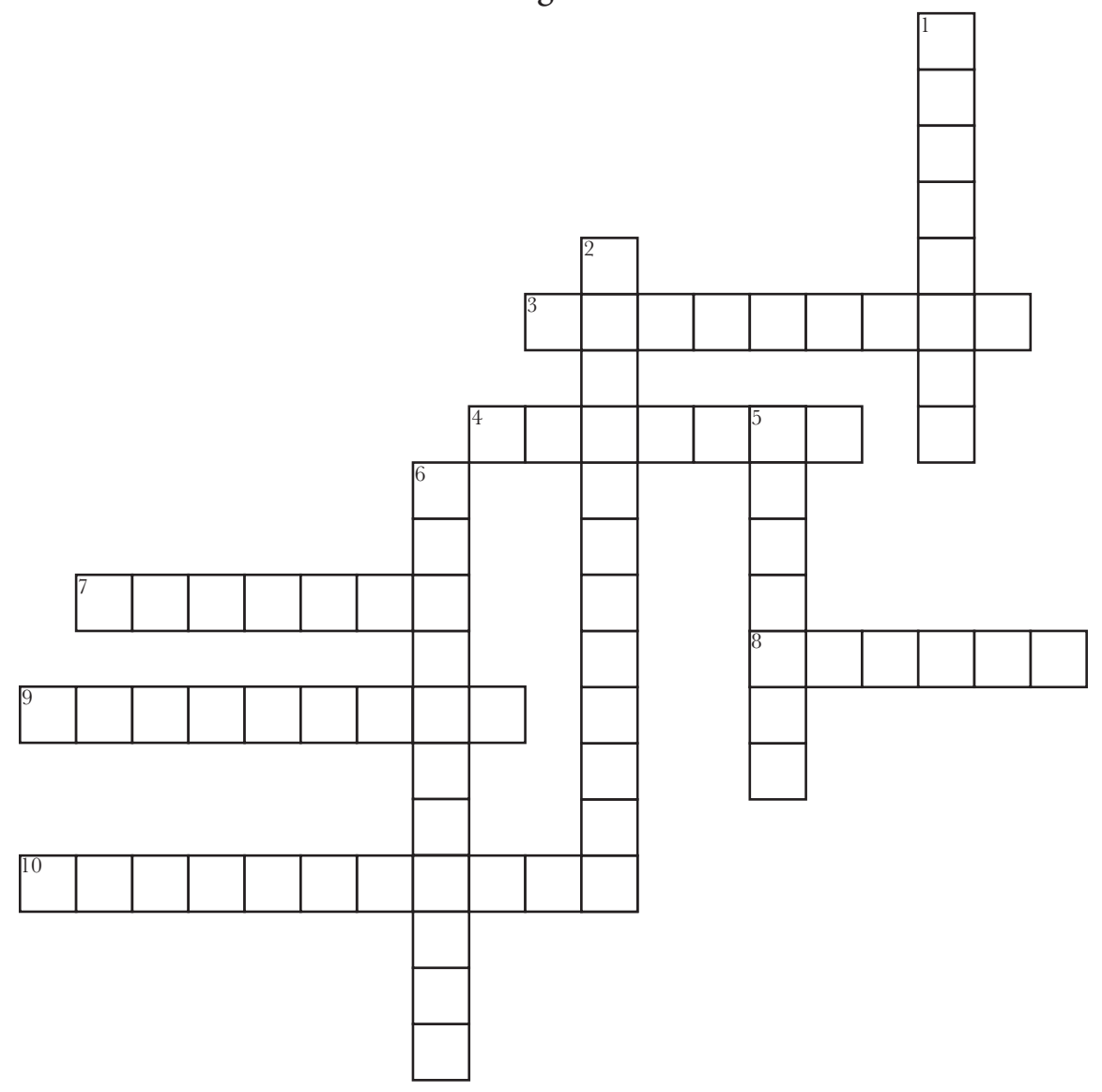

\section{Horizontal}

3. Repartir, dividir, distribuir algo en partes.

4. Habilidad o destreza en lo que se ejecuta.

7. Prenda o conjunto de prendas exteriores con que se cubre el cuerpo.

8. Entrada o paso.

9. Bien que se hace o se recibe.

10. Conjunto o cuerpo de leyes por las cuales se gobierna un Estado.

\section{Vertical}

1. Que está más alta y en lugar preeminente respecto de otra.

2. Acción y efecto de codificar.

5. Cosa que es resultado de la actividad humana.

6. Acción y efecto de prohibir. 
Este libro forma parte del acervo de la Biblioteca Jurídica Virtual del Instituto de Investigaciones Jurídicas de la UNAM

\section{BIOgRAFÍA 7 JOHN RAWLS}

Baltimore, Estados Unidos, 21 de febrero de 1921-Lexington, Mass., Estados Unidos, 24 de noviembre de 2002

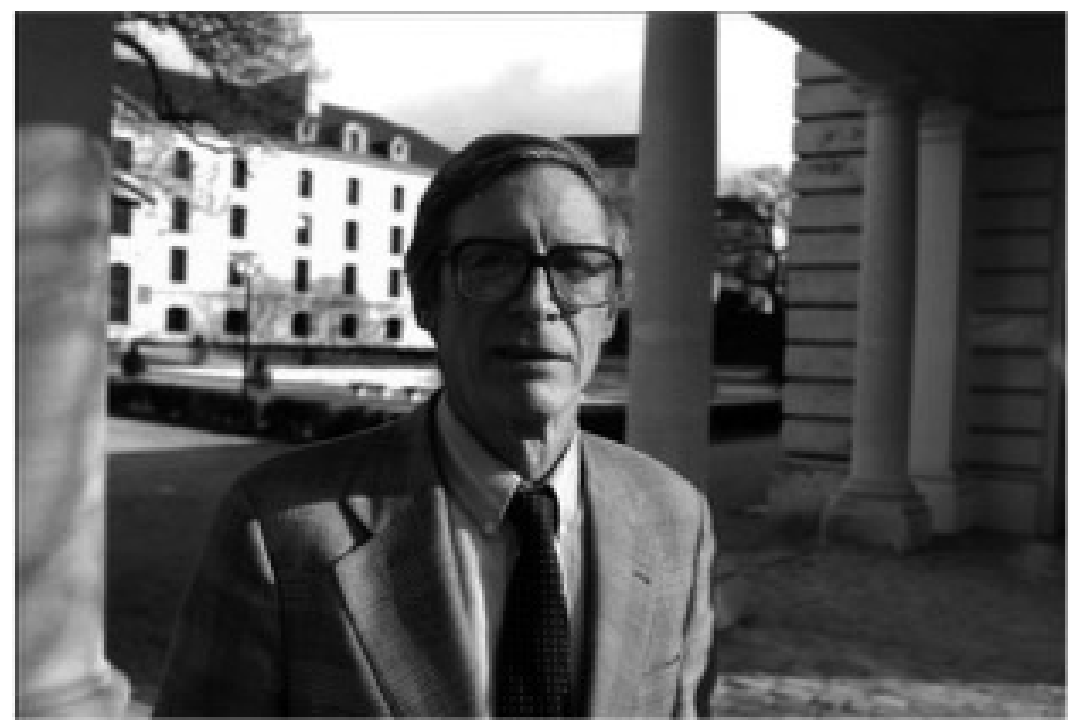

Filósofo estadounidense, profesor de filosofía política en la Universidad de Harvard. Es ampliamente considerado como uno de los filósofos políticos más importantes del siglo XX.

Rawls estuvo en la Universidad de Princeton, donde comenzó a interesarse en la filosofía, y fue electo para el The Ivy Club. En 1943, completó su Bachelor of Arts y se unió a la Armada de los Estados Unidos.

Durante la Segunda Guerra Mundial, Rawls sirvió como un infante en el Pacífico, donde estuvo en Nueva Guinea, las Filipinas, y Japón; es este último presenció las secuelas del bombardeo sobre Hiroshima.

Tras esta experiencia, Rawls rechazó una oferta para convertirse en un oficial y deja la armada como privado en 1946. A partir de entonces, retorna a Princeton para obtener el doctorado en filosofía moral.

Luego de obtener su Ph. D. de Princeton en 1950, Rawls se dedica a enseñar hasta 1952, cuando recibe un Programa Fulbright para la Universidad de Oxford, donde fue influenciado por el teórico político liberal e historiador Isaiah Berlin y, más fuertemente, por el teórico jurídico H. L. A. Hart. Después de retornar a los Estados Unidos, sirvió 
Este libro forma parte del acervo de la Biblioteca Jurídica Virtual del Instituto de Investigaciones Jurídicas de la UNAM

como asistente y luego como profesor asociado en la Cornell University. En 1962, se convierte en profesor de filosofía de jornada completa en Cornell, y pronto alcanzaría una posición en el MIT. En 1964 se transfirió a la Harvard University, donde enseñó por al menos cuarenta años, y donde preparó a muchas de las contemporáneas figuras que lideran hoy en día la filosofía política y moral, incluyendo a Thomas Nagel, David Lyons, Thomas Hill, Joshua Cohen, Christine Korsgaard, Elizabeth S. Anderson, y Barbara Herman.

Autor, entre otros textos, de Teoría de la justicia (1971), Liberalismo político (1993), The Law of Peoples (1999) y Justice as Fairness: A Restatement (2001).

Su teoría política propone dos principios sobre los cuales basar la noción de justicia, a partir de una posición original en el espíritu contractualista de los filósofos políticos clásicos.

Rawls fue reconocido con el Premio Schock para lógica y filosofía y con la National Humanities Medal de manos del presidente Bill Clinton en 1999, en reconocimiento a "su ayuda a que toda una generación... reviviera su confianza en la democracia". 
Este libro forma parte del acervo de la Biblioteca Jurídica Virtual del Instituto de Investigaciones Jurídicas de la UNAM

\section{Biografía 8 \\ RONALD M. DWORKIN}

Worcester, Massachusetts, Estados Unidos, 11 de diciembre de 1931-Londres, Inglaterra, Reino Unido, 14 de febrero de 2013

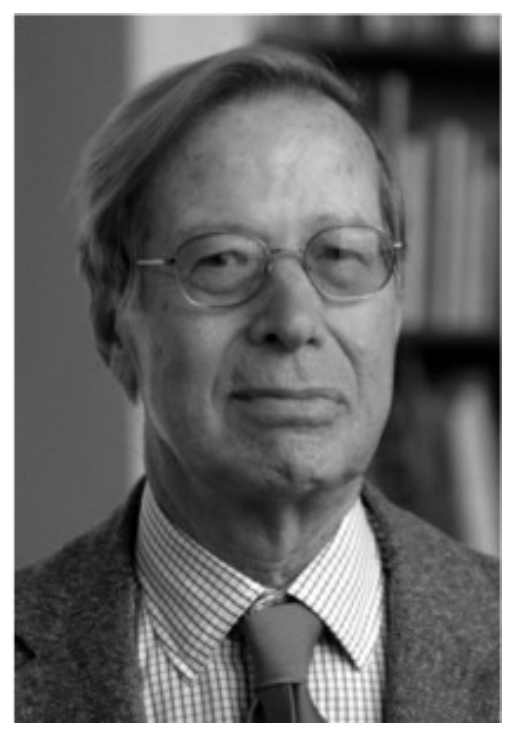

Destacado filósofo del derecho y catedrático de derecho constitucional. Su teoría del derecho es una de las contemporáneas más influyentes respecto de la naturaleza del derecho.

Estudió en la Universidad de Harvard y en el Magdalen College (Oxford), en donde fue becario Rhodes y estudiante de Sir Rupert Cross. Trabajó como ayudante del juez Learned Hand, y en un despacho de abogados de Nueva York.

Su carrera como profesor de Jurisprudencia (Teoría del derecho) comenzó en la Universidad de Yale, en la Cátedra Wesley N. Hohfeld. Desde 1969 fue profesor en la Universidad de Oxford, donde sucedió a H. L. A. Hart, uno de los filósofos del derecho más destacados del siglo XX. También impartió clases de derecho y filosofía en el University College London, y en la Universidad de Nueva York.

En cuanto a su pensamiento, a partir de su primer texto ¿Es el derecho un sistema de normas? (1969) formuló una crítica al positivismo analítico de H. L. A. Hart y otros como J. Bentham y J. Austin. Su crítica se basó en que, según él, el positivismo sólo tomaría en cuenta las 
Este libro forma parte del acervo de la Biblioteca Jurídica Virtual del Instituto de Investigaciones Jurídicas de la UNAM

normas jurídicas, sin considerar otros factores importantes, como los principios; con ello, también separa la división positivista entre moral y derecho.

A partir de esto, se rompería la vieja impresión de las "lagunas jurídicas", ya que todos los casos judiciales tendrían una respuesta posible para su resolución. Esto permitió a Dworkin hacer una defensa de los derechos humanos en cuanto "triunfos de la mayoría" a partir de los derechos individuales realmente vigentes. Esto da paso a una sociedad liberal igualitaria, en cuanto la libertad no es entendida como un único deber de abstención del Estado ("libertad negativa"), sino que sólo se realiza en la medida que exista una correspondencia activa cuando hay medios y recursos para aquello, cuya tarea principal es del Estado.

Siempre defendió los espacios de autonomía personal en el ejercicio de los derechos humanos, y en ese sentido apoyó el aborto y la eutanasia, así como se opuso a las políticas públicas del gobierno estadounidense bajo la administración de George W. Bush tras su Patriot Act que, en el contexto de la "guerra contra el terrorismo" (tras el ataque a las Torres Gemelas de 2001), supuso un límite fortísimo a las libertades individuales. Esto lo tradujo en su texto Is Democracy Possible Here? (2004),

Entre sus libros más importantes, encontramos Los derechos en serio (1977), La filosofía del derecho (1977), El Imperio de la justicia (1988), Ética privada e igualitarismo político (1990) y Virtud soberana. Teoría de la práctica de la igualdad (2000).

Entre otros premios, en 2006 recibió el Premio Internacional de Investigación en Derecho "Dr. Héctor Fix-Zamudio" del Instituto de Investigaciones Jurídicas de la UNAM. Por su contribución a la filosofía del derecho y la filosofía política, recibió en 2007 el premio Holberg por la Universidad de Bergen, en Noruega, reconociendo sus "innovaciones en el trabajo académico de impacto mundial".

Fue destacado por The Journal of Legal Studies como el segundo autor estadounidense del siglo XX más citado en el campo del derecho. 


\section{GRUPO 5}

Objetivos: Incrementar el vocabulario básico, y ampliarlo en la mente del estudiante, de manera que pueda entregarle competencias para desenvolverse de mejor forma en la aproximación y comprensión de textos.

Las soluciones respectivas, para mayor comprensión, que te permitirán comprobar tu avance, las podrás encontrar en el apartado correspondiente al final de este libro.

\section{Ejercicio léxico 1}

I. Observa bien las siguientes palabras:

1. Pura

2. Obligación

3. Orden

4. Riesgo

5. Instrumento

6. Alcanzar

7. Sujeto

8. Validez

9. Bases

10. Ley

11. Normativa

12. Teoría

13. Deber
14. Estudio

15. Neutro

16. Fórmula

17. Autónomas

18. Realidades

19. Conducta

20. Moral

21. Género

22. Expresión

23. Aplica

24. Diversidad

25. Nombre

26. Hacer

II. Consulta en tu diccionario qué significan las palabras anteriores que ya observaste. 
Este libro forma parte del acervo de la Biblioteca Jurídica Virtual del Instituto de Investigaciones Jurídicas de la UNAM

III. De las palabras anteriores, selecciona la palabra o frase acorde al texto o al sentido expresado en el enunciado: ${ }^{5}$

1. El deber ser jurídico, la de las leyes, es totalmente independiente del ser, o sea, de los deseos y otros movimientos psíquicos de los individuos.

2. Así que la primera distinción se realiza con base en el mundo del ser (ley natural) y el ser (ley moral o norma).

3. La natural se aplica a la explicación de hechos reales, es una proposición explicativa, proviene del plano del ser, donde todo está sujeto al principio de causalidad.

4. Distinguió a la ley de la norma jurídica, la primera se encuentra en un punto intermedio entre la ley natural y la norma jurídica, dejando la contraposición formal entre ser y deber ser en segundo plano, causa de ello es que la moral es autónoma.

5. Las leyes morales (jurídicas, lógicas, gramaticales, estéticas) conocidas también con el nombre de normas son proposiciones que prescriben una , exigen que algo sea o no sea, establecen lo que debe ser y lo que no debe ser, proponen lo que debería ser, formulan deberes.

6. La obra de Hans Kelsen Teoría del derecho, texto que sentó las bases de lo que en la doctrina se conoce como positivismo jurídico, ha marcado la forma de aproximación al estudio del derecho, aún en nuestros días.

7. Así Kelsen, en su obra Los problemas capitales, en donde sienta las bases de la teoría pura, considera a la norma como de la voluntad del Estado, voluntad que es una construcción jurídica con vista a la imputación.

8. En cambio, las normas jurídicas no son , las leyes no se las dan a sí mismos los propios individuos, el derecho es heterónomo, viene de un poder externo, la voluntad del Estado, es válido para todos los individuos, aunque éstos no quieran o no acepten las normas.

5 Lo anterior, asumiendo que puedes adecuar la mejor conjugación verbal y la relación entre género y número, para dar a la frase un sentido coherente. 
Este libro forma parte del acervo de la Biblioteca Jurídica Virtual del Instituto de Investigaciones Jurídicas de la UNAM www.juridicas.unam.mx

\section{Ejercicio léxico 2}

Marca con una "X" la palabra que mejor consideres para la definición dada.

1. Imposición o exigencia moral que debe regir la voluntad libre.

\begin{tabular}{|l|l|l} 
Obligación ( ) & Relación ( ) & Consecuencia ( )
\end{tabular}

2. Objeto fabricado, relativamente sencillo, con el que se puede realizar una actividad.

\begin{tabular}{|l|l|l|}
\hline Elemento ( ) & Instrumento ( ) & Control ( ) \\
\hline
\end{tabular}

3. Conjunto de normas aplicables a una determinada materia o actividad.

\begin{tabular}{|l|l|l|}
\hline Realidad ( ) & Normativa ( ) & Sistema ( ) \\
\hline
\end{tabular}

4. Llegar a juntarse con alguien o algo que va delante.

\begin{tabular}{|l|l|l|}
\hline Mirar ( ) & Pretender ( ) & Alcanzar ( ) \\
\hline
\end{tabular}

5. Asunto o materia sobre que se habla o escribe.

\begin{tabular}{|c|c|c|}
\hline Sujeto ( ) & Tema ( ) & Entendimiento ( ) \\
\hline
\end{tabular}

6. Contingencia o proximidad de un daño.

\begin{tabular}{|l|l|l|}
\hline Causalidad ( ) & Problema ( ) & Riesgo ( ) \\
\hline
\end{tabular}

7. Conocimiento especulativo considerado con independencia de toda aplicación.

\begin{tabular}{|c|c|c|}
\hline Teoría ( ) & Ocasión ( ) & Dilema ( ) \\
\hline
\end{tabular}


Este libro forma parte del acervo de la Biblioteca Jurídica Virtual del Instituto de Investigaciones Jurídicas de la UNAM

\section{Ejercicio léxico 3}

Anota la opción que consideres como mejor definición de las siguientes palabras:

1. Hacer ( )

a. Ir más allá de un punto limitado o determinado.

b. Producir algo, darle el primer ser.

c. Convocar, citar.

2. Orden ( )

a. Objeto de establecer un sistema.

$b$. Regla o modo que se observa para hacer las cosas.

c. Modalidad pretendida en un momento determinado.

3. Estudio ( )

a. Esfuerzo que pone el entendimiento aplicándose a conocer algo.

b. Ocupación en un área determinada.

c. Síntesis de un tema en particular.

4. Neutro ( )

a. En sentido contrario.

b. Orientación dudosa de algo.

c. Carente de rasgos distintivos o expresivos.

5. Base ( )

a. Parte de abajo de un objeto.

b. Fundamento o apoyo principal de algo.

c. Principio de todas las cosas.

6. Fórmula ( )

a. Composición de una mezcla e instrucciones para su elaboración.

b. Brebaje para curar una enfermedad.

c. Orden específico de los números. 


\section{Aplicar ( )}

a. Establecer un orden para seguir un objetivo.

b. Usar un determinado utensilio de trabajo.

c. Poner algo sobre otra cosa o en contacto de otra cosa.

8. Diversidad ( )

a. Complejidad de una cosa.

b. Variedad, desemejanza, diferencia.

c. Muestra de diversos elementos.

9. Nombre ( )

a. Expresión para referirse a un amigo.

b. Palabra que designa o identifica seres animados o inanimados.

c. Parte de una oración.

10. Género（ ）

a. Clase o tipo a que pertenecen personas o cosas.

$b$. Identificación por la orientación sexual.

c. Expresión alusiva a lo masculino. 
Este libro forma parte del acervo de la Biblioteca Jurídica Virtual del Instituto de Investigaciones Jurídicas de la UNAM

\section{Ejercicio léxico 4}

Haz una relación entre ambas columnas, trazando una línea entre el vocablo de la columna del lado izquierdo con la definición del lado derecho, que a tu juicio establezcan una relación correcta.

\begin{tabular}{|l|l|}
\hline \multicolumn{1}{|c|}{ Vocablo } & \multicolumn{1}{c|}{ Definición } \\
\hline Sujeto & $\begin{array}{l}\text { 1. Cosa o persona de que alguien se sirve } \\
\text { para hacer algo o conseguir un fin. }\end{array}$ \\
\hline Instrumento & $\begin{array}{l}\text { 2. Conjunto de normas aplicables a una de- } \\
\text { terminada materia o actividad. }\end{array}$ \\
\hline Ley & $\begin{array}{l}\text { 3. Manera con que las personas se compor- } \\
\text { tan en su vida y acciones. }\end{array}$ \\
\hline Normativa & $\begin{array}{l}\text { 4. Palabra, locución o conjunto de palabras } \\
\text { sujetas a alguna pauta. }\end{array}$ \\
\hline Teoría & $\begin{array}{l}\text { 5. Asunto o materia sobre la que se habla o } \\
\text { escribe. }\end{array}$ \\
\hline Deber & $\begin{array}{l}\text { 6. Serie de las leyes que sirven para relacio- } \\
\text { nar determinado orden de fenómenos. }\end{array}$ \\
\hline Moral & $\begin{array}{l}\text { 7. Cumplir obligaciones nacidas de respeto, } \\
\text { gratitud u otros motivos. }\end{array}$ \\
\hline Expresión & $\begin{array}{l}\text { 8. Precepto dictado por la autoridad compe- } \\
\text { tente, en que se manda o prohíbe algo en } \\
\text { consonancia con la justicia y para el bien de } \\
\text { los gobernados. }\end{array}$ \\
\hline Conducta & $\begin{array}{l}\text { 9. Conforme con las normas que una perso- } \\
\text { na tiene del bien y del mal. }\end{array}$ \\
\hline
\end{tabular}


Este libro forma parte del acervo de la Biblioteca Jurídica Virtual del Instituto de Investigaciones Jurídicas de la UNAM www.juridicas.unam.mx

\section{Ejercicio léxico 5}

En las columnas siguientes anota, en el casillero correspondiente, el sinónimo (es decir, la palabra más parecida), así como el correspondiente antónimo (es decir, la palabra que signifique lo contrario), que más te parezca, del vocablo de la columna izquierda.

\begin{tabular}{|c|l|l|}
\hline Vocablo & Sinónimo & Antónimo \\
\hline Neutro & & \\
\hline Diversidad & & \\
\hline Hacer & & \\
\hline Autónoma & & \\
\hline Aplicar & & \\
\hline Orden & & \\
\hline Expresión & & \\
\hline Base & & \\
\hline Pura & & \\
\hline Moral & & \\
\hline Deber & & \\
\hline Realidades & & \\
\hline Validez & & \\
\hline Género & & \\
\hline Riesgo & & \\
\hline Alcanzar & & \\
\hline Estudio & & \\
\hline
\end{tabular}


Este libro forma parte del acervo de la Biblioteca Jurídica Virtual del Instituto de Investigaciones Jurídicas de la UNAM

\section{Ejercicio léxico 6 \\ Crucigrama 5}

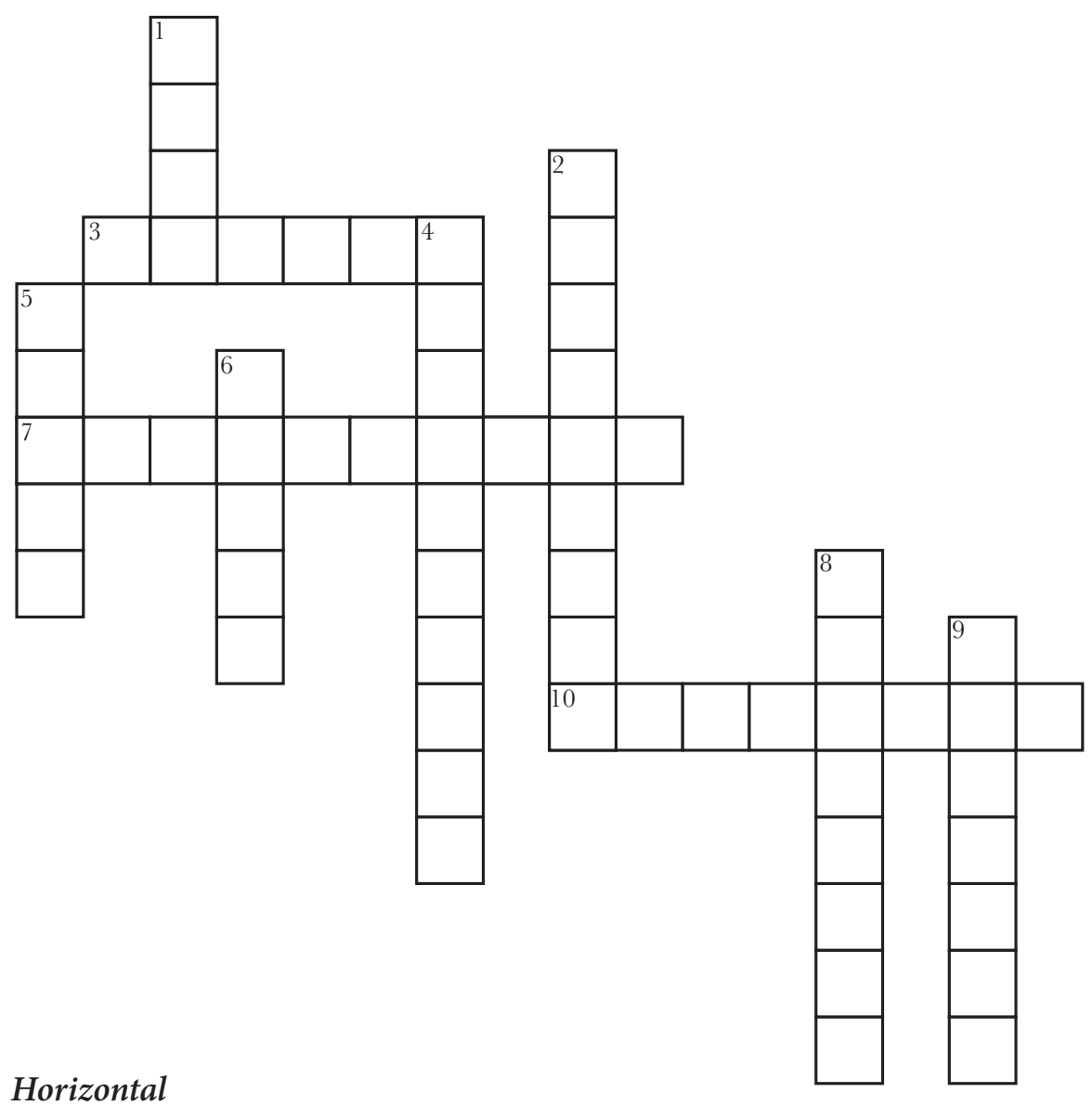

3. Carente de rasgos distintivos o expresivos.

7. Variedad, desemejanza, diferencia.

10. Llegar a poseer lo que se busca o solicita.

\section{Vertical}

1. Fundamento o apoyo principal de algo.

2. Conjunto de normas aplicables a una determinada materia o actividad.

4. Aquello que alguien está obligado a hacer.

5. Colocación de las cosas en el lugar que les corresponde.

6. Cumplir obligaciones nacidas de respeto, gratitud u otros motivos.

8. Manera con que los hombres se comportan en su vida y acciones.

9. Cualidad de válido. 
Este libro forma parte del acervo de la Biblioteca Jurídica Virtual del Instituto de Investigaciones Jurídicas de la UNAM

\section{BIOGRAFÍA 9 \\ Richard Allen Posner}

New York, Estados Unidos, 11 de enero de 1939

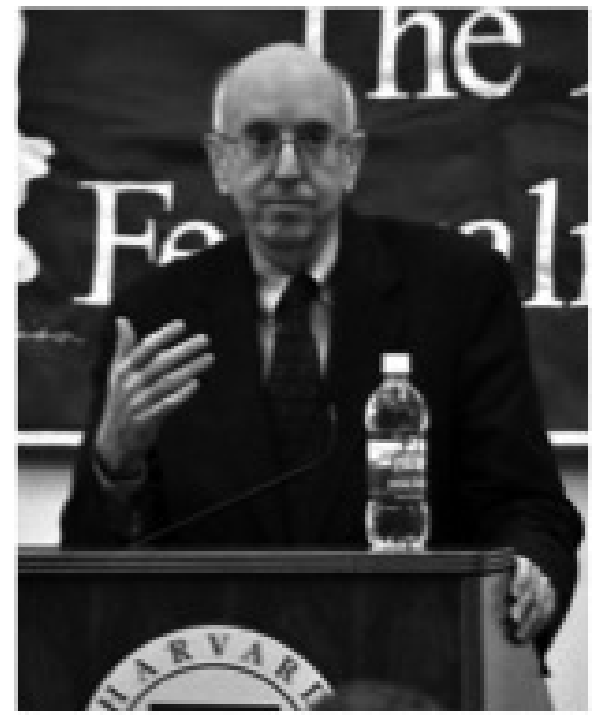

Jurista, teórico y magistrado estadounidense, destacado por su influencia en el derecho económico. Graduado en 1959 en la Facultad de Derecho de la Universidad de Yale, se licenció en derecho en la Harvard Law School en 1962. Entró como profesor en 1968 en Stanford University, de donde pasó a la Law School de la Universidad de Chicago (1969-1981), en cuyas actividades académicas y docentes continúa participando regularmente.

Magistrado desde 1981 de la Corte Suprema de los Estados Unidos, que presidió de 1993 a 2000.

Posner ha investigado sobre la aplicación de la teoría económica a diversos campos jurídicos como la legislación antimonopolista, la regulación de los contratos mercantiles y el procedimiento judicial. Propuso y defendió la idea de que la ley puede ser explicada mejor bajo el supuesto de que los jueces tratan de promover la eficiencia económica y la maximización de la riqueza como objetivo de la política legal y social. Se convirtió así en uno de los más destacados líderes de la corriente del análisis económico del derecho (Law and Economics), aplicando el análisis económico al derecho de familia, la discriminación racial, la jurisprudencia y la privacidad. 
Este libro forma parte del acervo de la Biblioteca Jurídica Virtual del Instituto de Investigaciones Jurídicas de la UNAM

Es fundador del Journal of Legal Studies; presidió la American Law and Economics Association (1995-96) y es coeditor de la American Law and Economics Review. También es autor de aproximadamente cuarenta libros sobre teoría jurídica, filosofía del derecho y otros temas, que incluyen Economic Analysis of Law (1973), The Problems of Jurisprudence (1990), Sex and Reason (1992), Overcoming Law (1995), The Problematics of Moral and Legal Theory (2000) y Law, Pragmatism and Democracy (2003).

Es doctor honorífico por las universidades de Syracuse (1986), Duquesne (1987), Georgetown (1993), Gante (1995), Yale (1996), Pennsylvania (1997), Brooklyn (2000) y Northwestern (2001), entre otras. 
Este libro forma parte del acervo de la Biblioteca Jurídica Virtual del Instituto de Investigaciones Jurídicas de la UNAM www.juridicas.unam.mx

\section{BIOGRAFÍA 10 \\ Carlos Santiago Nino}

Buenos Aires, Argentina, 1943-La Paz, Bolivia, 29 de agosto de 1993

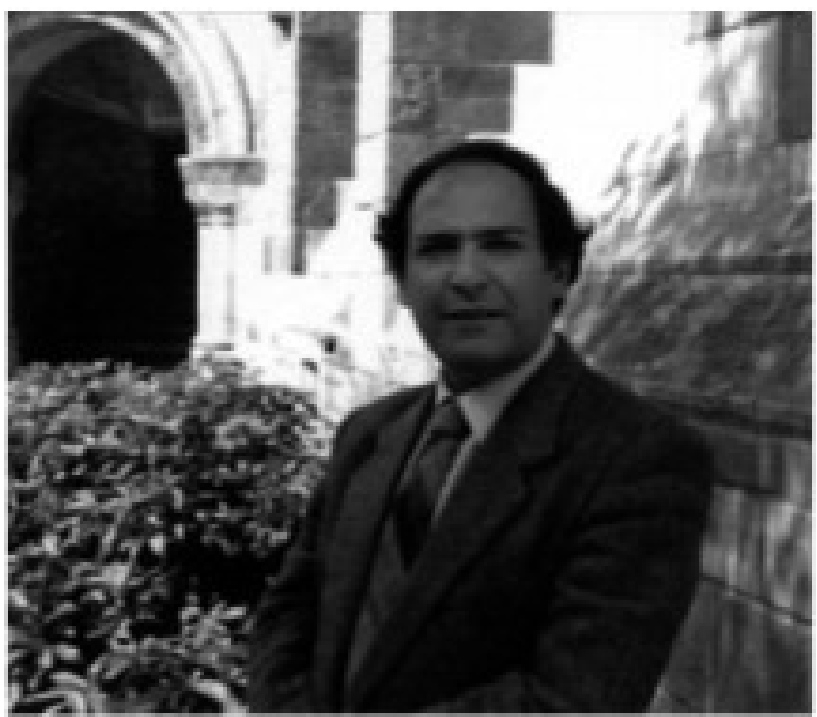

Filósofo y jurista argentino. Se graduó como abogado en la Universidad de Buenos Aires, y obtuvo el Doctorado en Leyes en la Universidad de Oxford (1977).

Profesor titular de Filosofía del Derecho en las facultades de Derecho y Filosofía y Letras de la Universidad de Buenos Aires, y profesor visitante regular de las facultades de derecho de las universidades de Yale y Pompeu Fabra.

Durante el periodo de transición democrática en Argentina, después del periodo de dictaduras militares, fue asesor del entonces presidente Raúl Alfonsín en cuestiones de derechos humanos, así como coordinador del Consejo para la Coordinación de la Democracia, un organismo ad honórem para el estudio y diseño de reformas constitucionales. También estuvo entre los autores del nuevo Plan de Estudios de la Facultad de Derecho de la Universidad de Buenos Aires, reforma que modernizó el currículum y la estructura de la enseñanza del derecho en el país austral.

Autor de una vasta obra, fue uno de los juristas que alcanzó mayor notoriedad académica a escala internacional en la segunda mitad del 
siglo XX. Entre sus principales libros destacan Notas de introducción al derecho (Buenos Aires, 1973, ampliada con el título Introducción al análisis del derecho, 1989), Consideraciones sobre la dogmática jurídica (México, UNAM, 1974), La legítima defensa. Fundamentación y régimen jurídico (Buenos Aires, Astrea, 1982). 


\section{GRUPO 6}

Objetivos: Incrementar el vocabulario básico, y ampliarlo en la mente del estudiante, de manera que pueda entregarle competencias para desenvolverse de mejor forma en la aproximación y comprensión de textos.

Las soluciones respectivas, para mayor comprensión, que te permitirán comprobar tu avance, las podrás encontrar en el apartado correspondiente al final de este libro.

\section{Ejercicio léxico 1}

I. Observa bien las siguientes palabras:

1. Realizar

2. Entender

3. Decir

4. Sentido

5. Fuerte

6. Alcanzar

7. Omitir

8. Universal

9. Concepción

10. Discurrir

11. Predecir

12. Importar

13. Maternidad

14. Elemento

15. Escandinavo
16. Complejo

17. Metodología

18. Frontera

19. Predicción

20. Realismo

21. Futuro

22. Cumpla

23. Individuos

24. Virtud

25. Frontera

26. Análisis

27. Efecto

28. Promover

29. Generación

30. Propiciar

II. Consulta en tu diccionario qué significan las palabras anteriores que ya observaste. 
Este libro forma parte del acervo de la Biblioteca Jurídica Virtual del Instituto de Investigaciones Jurídicas de la UNAM

III. De las palabras anteriores, selecciona la palabra o frase acorde al texto o al sentido expresado en el enunciado. ${ }^{6}$

1. Actualizando al derecho científicamente para enfrentar problemas y realizar investigaciones de que resuelvan temas complejos como seguridad pública, clonación, regulación de ADN, maternidad subrogada, medio ambiente, educación en derechos humanos, costumbres contrarias a derechos humanos, etcétera.

2. Lo que se llama deber jurídico no es sino la predicción de lo que, si un hombre hace u omite ciertas cosas, tendrá que sufrir en una o en otra forma, en de una sentencia del tribunal; pudiendo decirse lo propio de un derecho subjetivo.

3. El objeto de nuestro estudio es entonces la de la interferencia de las fuerzas públicas a través del instrumento de los tribunales, entiendo por derecho las profecías acerca de lo que los tribunales harán realmente, y nada más.

4. Dentro del mismo realismo, Roscoe Pound, quien se inspira en Holmes, afirma que la investigación sociológica en el campo del derecho debe realizarse con un de los factores preceptivos: reglas, principios, doctrinas; y de los intereses individuales, públicos y sociales.

5. LoS desean saber en qué circunstancias y hasta qué punto correrán el riesgo de ir contra de lo que es mucho más fuerte para ellos, por lo que se proponen la tarea de discurrir cuando ese peligro ha de ser temido.

6. Dentro del derecho se hace necesaria promover otra visión más abierta que permita el acercamiento con las ciencias sociales y propicie por tanto la interdisciplinariedad.

7. La obligación de celebrar un contrato de acuerdo con el common law, implica la predicción de que quien no lo tendrá que pagar los consiguientes daños y perjuicios, y nada más.

8. Se clasifican en dos grandes ramas: el realismo estadounidense y el europeo; este último incluyendo al realismo escandinavo, que presenta un mayor desarrollo metodológico.

6 Lo anterior, asumiendo que puedes adecuar la mejor conjugación verbal y la relación entre género y número, para dar a la frase un sentido coherente. 
Este libro forma parte del acervo de la Biblioteca Jurídica Virtual del Instituto de Investigaciones Jurídicas de la UNAM www.juridicas.unam.mx

9. Puede definirse al sociologismo o realismo jurídico como la del derecho en que prevalecen los elementos conductuales entre los normativos.

\section{Ejercicio léxico 2}

Marca con una "X" la palabra que mejor consideres para la definición dada.

1. Manifestar con palabras el pensamiento

\begin{tabular}{|l|l|l|}
\hline Reflexionar ( ) & Decir ( ) & Sopesar ( ) \\
\hline
\end{tabular}

2. Capacidad para percibir estímulos externos o internos mediante determinados órganos

\begin{tabular}{|l|l|l} 
Parámetro ( ) & Intuición ( ) & Sentido ( )
\end{tabular}

3. Acción y efecto de concebir

\begin{tabular}{l|l|l} 
Concepción ( ) & Fecha ( ) & Útil ( )
\end{tabular}

4. Estado o cualidad de madre

\begin{tabular}{l|l|l} 
Femenina ( ) & Maternidad ( ) & Creadora ( )
\end{tabular}

5. Parte constitutiva o integrante de algo

\begin{tabular}{|l|l|l|}
\hline Elemento ( ) & Pedazo ( ) & Cuerpo ( ) \\
\hline
\end{tabular}

6. Natural de Escandinavia, región del norte de Europa

\begin{tabular}{|l|l|l} 
Escandinavo ( ) & Europeo ( ) & Norteño ( )
\end{tabular}

7. Conjunto de métodos que se siguen en una investigación científica o en una exposición doctrinal

\begin{tabular}{|l|l|l|}
\hline Elemento ( ) & Europeo ( ) & Metodología ( ) \\
\hline
\end{tabular}


Este libro forma parte del acervo de la Biblioteca Jurídica Virtual del Instituto de Investigaciones Jurídicas de la UNAM

8. Anunciar por revelación, conocimiento fundado, intuición o conjetura algo que ha de suceder

\begin{tabular}{|l|l|l|}
\hline Comunicar ( ) & Realizar ( ) & Predecir ( ) \\
\hline
\end{tabular}

9. Cada ser organizado, sea animal o vegetal, respecto de la especie a que pertenece

\begin{tabular}{|l|l|l|}
\hline Especie ( ) & Individuo ( ) & Ser ( ) \\
\hline
\end{tabular}

10. Actividad o fuerza de las cosas para producir o causar sus efectos

\begin{tabular}{|c|c|c|}
\hline Virtud ( ) & Forma ( ) & Bondad ( ) \\
\hline
\end{tabular}

\section{Ejercicio léxico 3}

Anota la opción que consideres como mejor definición de las siguientes palabras:

1. Fuerte ( )
a. Con enorme valor.
b. Que tiene gran resistencia.
c. Con mucho carácter.

2. Frontera ( )
a. Confín de un Estado.
$b$. Separación de un lugar con otro.
c. Etapa de definición de una época histórica.

3. Predicción ( )

a. Vaticinio hecho por un astrólogo.

b. Arte de echar las cartas para adivinar el futuro.

c. Acto de anunciar por revelación, conocimiento fundado, intuición o conjetura algo que ha de suceder. 
Este libro forma parte del acervo de la Biblioteca Jurídica Virtual del Instituto de Investigaciones Jurídicas de la UNAM

4. Cumplir ( )

a. Lograr una meta.

b. Llevar a efecto algo.

c. Alcanzar un compromiso.

5. Análisis ( )

a. Encuentro de opiniones acabadas sobre cierto asunto.

b. Comprensión específica de cierta materia, naturaleza o circunstancia.

c. Estudio detallado de algo, especialmente de una obra o de un escrito.

6. Generación（ ）

a. Origen de una cosa, en un determinado tiempo.

$b$. Conjunto de las personas que tienen aproximadamente la misma edad.

c. Agrupación de personas que convergen en un determinado tiempo.

7. Promover ( )

a. Impulsar el desarrollo o la realización de algo.

b. Asumir la realización de un objetivo.

c. Establecer un compromiso a largo plazo.

8. Efecto ( )
a. Resultado obtenido de una dura tarea.
$b$. Aquello que sigue por virtud de una causa.
c. Consecuencia derivada de un largo esfuerzo.

9. Discurrir ( )

a. Pensar o reflexionar sobre algo.

b. Dejar fluir un determinado pensamiento.

c. Exageración respecto de una opinión.

10. Propiciar ( )

a. Realizar eventos con el objeto de establecer una decisión.

$b$. Señalar un vínculo entre un punto y otro.

c. Favorecer que algo acontezca o se realice. 


\section{Ejercicio léxico 4}

Haz una relación entre ambas columnas, trazando una línea entre el vocablo de la columna del lado izquierdo con la definición del lado derecho, que a tu juicio establezcan una relación correcta.

\begin{tabular}{|c|c|}
\hline Vocablo & Definición \\
\hline Entender & 1. Abstenerse de hacer algo. \\
\hline Realismo & $\begin{array}{l}\text { 2. Que lo comprende todo en la especie de } \\
\text { que se habla. }\end{array}$ \\
\hline Alcanzar & $\begin{array}{l}\text { 3. Introducir en un país géneros, artículos o } \\
\text { costumbres extranjeros. }\end{array}$ \\
\hline Omitir & 4. Tener idea clara de las cosas. \\
\hline Futuro & 5. Que se compone de elementos diversos. \\
\hline Realizar & 6. Que está por venir. \\
\hline Universal & 7. Forma de ver las cosas sin idealizarlas. \\
\hline Importar & $\begin{array}{l}\text { 8. Efectuar, llevar a cabo algo o ejecutar una } \\
\text { acción. }\end{array}$ \\
\hline Complejo & $\begin{array}{l}\text { 9. Llegar a juntarse con alguien o algo que va } \\
\text { delante. }\end{array}$ \\
\hline
\end{tabular}


Este libro forma parte del acervo de la Biblioteca Jurídica Virtual del Instituto de Investigaciones Jurídicas de la UNAM www.juridicas.unam.mx

\section{Ejercicio léxico 5}

En las columnas siguientes anota, en el casillero correspondiente, el sinónimo (es decir, la palabra más parecida), así como el correspondiente antónimo (es decir, la palabra que signifique lo contrario), que más te parezca, del vocablo de la columna izquierda.

\begin{tabular}{|c|c|c|}
\hline Vocablo & Sinónimo & Antónimo \\
\hline Omitir & & \\
\hline Propiciar & & \\
\hline Importar & & \\
\hline Complejo & & \\
\hline Alcanzar & & \\
\hline Realismo & & \\
\hline Futuro & & \\
\hline Entender & & \\
\hline Virtud & & \\
\hline Maternidad & & \\
\hline Decir & & \\
\hline Cumplir & & \\
\hline Fuerte & & \\
\hline Efecto & & \\
\hline Universal & & \\
\hline & & \\
\hline
\end{tabular}


Este libro forma parte del acervo de la Biblioteca Jurídica Virtual del Instituto de Investigaciones Jurídicas de la UNAM www.juridicas.unam.mx

\section{Ejercicio léxico 6}

Crucigrama 6

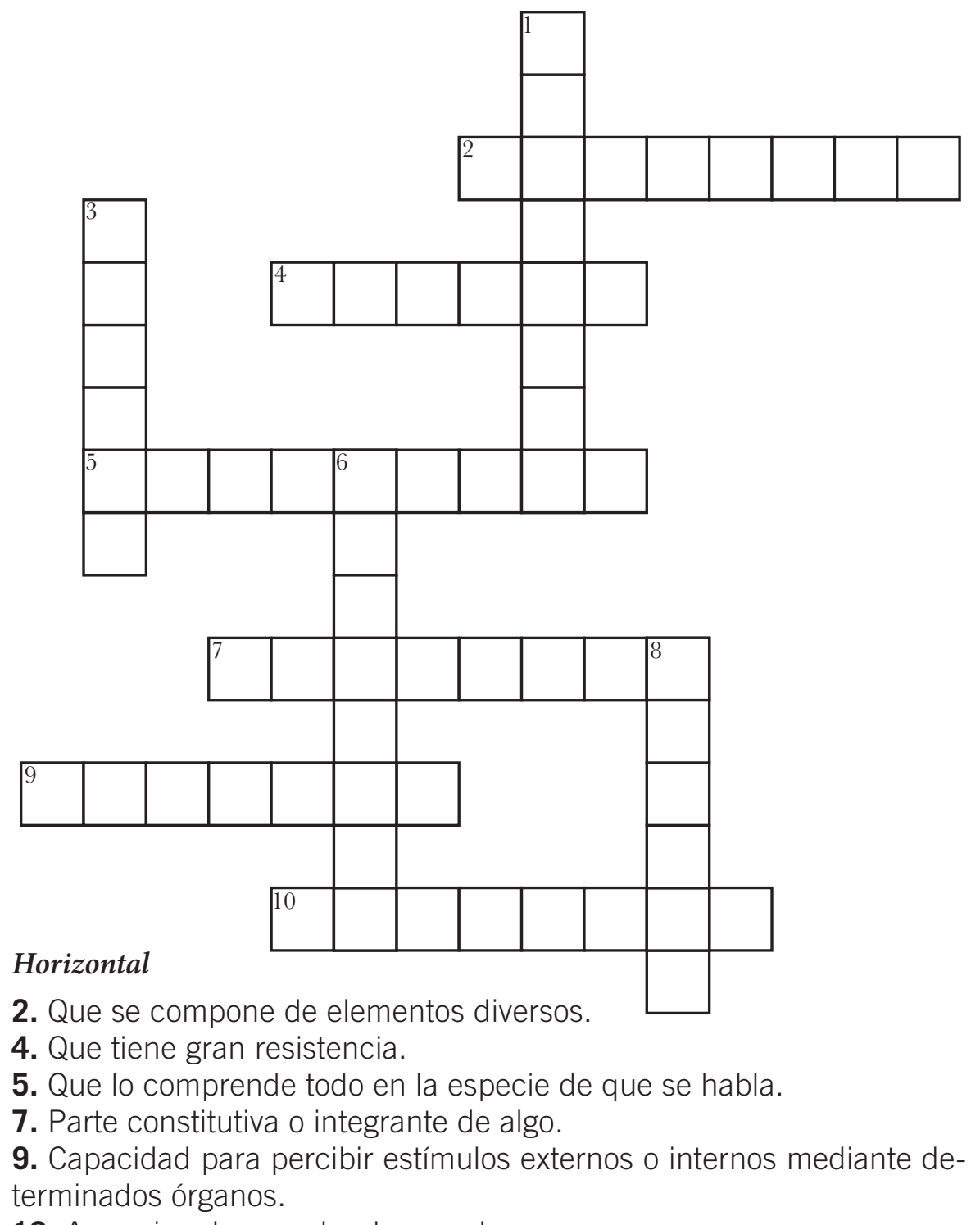

10. Anunciar algo que ha de suceder.

\section{Vertical}

1. Confín de un Estado.

3. Integridad de ánimo y bondad de vida.

6. Tener idea clara de las cosas.

8. Abstenerse de hacer algo. 
Este libro forma parte del acervo de la Biblioteca Jurídica Virtual del Instituto de Investigaciones Jurídicas de la UNAM

\section{BIOGRAFÍA 11 BENITO JUÁREZ GARCía}

San Pablo Guelatao, Oaxaca, 21 de marzo de 1806-Ciudad de México, 18 de julio de 1872

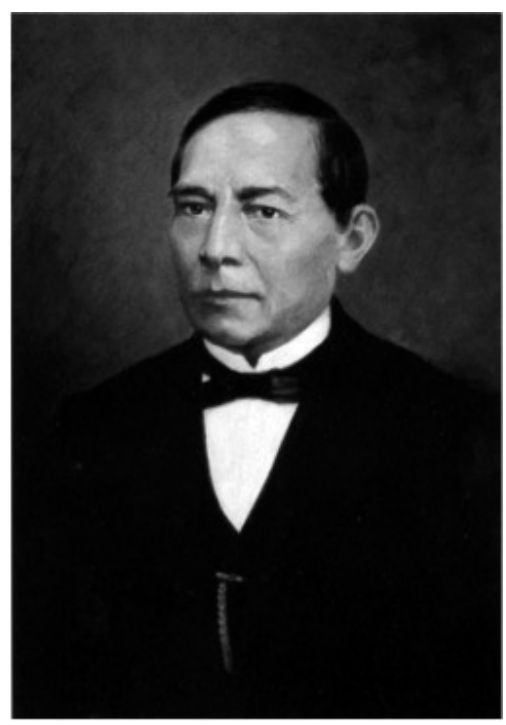

Abogado y político mexicano, de origen indígena (zapoteco). Presidente de México en diversas ocasiones, y Benemérito de las Américas. Hijo de un matrimonio indígena de humilde condición, Benito Juárez quedó huérfano siendo niño y cursó sus primeros estudios en su pueblo natal. Tenía veinte años cuando ingresó en el Instituto de Ciencias de Oaxaca, donde se licenció en derecho. Su preocupación por la realidad social y en particular por la situación de los campesinos lo llevó a expresar sus puntos de vista liberales y a participar activamente en política.

En 1831 fue electo regidor del ayuntamiento de Oaxaca y, un año después, diputado al Congreso del Estado. Era éste el primer paso de una actividad que le llevaría a ser el máximo mandatario de la nación, aunque para ello debió ascender lentamente en el escalafón político, sortear dificultades sin cuento, padecer el exilio, sufrir la cárcel, encabezar una guerra civil y atraerse la ira de numerosos enemigos. La energía con que defendió los intereses que representaba le valió en 1846 ser diputado por Oaxaca ante el Congreso de la Unión. Un año 
Este libro forma parte del acervo de la Biblioteca Jurídica Virtual del Instituto de Investigaciones Jurídicas de la UNAM

más tarde fue designado gobernador de su estado natal, cargo en el que permaneció hasta 1852.

Su oposición al tratado de Guadalupe-Hidalgo, por el que México perdió vastas zonas de su territorio en favor de Estados Unidos, encontró cauce en las filas liberales y en la defensa de un proyecto federalista. Sin embargo, los conservadores lograron una vez más hacerse con el poder en 1853, acaudillados por el general Antonio López de Santa Anna, y Juárez se vio obligado a exiliarse en Cuba.

Al cabo de dos años regresó y se adhirió al plan de Ayutla, entre cuyos firmantes figuraban los generales Villarreal, Comonfort y Álvarez. Al triunfar el pronunciamiento fue designado consejero de Estado y, bajo la presidencia de Ignacio Comonfort (1855-1857), ministro de Justicia; como tal, promulgó una serie de leyes que restablecían las libertades de enseñanza, imprenta y trabajo y anulaban las prerrogativas del clero y el ejército.

Sus disposiciones legislativas, que inspiraron la Constitución de 1857, de corte liberal, motivaron la reacción de los conservadores, quienes se pronunciaron al año siguiente en el Plan de Tacubaya. Comonfort pactó con ellos, dio un golpe de Estado y encarceló a Juárez, lo cual fue el detonante del conflicto civil llamado la guerra de Reforma (1858-1860).

Como presidente de la Suprema Corte de Justicia, Juárez, que había conseguido huir, se convirtió en el presidente legítimo, de acuerdo con la Constitución. Presionado por sus enemigos, hubo de refugiarse en Panamá, pero regresó en mayo de 1858 para establecer su gobierno en Veracruz. Desde allí expidió las leyes de Reforma y proclamó una Constitución más radical que la anterior. En 1859 su gobierno fue reconocido por los Estados Unidos, y, con su ayuda, Ios liberales derrotaron finalmente a los conservadores en 1860.

Con todo, Juárez vivió severas crisis económicas que redundaron en conflictos con potencias extranjeras como Gran Bretaña y Francia, Io que terminó derivando en la invasión de esta última potencia a nuestro territorio en 1863, y la imposición de Maximiliano de Habsburgo como emperador del país en 1864.

Producto de ello, Juárez se retiró a Paso del Norte, desde donde organizó la resistencia republicana, manteniéndose en esas difíciles circunstancias como presidente de México. Pese a todo, logró el triunfo para las fuerzas republicanas y liberales, consolidado tras la victoria en Querétaro en 1867 y el fusilamiento de Maximiliano el 19 de junio de ese mismo año. 
Con el país empobrecido y desunido, Juárez fue reelegido por séptima vez en agosto de 1867, restaurando la República federal y dando vigencia a las Leyes de Reforma. Ello, no sin dificultades en la conducción del país, agravado con la sublevación de Porfirio Díaz; y que Sebastián Lerdo de Tejada, otrora de sus principales colaboradores, fundara su propio partido.

Con todo, Juárez fue reelecto presidente en diciembre de 1871, a pesar de que continuaron dándose los conflictos internos. No alcanzó a completar su mandato, falleciendo el 18 de julio de 1872. 
Este libro forma parte del acervo de la Biblioteca Jurídica Virtual del Instituto de Investigaciones Jurídicas de la UNAM

\section{BIOGRAFÍA 12 \\ Sebastián Lerdo de Tejada}

Jalapa, México, 1827-Nueva York, Estados Unidos, 1889

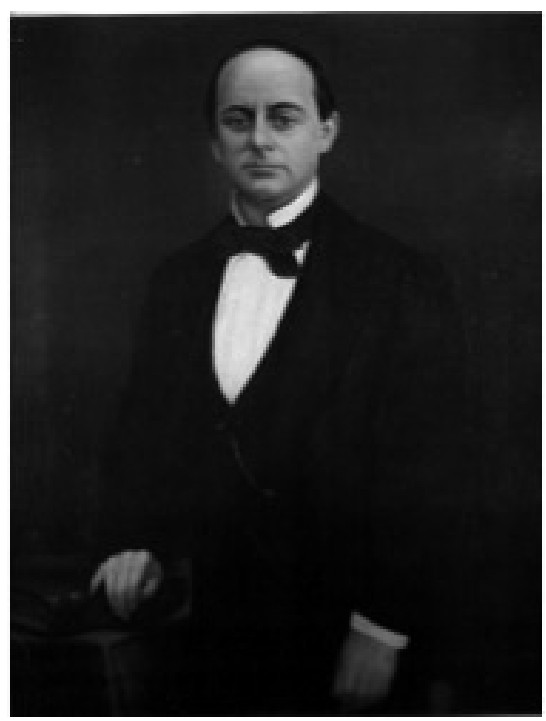

Político mexicano que fue presidente de la República entre 1872 y 1876. Recibió las órdenes menores, pero renunció al sacerdocio para dedicarse a la abogacía. Sirvió como fiscal en la Suprema Corte (1855) y fue ministro de Relaciones Exteriores con el presidente Ignacio Comonfort del 5 de junio al 16 de septiembre de 1857.

Elegido para el Congreso de la Unión, lo presidió en tres ocasiones. El 31 de mayo de 1863, cuando el gobierno republicano abandonó la capital, se unió a Benito Juárez y fue nombrado ministro de Relaciones, Gobernación y Justicia, el 12 de septiembre, en San Luis Potosí. Luchó junto al presidente Benito Juárez contra la invasión francesa de México. Cuando triunfó la República, llegó a ser, de manera simultánea, ministro de Relaciones Exteriores y de Gobernación, presidente de la Suprema Corte y diputado.

En 1871 se opuso a la reelección de Juárez y abandonó el Partido Liberal para constituir su propia agrupación política, el Partido Lerdista. Reelecto Juárez, fue nombrado presidente de la Suprema Corte de Justicia y, tras la muerte de Juárez, pasó por imperativo legal a presidir el país entre 1872 y 1876. 
Continuó el proceso de cambio iniciado con las Leyes de Reforma de Juárez, cuya aplicación se había visto interrumpida por la intervención francesa. Como nuevo presidente, elevó estas leyes a la categoría de constitucionales. Su gestión económica no fue demasiado afortunada y se atrajo la oposición de los católicos.

En 1876, cuando había sido reelegido, el general Porfirio Díaz se pronunció contra la reelección de Lerdo para un nuevo periodo, promulgó el plan de Tuxtepec y derrotó a sus fuerzas en la batalla de Tecoac (16 de noviembre). Lerdo hubo de exiliarse a Estados Unidos, donde pasó el resto de su vida. 


\section{GRUPO 7}

Objetivos: Incrementar el vocabulario básico, y ampliarlo en la mente del estudiante, de manera que pueda entregarle competencias para desenvolverse de mejor forma en la aproximación y comprensión de textos.

Las soluciones respectivas, para mayor comprensión, que te permitirán comprobar tu avance, las podrás encontrar en el apartado correspondiente al final de este libro.

\section{Ejercicio léxico 1}

I. Observa bien las siguientes palabras:

1. Derivar

2. Atribución

3. Etimología

4. Facultad

5. Contar

6. Común

7. Raíces

8. Juicio

9. Caso

10. Dirimir

11. Regla

12. General

13. Significado

14. Impartir

15. Gobernar
16. Apartan

17. Ejecución

18. Fiscal

19. Constituir

20. Juntas

21. Litigios

22. Encargar

23. Dirimir

24. Formal

25. Conciliación

26. Hacer

27. Existir

28. Proclamar

29. Medio

30. Pertenecer

II. Consulta en tu diccionario qué significan las palabras anteriores que ya observaste. 
Este libro forma parte del acervo de la Biblioteca Jurídica Virtual del Instituto de Investigaciones Jurídicas de la UNAM

III. De las palabras anteriores, selecciona la palabra o frase acorde al texto o al sentido expresado en el enunciado: ${ }^{7}$

1. Los arbitrajes, en materia laboral constituyen un caso especial, ya que las de Conciliación y Arbitraje, aun cuando formalmente no son tribunales, cuentan con plena jurisdicción para emitir sus laudos y para hacerlos cumplir incluso coactivamente.

2. En primer término, jurisdicción significa "poder o autoridad que tiene alguien para gobernar y poner en las leyes o para aplicarlas en juicio".

3. Estas definiciones etimológicas no se mucho de lo que, en materia procesal, quiere decir jurisdicción.

4. Etimológicamente, la palabra jurisdicción deriva de dos latinas.

5. El Estado cuenta, entre su cúmulo de atribuciones, con la de instalar órganos - precisamente llamados jurisdiccionales- que se encargan de justicia entre los gobernados.

6. Los órganos jurisdiccionales, por regla , son públicos y pertenecen al Poder Judicial de la Federación, a los poderes judiciales locales, o bien, al Poder Ejecutivo, como en el caso del Tribunal Federal de Justicia Fiscal y Administrativa.

7. En términos genéricos, se ha definido a la jurisdicción como la facultad que tiene el Estado para dirimir de trascendencia jurídica, a través de alguno de sus órganos o por medio de árbitros, mediante la aplicación de normas jurídicas e individualizadas.

7 Lo anterior, asumiendo que puedes adecuar la mejor conjugación verbal y la relación entre género y número, para dar a la frase un sentido coherente. 
Este libro forma parte del acervo de la Biblioteca Jurídica Virtual del Instituto de Investigaciones Jurídicas de la UNAM www.juridicas.unam.mx

\section{Ejercicio léxico 2}

Marca con una "X" la palabra que mejor consideres para la definición dada.

1. Origen de las palabras, razón de su existencia, de su significación y de su forma.

\begin{tabular}{|l|l|l|}
\hline Génesis ( ) & Etimología ( ) & Inicio ( ) \\
\hline
\end{tabular}

2. Pleito, altercado en juicio.

\begin{tabular}{|l|l|l|}
\hline Litigio ( ) & Problema ( ) & Causa ( ) \\
\hline
\end{tabular}

3. Aquello que ha de cumplirse por estar convenido en una colectividad.

\begin{tabular}{|l|l|l} 
Forma ( ) & Regla ( ) & Efecto ( )
\end{tabular}

4. Causa u origen de algo.

\begin{tabular}{l|l|l} 
Raíz ( ) & Efecto ( ) & Razón ( )
\end{tabular}

5. Acción y efecto de juzgar.

\begin{tabular}{l|l|l} 
Sentencia ( ) & Juicio ( ) & Decisión ( )
\end{tabular}

6. Quitar a alguien o algo del lugar donde estaba, para dejarlo desocupado.

\begin{tabular}{|l|l|l|}
\hline Apartar ( ) & Establecer ( ) & Dividir ( ) \\
\hline
\end{tabular}

7. Procedimiento judicial con embargo y venta de bienes para pago de deudas.

\begin{tabular}{l|l|l} 
Embargar ( ) & Asunción ( ) & Ejecución ( )
\end{tabular}

8. Común, frecuente, usual.

\begin{tabular}{|l|l|l|}
\hline General ( ) & Amplio ( ) & Realizable ( ) \\
\hline
\end{tabular}


Este libro forma parte del acervo de la Biblioteca Jurídica Virtual del Instituto de Investigaciones Jurídicas de la UNAM

9. Acto de señalar o asignar algo a alguien como de su competencia.

\begin{tabular}{|l|l|l|}
\hline Decidir ( ) & Atribuir ( ) & $\operatorname{Mirar}($ ) \\
\hline
\end{tabular}

10. Asunto de que se trata o que se propone para consultar a alguien y pedirle su dictamen.

\begin{tabular}{|l|l|l|}
\hline Consulta ( ) & Expediente ( ) & Caso ( ) \\
\hline
\end{tabular}

\section{Ejercicio léxico 3}

Anota la opción que consideres como mejor definición de las siguientes palabras:

\section{Común ( )}

a. Que es usado por todo el mundo.

b. Corriente, recibido y admitido de todos o de la mayor parte.

c. Que pertenece a una comunidad.

2. Significar ( )

a. Hacer saber, declarar o manifestar algo.

b. Dar sentido a un determinado objeto.

c. Permitir adentrarse a los contenidos de una situación.

3. Dirimir ( )
a. Resolver una ecuación matemática.
b. Concluir una etapa de la vida.
c. Ajustar, concluir, componer una controversia.

4. Facultad ( )
a. Lugar de encuentro entre estudiantes de derecho.
b. Poder o derecho para hacer algo.
c. Cada uno de los lugares donde se señala la técnica jurídica. 
5. Junta ( )

a. Reunión de varias personas para conferenciar o tratar de un asunto.

b. Agrupación de individuos para establecer diferentes oportunidades.

c. Grupo de personas para una determinada lectura.

6. Formal ( )

a. Que se refiere a la formalidad.

b. Opuesto a lo informal.

c. Expreso, preciso, determinado.

7. Encargar ( )

a. Dar a conocer una determinada situación.

b. Imponer una obligación.

c. Relación entre un compromiso y sus efectos. 
Este libro forma parte del acervo de la Biblioteca Jurídica Virtual del Instituto de Investigaciones Jurídicas de la UNAM

\section{Ejercicio léxico 4}

Haz una relación entre ambas columnas, trazando una línea entre el vocablo de la columna del lado izquierdo con la definición del lado derecho, que a tu juicio establezcan una relación correcta.

\begin{tabular}{|c|c|}
\hline Vocablo & Definición \\
\hline Derivar & $\begin{array}{l}\text { 1. Dar o distribuir algo, especialmente de ca- } \\
\text { rácter no material. }\end{array}$ \\
\hline Gobernar & $\begin{array}{l}\text { 2. Persona que representa y ejerce el minis- } \\
\text { terio público en los tribunales. }\end{array}$ \\
\hline Medio & $\begin{array}{l}\text { 3. Encaminar, conducir algo de una parte a } \\
\text { otra. }\end{array}$ \\
\hline Fiscal & $\begin{array}{l}\text { 4. Publicar en alta voz algo para que se haga } \\
\text { notorio a todos. }\end{array}$ \\
\hline Conciliación & 5. Producir algo, darle el primer ser. \\
\hline Dirimir & 6. Mandar con autoridad o regir algo. \\
\hline Impartir & $\begin{array}{l}\text { 7. Ajustar, concluir, componer una controver- } \\
\text { sia. }\end{array}$ \\
\hline Hacer & $\begin{array}{l}\text { 8. Acuerdo de los litigantes para evitar un } \\
\text { pleito o desistir del ya iniciado. }\end{array}$ \\
\hline Proclamar & 9. Que está intermedio en lugar o tiempo. \\
\hline
\end{tabular}


Este libro forma parte del acervo de la Biblioteca Jurídica Virtual del Instituto de Investigaciones Jurídicas de la UNAM www.juridicas.unam.mx

\section{Ejercicio léxico 5}

En las columnas siguientes anota, en el casillero correspondiente, el sinónimo (es decir, la palabra más parecida), así como el correspondiente antónimo (es decir, la palabra que signifique lo contrario), que más te parezca, del vocablo de la columna izquierda.

\begin{tabular}{|c|c|c|}
\hline Vocablo & Sinónimo & Antónimo \\
\hline Juicio & & \\
\hline Conciliar & & \\
\hline Gobernar & & \\
\hline Pertenecer & & \\
\hline Regla & & \\
\hline Litigio & & \\
\hline Formal & & \\
\hline Apartar & & \\
\hline Existir & & \\
\hline Dirimir & & \\
\hline Hacer & & \\
\hline Derivar & & \\
\hline Contar & & \\
\hline General & & \\
\hline Común & & \\
\hline Impartir & & \\
\hline
\end{tabular}


Este libro forma parte del acervo de la Biblioteca Jurídica Virtual del Instituto de Investigaciones Jurídicas de la UNAM www.juridicas.unam.mx

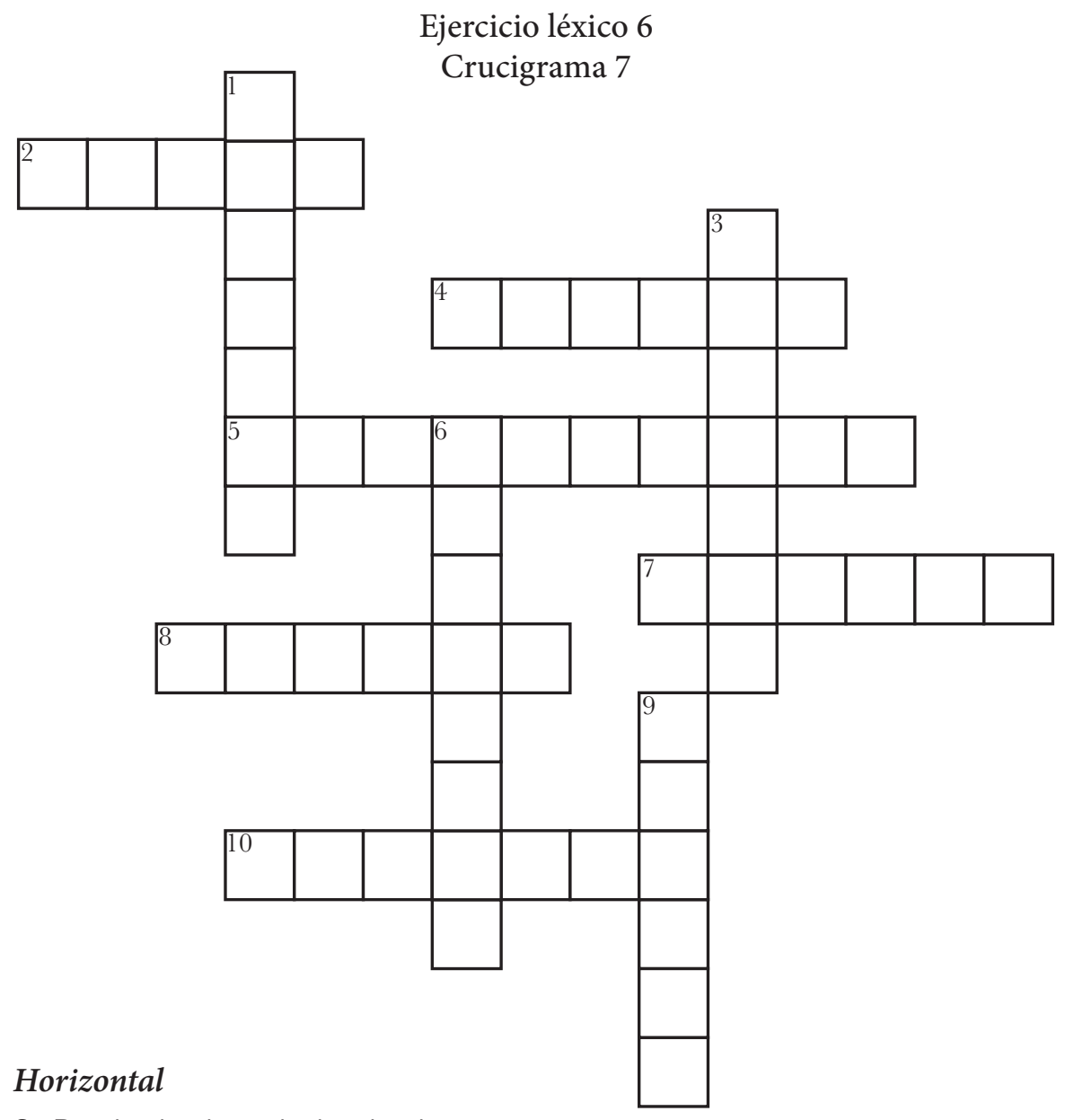

2. Producir algo, darle el primer ser.

4. Conocimiento de una causa en la cual el juez ha de pronunciar la sentencia.

5. Acción de atribuir.

7. Persona que representa y ejerce el ministerio público en los tribunales.

8. Referir un suceso verdadero o fabuloso.

10. Ajustar, concluir, componer una controversia.

\section{Vertical}

1. Común, frecuente, usual.

3. Pleito, altercado en juicio.

6. Dar o distribuir algo, especialmente de carácter no material.

9. Perteneciente o relativo a la forma. 
Este libro forma parte del acervo de la Biblioteca Jurídica Virtual del Instituto de Investigaciones Jurídicas de la UNAM

\author{
BIOGRAFÍA 13 \\ IgNaCio Luis VallaRTa Ogazón \\ Guadalajara, Jalisco, 25 de agosto de 1830-Ciudad de México, \\ 30 de diciembre de 1893
}

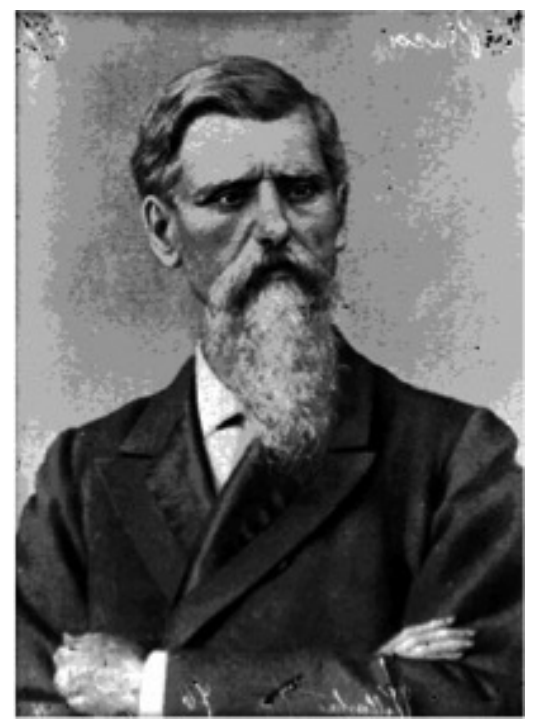

Político y jurista nacional, uno de los más destacados del siglo XIX. Estudió en el Seminario Conciliar de Guadalajara, después en el Instituto de Ciencias de Jalisco. En 1854 terminó la carrera de jurisprudencia en la Universidad de Guadalajara con el título de abogado, presentando la tesis con el tema Es lícito al hijo acusar criminalmente a su padre.

Se dedicó a su profesión como defensor de pobres y después como fiscal jurado de imprenta. Se incorporó a la revolución de Ayutla y con el apoyo de su tío, Pedro Ogazón, fue integrado al mundo de la administración pública y la política, en momentos de gran trascendencia para la historia nacional. Al ser nombrado gobernador del Estado el general Santos Degollado, lo nombró maestro de Derecho Natural, de Gentes, de Historia y Economía Política. En 1856, fue electo diputado por Jalisco al Congreso Constituyente, en donde tuvo muy pocas, pero importantes intervenciones. En términos generales puede decirse que militó en la fracción moderada del Congreso. Su talento sin embargo se mostró nítidamente en sus intervenciones sobre la expulsión de los jesuitas, los jurados y la libertad de trabajo. De regreso en Guadalajara 
Este libro forma parte del acervo de la Biblioteca Jurídica Virtual del Instituto de Investigaciones Jurídicas de la UNAM

fue nombrado consejero suplente del gobierno del Estado. En $1858 \mathrm{su}$ tío Pedro Ogazón, nombrado por Juárez gobernador de Jalisco, nombró a Vallarta como secretario de gobierno; colaboró con el boletín del Ejército Federal en el que expuso las tesis que defendían los liberales atacando con firmeza al clero por su participación directa en la Guerra de Reforma. Antes de ocupar este cargo se había desempeñado como ministro del Tribunal Superior de Justicia del Estado y defensor de indios, siendo gobernador del Estado Ignacio Herrera y Cairo.

A principio de 1866 embarcó a San Francisco, California, regresó al territorio nacional ese mismo año, en su ciudad natal reanudó con éxito su profesión de abogado.

En 1868 Vallarta fue nombrado secretario de Gobernación; sin embargo, pronto chocó con Lerdo de Tejada, y en cinco ocasiones le planteó al presidente Juárez que decidiera por él o por Lerdo. Juárez se quedó con Lerdo (mayo de 1871).

El 12 de abril de 1871, con el apoyo de Ramón Corona, fue postulado como candidato al gobierno del Estado de Jalisco. Se le declaró gobernador de Jalisco el 27 de junio de 1871, pero tomó posesión del puesto hasta el 27 de septiembre, siendo su periodo de gobierno de 1871 a 1875, teniendo que enfrentarse el 8 de noviembre a la rebelión de La Noria acaudillada por el general Porfirio Díaz. Entonces, Vallarta recibió del Congreso facultades extraordinarias para enfrentar los brotes rebeldes en el estado, sobresaliendo entre ellos el encabezado por Donato Guerra en Los Altos. En su gobierno, impulsó diversas obras de carácter social y administrativo.

Vallarta se incorporó al Plan de Tuxtepec y formó parte junto a Ogazón y Protacio Tagle del Directorio Revolucionario que redactó el plan y adiciones al mismo, promulgadas en Palo Blanco. Al triunfar el movimiento tuxtepecano, el 27 de septiembre de 1876, Porfirio Díaz formó su gabinete provisional y Vallarta fue nombrado secretario de Relaciones Exteriores. Luego fue electo presidente de la Suprema Corte de Justicia de la Nación, cargo desde el que trató de interpretar la Constitución de 1857, dando sus famosos Votos; éstos tratan puntos de derecho constitucional y es uno de los estudios clásicos de la materia. Llegó a la Corte, dejando en el camino a tres importantes figuras: Juan N. Méndez, Vicente Riva Palacio y Protacio Tagle. Como presidente de la Suprema Corte de Justicia, Vallarta que con el tiempo se había convertido en enemigo acérrimo de las comunidades indígenas, el 8 de enero de 1882 en un juicio promovido por los indígenas de Chicontepec, Veracruz, en contra del jefe político del lugar, declaró que no debía tolerarse la sub- 
sistencia de comunidades indígenas y sus bienes debían repartirse de manera individual y privada. Con este argumento jurídico que declaró la insubsistencia legal de las comunidades indígenas, se inició el gran proceso de apropiación de la tierra que caracterizó al Porfiriato; este sería uno de los puntos a resolver a fines del gobierno porfirista, y con el proceso revolucionario de 1910, con la instalación de las propiedades ejidales en la Constitución de 1917.

En noviembre de 1882, Vallarta presentó su renuncia a la presidencia de la Corte, retirándose al ejercicio privado de su profesión.

Murió en la Ciudad de México, de tifo exantemático, el 31 de diciembre de 1893. 
Este libro forma parte del acervo de la Biblioteca Jurídica Virtual del Instituto de Investigaciones Jurídicas de la UNAM

\section{BIOGRAFÍA 14 \\ Mario de la Cueva y de la Rosa}

Distrito Federal, México, 11 de julio de 1901-Distrito Federal, México, 6 de marzo de 1981

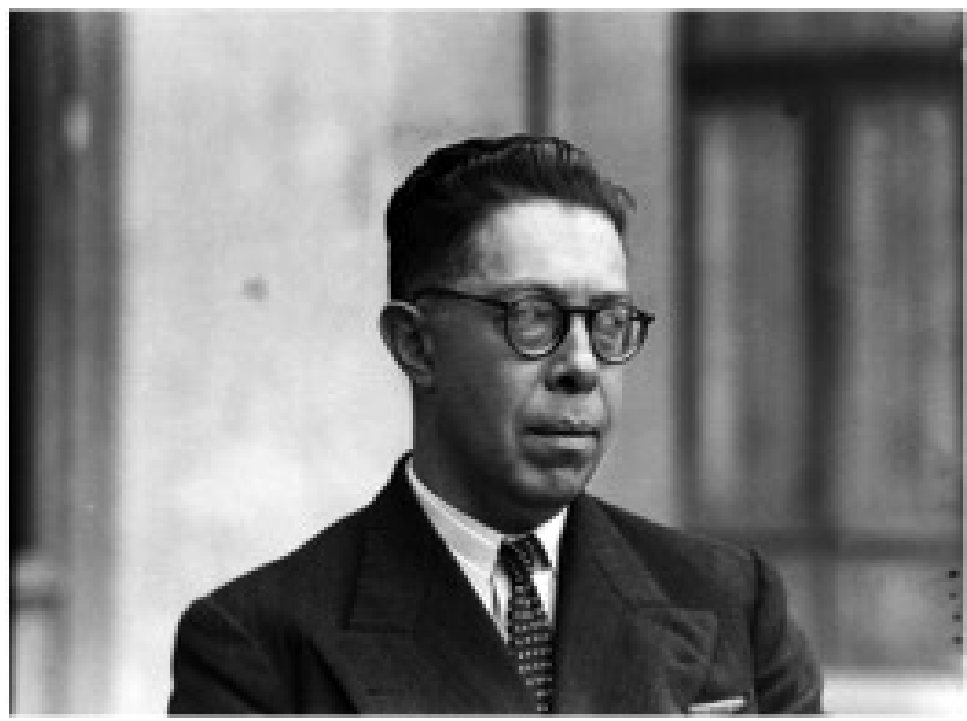

Académico y destacado jurista, que fuera rector de la Universidad Nacional Autónoma de México (UNAM) de 1940 a 1942. Realizó sus estudios preparatorianos en el Colegio Francés. Posteriormente, ingresó a la Escuela Nacional de Jurisprudencia (actual Facultad de Derecho de la UNAM), de donde obtuvo el título de abogado.

Impartió cátedra desde 1929 en la Escuela Nacional de Jurisprudencia y desde su fundación en la Escuela Nacional de Economía. Secretario de Estudio y Cuenta de la Suprema Corte de Justicia de la Nación (1934-1938). En agosto de 1938, el rector Gustavo Baz lo nombró secretario general de la UNAM y al concedérsele licencia indefinida al doctor Baz para separarse de su encargo, De la Cueva es nombrado rector provisional para concluir el periodo hasta 1942. Dos años después forma parte de la Junta de ex rectores que provisionalmente dirigió la Universidad y en 1951 es nombrado director de la Facultad de Derecho (1952-1954). En 1961 el rector Ignacio Chávez lo designa profesor emérito de la Facultad de Derecho. También fue coordinador de Humanidades de la UNAM (1962-1966). En atención a sus méritos 
Este libro forma parte del acervo de la Biblioteca Jurídica Virtual del Instituto de Investigaciones Jurídicas de la UNAM

le fue otorgado el Doctorado honoris causa por la UNAM y por la Universidad de San Carlos de Guatemala. Recibió el Premio Nacional de Ciencias y Artes en el área de Historia, Ciencias Sociales y Filosofía en 1978.

Entre sus textos, destacan Derecho mexicano del trabajo (1934), Teoría del Estado (1950), Historia del derecho constitucional mexicano de 1857 a 1917 (1960), Nuevo derecho mexicano del trabajo (1972) y La idea del Estado (1975).

En su honor, la UNAM nombró el Circuito Exterior de Humanidades de Ciudad Universitaria como "Maestro Mario de la Cueva". 


\section{GRUPO 8}

Objetivos: Incrementar el vocabulario básico, y ampliarlo en la mente del estudiante, de manera que pueda entregarle competencias para desenvolverse de mejor forma en la aproximación y comprensión de textos.

Las soluciones respectivas, para mayor comprensión, que te permitirán comprobar tu avance, las podrás encontrar en el apartado correspondiente al final de este libro.

\section{Ejercicio léxico 1}

I. Observa bien las siguientes palabras:

1. Territorio

2. Precepto

3. Específico

4. Corresponder

5. Disposición

6. Gestión

7. Procesos

8. Ejercicio

9. Especie

10. Contenciosa

11. Visión

12. Prever

13. Disponer

14. Ordinaria

15. Cualidad
16. Intervención

17. Propia

18. Reservado

19. Tratar

20. Sustanciar

21. Constitucional

22. Asunto

23. Judicial

24. Involucrar

25. Resolución

26. Excepcional

27. Existencia

28. Diccionario

29. Rural

II. Consulta en tu diccionario qué significan las palabras anteriores que ya observaste. 
Este libro forma parte del acervo de la Biblioteca Jurídica Virtual del Instituto de Investigaciones Jurídicas de la UNAM

III. De las palabras anteriores, selecciona la palabra o frase acorde al texto o al sentido expresado en el enunciado:8

1. La jurisdicción se relaciona con lo dispuesto por el artículo 13 de la Constitución Política de los Estados Unidos Mexicanos, que prevé la improcedencia de procesos sustanciados ante tribunales especiales.

2. Jurisdicción es la que corresponde a los órganos especializados en la resolución de asuntos derivados de la interpretación y aplicación de los preceptos constitucionales.

3. La jurisdicción es la que corresponde a los juzgadores de los Poderes Judiciales de la Federación, de los estados y del Distrito Federal.

4. La jurisdicción es aquella a la que se atribuye el conocimiento de asuntos no reservados a una jurisdicción especial, que es la que tiene lugar en atención a las cualidades de una persona que sólo se puede ver involucrada en un tipo específico de asuntos.

5. La jurisdicción —o "retenida" - la concede la propia ley a los órganos jurisdiccionales, a través de disposiciones en las que se establece exactamente cuál es su jurisdicción

6. Voluntaria y Esta clasificación se basa en la existencia o inexistencia de una controversia.

7. La jurisdicción concurrente supone la intervención, en la misma especie de asuntos, de órganos del Poder Judicial de la Federación y de la entidad federativa del de que se trate.

8 Lo anterior, asumiendo que puedes adecuar la mejor conjugación verbal y la relación entre género y número, para dar a la frase un sentido coherente. 
Este libro forma parte del acervo de la Biblioteca Jurídica Virtual del Instituto de Investigaciones Jurídicas de la UNAM www.juridicas.unam.mx

\section{Ejercicio léxico 2}

Marca con una "X" la palabra que mejor consideres para la definición dada.

1. Que es propio de algo y lo caracteriza y distingue de otras cosas.

\begin{tabular}{|l|l|l} 
Específico ( ) & Propio ( ) & Razonable ( )
\end{tabular}

2. Conjunto de las fases sucesivas de un fenómeno natural o de una operación artificial.

\begin{tabular}{|l|l|l|}
\hline Avance ( ) & Razón ( ) & Proceso ( ) \\
\hline
\end{tabular}

3. Llevar adelante una iniciativa o un proyecto.

\begin{tabular}{|c|c|c|}
\hline Gestión ( ) & Operación ( ) & Cláusula ( ) \\
\hline
\end{tabular}

4. Conjunto de elementos semejantes entre sí por tener uno o varios caracteres comunes.

\begin{tabular}{|l|l|l|}
\hline Similar ( ) & Especie ( ) & Asunto ( ) \\
\hline
\end{tabular}

5. Precepto legal o reglamentario, deliberación, orden y mandato de la autoridad.

\begin{tabular}{|l|l|l|}
\hline Ley ( ) & Disposición ( ) & Decisión ( ) \\
\hline
\end{tabular}

6. Hacer uso de un derecho, capacidad o virtud.

\begin{tabular}{|l|l|l} 
Ejercicio ( ) & Facultad ( ) & Percepción ( )
\end{tabular}

7. Pagar con igualdad, relativa o proporcionalmente, afectos, beneficios o agasajos.

\begin{tabular}{|l|l|l|}
\hline Ayudar ( ) & Relacionar ( ) & Corresponder ( ) \\
\hline
\end{tabular}

8. Punto de vista particular sobre un tema, un asunto, etcétera.

\begin{tabular}{|c|c|c|}
\hline Visión ( ) & Prisma ( ) & Posición ( ) \\
\hline
\end{tabular}


Este libro forma parte del acervo de la Biblioteca Jurídica Virtual del Instituto de Investigaciones Jurídicas de la UNAM

9. Elemento o carácter distintivo de la naturaleza de alguien o algo.

\begin{tabular}{|l|l|l|} 
Cualidad ( ) & Carácter ( ) & Especificidad ( )
\end{tabular}

10. Colocar, poner algo en orden y situación conveniente.

\begin{tabular}{|l|l|l|}
\hline Aclarar ( ) & Precisar ( ) & Disponer ( ) \\
\hline
\end{tabular}

\section{Ejercicio léxico 3}

Anota la opción que consideres como mejor definición de las siguientes palabras:

1. Territorio ( )

a. Parte de cualquier terreno.

b. Porción de la superficie terrestre perteneciente a una nación, región, provincia, etcétera.

c. Lugar que ocupa una comunidad para convivir.

2. Ordinario ( )

a. Que es de poca monta.

b. Común, regular y que sucede habitualmente.

c. Sin valor alguno.

3. Prevenir ( )

a. Preparar, aparejar y disponer con anticipación lo necesario para un fin.

b. Señalar el camino previo a cualquier asunto.

c. Establecer los lineamientos de un objetivo natural.

4. Intervenir ( )

a. Concluir forzosamente un conflicto.

$b$. Forzar a que se resuelva un asunto de determinada manera.

c. Tomar parte en un asunto. 
5. Propio ( )

a. Que pertenece de manera exclusiva a alguien.

$b$. Antecedente de cualquier nombre.

c. Relación singular entre una cosa y su dueño.

6. Sustanciar ( )

a. Calificar una materia según sus cualidades.

b. Tramitar un asunto o un juicio hasta que quede resuelto en una sentencia.

c. Señalar lo correspondiente a alguna materia.

7. Resolución（ ）

a. Acción y efecto de resolver o resolverse.

b. Definición de un problema por la fuerza.

c. Reiteración de un fin por sí mismo. 
Este libro forma parte del acervo de la Biblioteca Jurídica Virtual del Instituto de Investigaciones Jurídicas de la UNAM

\section{Ejercicio léxico 4}

Haz una relación entre ambas columnas, trazando una línea entre el vocablo de la columna del lado izquierdo con la definición del lado derecho, que a tu juicio establezcan una relación correcta.

\begin{tabular}{|l|l|}
\hline \multicolumn{1}{|c|}{ Vocablo } & \multicolumn{1}{c|}{ Definición } \\
\hline Reservado & 1. Abarcar, incluir, comprender. \\
\hline Asunto & $\begin{array}{l}\text { 2. Perteneciente o relativo al juicio, a la ad- } \\
\text { ministración de justicia o a la judicatura. }\end{array}$ \\
\hline Judicial & $\begin{array}{l}\text { 3. Mandato u orden que el superior hace } \\
\text { observar y guardar al inferior o súbdito. }\end{array}$ \\
\hline Constitucional & $\begin{array}{l}\text { 4. Que constituye excepción de la regla co- } \\
\text { mún. }\end{array}$ \\
\hline Existencia & $\begin{array}{l}\text { 5. Cauteloso, reacio en manifestar su inte- } \\
\text { rior. }\end{array}$ \\
\hline Precepto & $\begin{array}{l}\text { 6. Perteneciente o relativo a la vida del cam- } \\
\text { po y a sus labores. }\end{array}$ \\
\hline Involucrar & 7. Acción de tener vida. \\
\hline Excepcional & 8. Materia de que se trata. \\
\hline Rural & $\begin{array}{l}\text { 9. Perteneciente o relativo a la Constitución } \\
\text { de un Estado. }\end{array}$ \\
\hline
\end{tabular}


Este libro forma parte del acervo de la Biblioteca Jurídica Virtual del Instituto de Investigaciones Jurídicas de la UNAM www.juridicas.unam.mx

\section{Ejercicio léxico 5}

En las columnas siguientes anota, en el casillero correspondiente, el sinónimo (es decir, la palabra más parecida), así como el correspondiente antónimo (es decir, la palabra que signifique lo contrario), que más te parezca, del vocablo de la columna izquierda.

\begin{tabular}{|c|l|l|}
\hline Vocablo & Sinónimo & Antónimo \\
\hline Especie & & \\
\hline Corresponder & & \\
\hline Intervenir & & \\
\hline Ordinario & & \\
\hline Ejercicio & & \\
\hline Tratable & & \\
\hline Propia & & \\
\hline Contenciosa & & \\
\hline Gestión & & \\
\hline Excepcional & & \\
\hline Específico & & \\
\hline Prever & & \\
\hline Reservado & & \\
\hline Existencia & & \\
\hline Proceso & & \\
\hline Rural & & \\
\hline Disponer & & \\
\hline Asunto & & \\
\hline & & \\
\hline & & \\
\hline & & \\
\hline & & \\
\hline
\end{tabular}


Este libro forma parte del acervo de la Biblioteca Jurídica Virtual del Instituto de Investigaciones Jurídicas de la UNAM www.juridicas.unam.mx

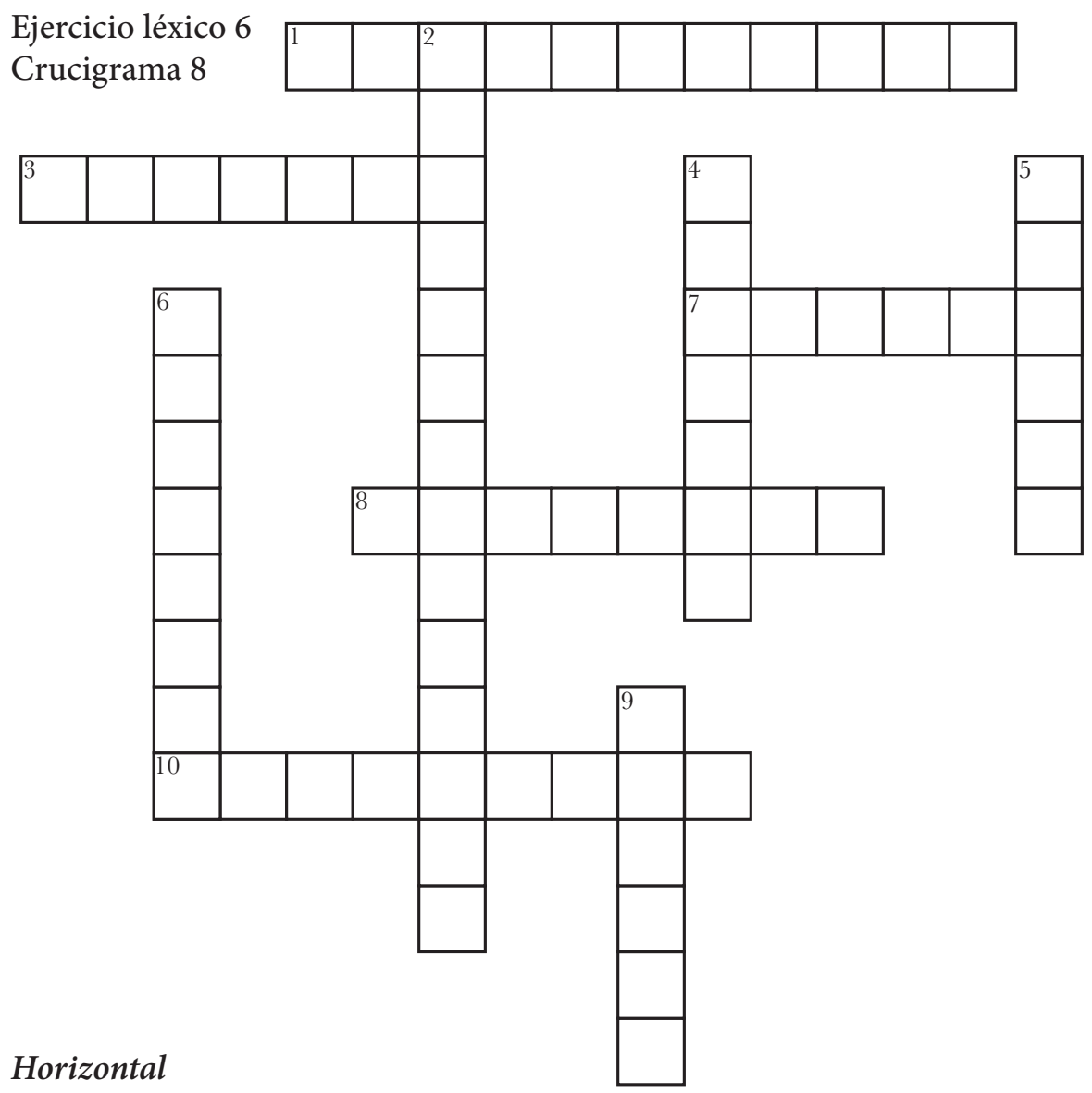

1. Que se aparta de lo ordinario, o que ocurre rara vez.

3. Cuasicontrato que se origina por el cuidado de intereses ajenos sin mandato de su dueño.

7. Característica, peculiar de cada persona o cosa.

8. Perteneciente o relativo al juicio, a la administración de justicia o a la judicatura.

10. Común, regular y que sucede habitualmente.

\section{Vertical}

2. Perteneciente o relativo a la Constitución de un Estado.

4. Conjunto de elementos semejantes entre sí por tener uno o varios caracteres comunes.

5. Manejar algo y usarlo materialmente.

6. Mandato u orden que el superior hace observar y guardar al inferior o súbdito.

9. Punto de vista particular sobre un tema, un asunto, etcétera. 
Este libro forma parte del acervo de la Biblioteca Jurídica Virtual del Instituto de Investigaciones Jurídicas de la UNAM

\section{BIOGRAFÍA 15 \\ EDUARDo García MÁYNEZ}

Ciudad de México, 11 de enero de 1908-Ciudad de México, 2 de septiembre de 1993

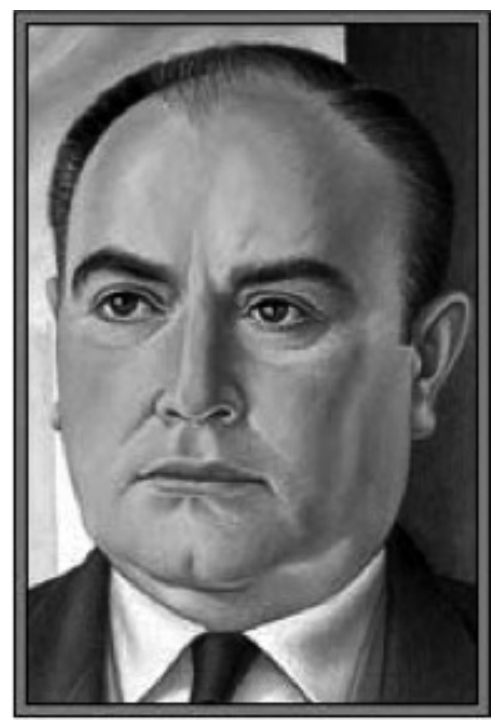

Académico, jurista y filósofo del derecho mexicano. Miembro del Colegio Nacional, director general del Instituto Tecnológico Autónomo de México, profesor emérito de la UNAM, secretario general e investigador emérito del Instituto de Investigaciones Filosóficas y autor de varias obras importantes de derecho

Profesor de la UNAM desde 1939; doctor en derecho y director de la Facultad de Filosofía y Letras a partir de 1953.

Sus investigaciones versaban sobre el problema de la ética y la filosofía del derecho, con una notable influencia de la tradición germánica. Propuso una axiología jurídica objetiva que tuviera por fundamento la idea de la libertad humana. Aplicando las propuestas de la moderna axiomática, estudió la posibilidad de elaborar una lógica del deber jurídico, que influyó de forma notable en América Latina. En su axiomática trabajó la aplicación al ámbito jurídico de los principios lógicos de identidad, contradicción, tercero excluido y razón suficiente.

Miembro del Colegio Nacional desde 1957, Premio Nacional de Historia, Ciencias Sociales y Filosofía (1976) y Premio UNAM (1987). 
Autor de Libertad como derecho y poder (1940), del clásico Introducción al estudio del derecho (1940), Ética (1944), Diálogo sobre las fuentes formales del derecho (1949) Introducción a la lógica jurídica (1951), Los principios de la ontología formal en el derecho (1953) y Lógica del juicio jurídico (1955), entre otros textos. 
Este libro forma parte del acervo de la Biblioteca Jurídica Virtual del Instituto de Investigaciones Jurídicas de la UNAM

\section{BIOGRAFÍA 16 Alfonso García Robles}

Zamora, Michoacán, 1911-Ciudad de México, 1991

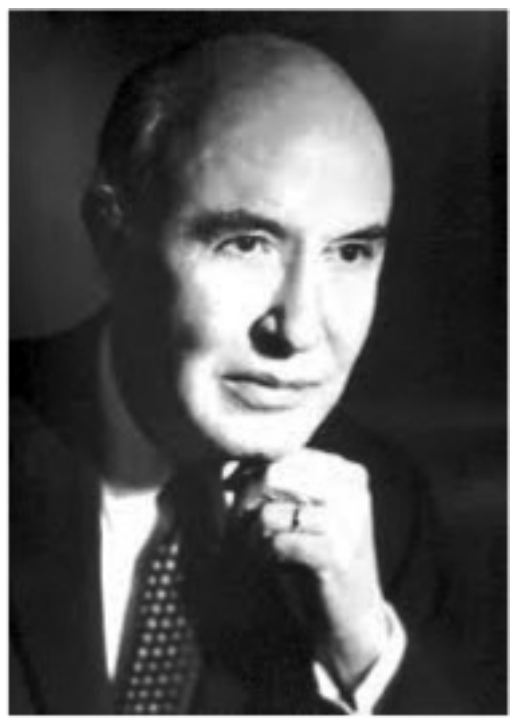

Diplomático y jurista mexicano. Sin duda uno de los especialistas más destacados en derecho y política internacional del país, figura entre los juristas y diplomáticos que contribuyeron a la fundación de la ONU y a la promulgación en 1945 de la Carta de las Naciones. Por la intensa actividad que desplegó a lo largo de su carrera en pro de la desnuclearización y el desarme, recibió en 1982 el Premio Nobel de la Paz.

Nacido en una familia de comerciantes, Alfonso García Robles recibió su formación secundaria en Guadalajara. Cursó sus estudios universitarios en Ciudad de México, donde obtuvo la Licenciatura en Derecho en la Facultad de Derecho de la UNAM. Su interés por el derecho internacional lo llevaría a completar sus estudios en Europa.

En 1936 obtuvo el premio extraordinario por la tesis que realizó en el Instituto de Estudios Internacionales de la Universidad de París. Continuó ampliando estudios en Holanda, donde en 1938 recibió el diploma de la Academia de Derecho Internacional de La Haya.

De regreso a México en 1939, ingresó en la diplomacia, y en octubre de ese mismo año fue enviado a Estocolmo como tercer secretario adscrito a la legación de México. En 1941 fue destinado a la Secretaría 
Este libro forma parte del acervo de la Biblioteca Jurídica Virtual del Instituto de Investigaciones Jurídicas de la UNAM

de Relaciones Exteriores de México, donde a lo largo de cinco años permaneció en calidad de subdirector de Asuntos Políticos del Servicio Diplomático.

Fue el representante de México en el proceso de creación de la ONU en 1945. Fue el representante de la ONU en la Conferencia de Bogotá (1948), que sancionaba la Carta de la OEA.

Fue embajador de México en Brasil (1961-1964), y se hizo cargo de la Subsecretaría de Relaciones Exteriores en 1970. En tal calidad presidió las reuniones para la desnuclearización de América Latina celebradas en México a partir de 1964, que culminarían con la firma del Tratado para la Proscripción de las Armas Nucleares en América Latina (1967), conocido como Tratado de Tlatelolco.

En 1975 fue nombrado secretario de Relaciones Exteriores.

Desde enero de 1977, como representante de México en la ONU, participó ante el Comité de Desarme de Naciones Unidas con sede en Ginebra. La experiencia que había acumulado le valió que fuera considerado como el decano de los diplomáticos especializados en desarme y, en 1978, su constancia aseguró el acuerdo en la primera Asamblea General de la ONU sobre desarme.

Embajador emérito en 1981, su carrera se vio coronada en 1982 cuando el Parlamento noruego decidió otorgarle, compartido con la socióloga sueca Alva Myrdal, el Premio Nobel de la Paz, por su labor en pro del desarme internacional.

Escribió numerosas obras sobre temas diplomáticos y geopolíticos, entre las que destacan El panamericanismo y la política de buena vecindad (1938), De la Carta del Atlántico a la conferencia de San Francisco (2 vols. 1949), La desnuclearización de América Latina (1967), El Tratado de Tlatelolco (1967) y La Asamblea General del Desarme (1979). 


\section{GRUPO 9}

Objetivos: Incrementar el vocabulario básico, y ampliarlo en la mente del estudiante, de manera que pueda entregarle competencias para desenvolverse de mejor forma en la aproximación y comprensión de textos.

Las soluciones respectivas, para mayor comprensión, que te permitirán comprobar tu avance, las podrás encontrar en el apartado correspondiente al final de este libro.

\section{Ejercicio léxico 1}

I. Observa bien las siguientes palabras:
1. Adecuación
16. Competencia
2. Repercutir
17. Interpretar
3. Forjar
18. Mecanismo
4. Adaptar
19. Internacional
5. Sustraer
20. Doctrina
6. Reforma
21. Mecanismo
7. Actuación
22. Data
8. Destacar
23. Estándar
9. Académica
24. Reglamento
10. Catálogo
25. De oficio
11. Decreto
26. Proteger
12. Régimen
27. Derecho
13. Ajustar
28. Verificar
14. Convencionalidad
29. Convencionalidad
15. Juez
30. Representación

II. Consulta en tu diccionario qué significan las palabras anteriores que ya observaste. 
Este libro forma parte del acervo de la Biblioteca Jurídica Virtual del Instituto de Investigaciones Jurídicas de la UNAM

III. De las palabras anteriores, selecciona la palabra o frase acorde al texto o al sentido expresado en el enunciado: ${ }^{9}$

1. Dentro de los contenidos de la constitucional de 2011 en materia de derechos humanos, uno de los que más destaca en la interpretación del juez y de toda autoridad jurisdiccional (y no sólo judicial) ha sido la del control de convencionalidad.

2. Para la mexicana Roselia Bustillo Marín, el control de convencionalidad se trata de un mecanismo que se ejerce para verificar que una ley, reglamento o acto de las autoridades del Estado, se ajusta a las normas, los principios y obligaciones de la Convención Americana de Derechos Humanos principalmente, en la que funda la competencia contenciosa de la Corte IDH.

3. Si llega a existir una manifiesta incompatibilidad entre la norma interna y el referido corpus iuris interamericano, es obligación de las respectivas autoridades estatales el de de aplicar la norma nacional, con el objeto de evitar la violación de los derechos humanos protegidos internacionalmente.

4. La del control de convencionalidad ha variado en relación a su definición: consiste en verificar la adecuación de las normas jurídicas internas que aplican en casos concretos a la Convención Americana sobre Derechos Humanos... y a los estándares interpretativos forjados por la Corte Interamericana de Derechos Humanos...

5. Existe una obligación a cargo de todas las autoridades de los Estados parte de la CADH, respecto a interpretar toda norma jurídica nacional (Constitución, ley, decreto, reglamento, jurisprudencia, etc.) de conformidad con la misma CADH

6. Así, estas autoridades estatales han de ejercer el control de convencionalidad, actuando siempre en el ámbito de sus respectivas competencias, así como tomando en cuenta las debidas regulaciones procesales establecidas en su legislación interna.

7. No es posible seccionar internacionalmente al Estado, obligar ante la Corte sólo a uno o algunos de sus órganos, entregar a éstos la del Estado en el juicio - sin que esa representación repercuta sobre el Estado en su conjunto-y sustraer a otros de este ré-

9 Lo anterior, asumiendo que puedes adecuar la mejor conjugación verbal y la relación entre género y número, para dar a la frase un sentido coherente. 
Este libro forma parte del acervo de la Biblioteca Jurídica Virtual del Instituto de Investigaciones Jurídicas de la UNAM www.juridicas.unam.mx

gimen convencional de responsabilidad, dejando sus actuaciones fuera del "control de convencionalidad" que trae consigo la jurisdicción de la Corte Internacional.

\section{Ejercicio léxico 2}

Marca con una " $X$ " la palabra que mejor consideres para la definición dada.

1. Apartar, separar, extraer.

\begin{tabular}{l|l|l} 
Sustraer ( ) & Alarmar ( ) & Discriminar ( )
\end{tabular}

2. Aquello que se propone, proyecta o ejecuta como innovación o mejora en algo.

\begin{tabular}{|l|l|l|}
\hline Vaivén ( ) & Reforma ( ) & Pensamiento ( ) \\
\hline
\end{tabular}

3. Persona que tiene autoridad y potestad para juzgar y sentenciar.

\begin{tabular}{|c|c|c|}
\hline Juez ( ) & Abogado ( ) & Autoridad ( ) \\
\hline
\end{tabular}

4. Relación ordenada de diversos libros, documentos, personas, objetos, etcétera, que están relacionados entre sí.

\begin{tabular}{|l|l|l|}
\hline Lista ( ) & Catálogo ( ) & Prioridad ( ) \\
\hline
\end{tabular}

5. Poner de relieve, resaltar.

\begin{tabular}{|l|l|l|}
\hline Señalar ( ) & $\operatorname{Decir}($ ) & $\operatorname{Destacar}($ ) \\
\hline
\end{tabular}

6. Sistema político por el que se rige una nación.

\begin{tabular}{|l|l|l|}
\hline Régimen ( ) & Estado ( ) & Partido ( ) \\
\hline
\end{tabular}

7. Conformar, acomodar algo a otra cosa, de suerte que no haya discrepancia entre ellas.

\begin{tabular}{|l|l|l} 
Ajustar ( ) & Relacionar ( ) & Precisar ( )
\end{tabular}


Este libro forma parte del acervo de la Biblioteca Jurídica Virtual del Instituto de Investigaciones Jurídicas de la UNAM

8. Conjunto de ideas u opiniones religiosas, filosóficas, políticas, etcétera, sustentadas por una persona o grupo.

\begin{tabular}{|c|c|c|}
\hline Idea ( ) & Doctrina ( ) & Convicción ( ) \\
\hline
\end{tabular}

9. Tiempo en que ocurre o se hace algo.

\begin{tabular}{|l|l|l} 
Espacio ( ) & Reloj ( ) & Data ( )
\end{tabular}

10. Que sirve como tipo, modelo, norma, patrón o referencia.

\begin{tabular}{|c|c|c|}
\hline Estándar ( ) & Útil ( ) & Ayuda ( ) \\
\hline
\end{tabular}

\section{Ejercicio léxico 3}

Anota la opción que consideres como mejor definición de las siguientes palabras:

1. Forjar ( )

a. Establecer un carácter determinado.

b. Inventar, fingir, fabricar.

c. Realizar con ingenio una cosa.

2. Decreto ( )

a. Resolución legislativa con carácter general y obligatoria.

b. Mandato de autoridad administrativa inferior.

c. Decisión de un gobernante o de una autoridad, o de un tribunal o juez, sobre la materia o negocio en que tengan competencia.

3. Convencionalidad ( )

a. Acto informal realizado entre particulares.

$b$. Control de derechos humanos, realizado ya por el sistema interamericano de derechos humanos, o por las autoridades públicas de cada país.

c. Evento por el cual se comprometen diversas personas jurídicas. 
Este libro forma parte del acervo de la Biblioteca Jurídica Virtual del Instituto de Investigaciones Jurídicas de la UNAM

4. Académico ( )

a. Perteneciente o relativo a centros oficiales de enseñanza, especialmente a los superiores.

b. Profesor universitario encargado de establecer nuevos conocimientos.

c. Relativo a la actividad universitaria.

5. Internacional ( )

a. Que no es del mundo.

b. Perteneciente o relativo a países distintos del propio.

c. Relacionado con los organismos de cada país.

6. Proteger ( )

a. Dar ayuda cuando hay un problema.

b. Otorgar apoyo ante las dificultades.

c. Amparar, favorecer, defender a alguien o algo.

7. Verificar ( )

a. Comprobar o examinar la verdad de algo.

$b$. Llevar el carro al servicio técnico.

c. Asegurarse que se brinde solución a un problema. 
Este libro forma parte del acervo de la Biblioteca Jurídica Virtual del Instituto de Investigaciones Jurídicas de la UNAM

\section{Ejercicio léxico 4}

Haz una relación entre ambas columnas, trazando una línea entre el vocablo de la columna del lado izquierdo con la definición del lado derecho, que a tu juicio establezcan una relación correcta.

\begin{tabular}{|c|c|}
\hline Vocablo & Definición \\
\hline Adaptar & $\begin{array}{l}\text { 1. Adaptar algo a las necesidades o condicio- } \\
\text { nes de una persona o de una cosa. }\end{array}$ \\
\hline Reglamento & $\begin{array}{l}\text { 2. Medios prácticos que se emplean en las } \\
\text { artes. }\end{array}$ \\
\hline Representación & 3. Acomodar, ajustar algo a otra cosa. \\
\hline Interpretar & $\begin{array}{l}\text { 4. Norma jurídica general y con rango inferior } \\
\text { a la ley, dictada por una autoridad adminis- } \\
\text { trativa. }\end{array}$ \\
\hline Actuar & 5. Trascender, causar efecto en otra. \\
\hline Competencia & $\begin{array}{l}\text { 6. Ejercer funciones propias de su cargo u } \\
\text { oficio. }\end{array}$ \\
\hline Repercutir & $\begin{array}{l}\text { 7. Ámbito legal de atribuciones que corres- } \\
\text { ponden a una entidad pública o a una autori- } \\
\text { dad judicial o administrativa }\end{array}$ \\
\hline Mecanismo & $\begin{array}{l}\text { 8. Acto de sustituir a alguien o hacer sus ve- } \\
\text { ces. }\end{array}$ \\
\hline Adecuar & $\begin{array}{l}\text { 9. Explicar o declarar el sentido de algo, y } \\
\text { principalmente el de un texto. }\end{array}$ \\
\hline
\end{tabular}


Este libro forma parte del acervo de la Biblioteca Jurídica Virtual del Instituto de Investigaciones Jurídicas de la UNAM www.juridicas.unam.mx

\section{Ejercicio léxico 5}

En las columnas siguientes anota, en el casillero correspondiente, el sinónimo (es decir, la palabra más parecida), así como el correspondiente antónimo (es decir, la palabra que signifique lo contrario), que más te parezca, del vocablo de la columna izquierda.

\begin{tabular}{|c|c|c|}
\hline Vocablo & Sinónimo & Antónimo \\
\hline Ajustar & & \\
\hline Actuar & & \\
\hline Sustraer & & \\
\hline Estándar & & \\
\hline Proteger & & \\
\hline Verificar & & \\
\hline Destacar & & \\
\hline Forjar & & \\
\hline Competencia & & \\
\hline Reforma & & \\
\hline Adecuar & & \\
\hline Repercutir & & \\
\hline Adaptar & & \\
\hline Representar & & \\
\hline
\end{tabular}


Este libro forma parte del acervo de la Biblioteca Jurídica Virtual del Instituto de Investigaciones Jurídicas de la UNAM

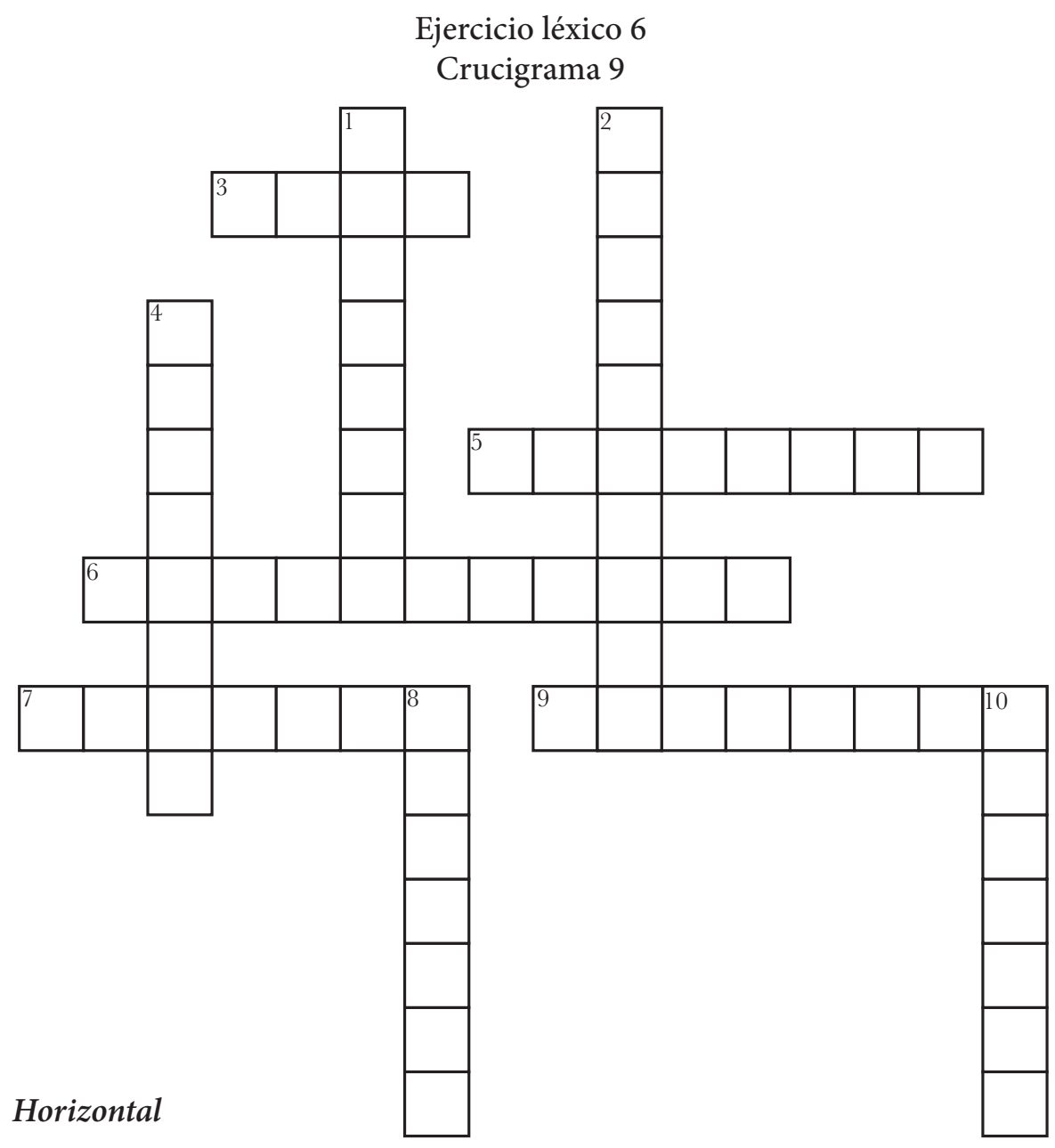

3. Persona que tiene autoridad y potestad para juzgar y sentenciar.

5. Conjunto de ideas u opiniones religiosas, filosóficas, políticas, etcétera, sustentadas por una persona o grupo.

6. Explicar o declarar el sentido de algo.

7. Acomodar, ajustar algo a otra cosa.

9. Amparar, favorecer, defender a alguien o algo.

\section{Vertical}

1. Poner de relieve, resaltar.

2. Trascender, causar efecto en otra cosa o persona.

4. Que sirve como tipo, modelo, norma, patrón o referencia.

8. Aquello que se propone, proyecta o ejecuta como innovación o mejora en algo.

10. Sistema político por el que se rige una nación. 
Este libro forma parte del acervo de la Biblioteca Jurídica Virtual del Instituto de Investigaciones Jurídicas de la UNAM

\section{BIOGRAFÍA 17 \\ HÉCTOR Fix-ZaMudio}

Ciudad de México, 4 de septiembre de 1924

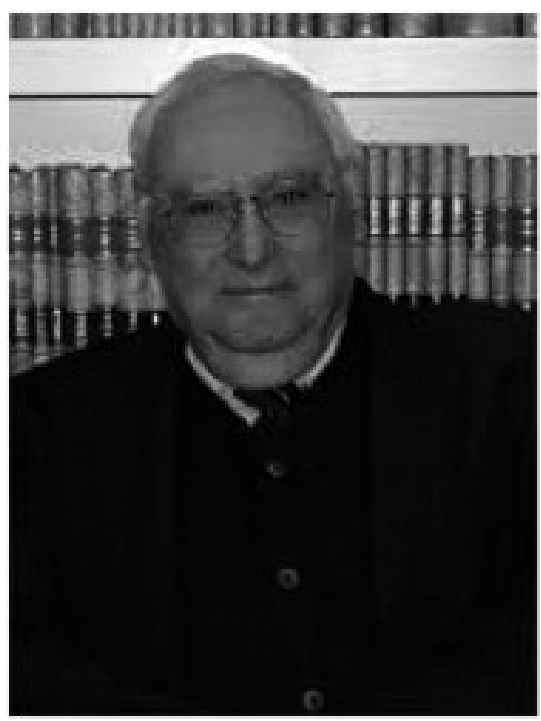

Jurista, académico y escritor mexicano, autor de numerosas obras de derecho en las áreas de derecho constitucional, derecho procesal constitucional y derechos humanos.

Ha ocupado cargos tales como auxiliar y secretario de estudio y cuenta en la Segunda Sala de la Suprema Corte de Justicia de la Nación, investigador y director del Instituto de Derecho Comparado de México (actual Instituto de Investigaciones Jurídicas de la UNAM), miembro del Consejo Consultivo de Ciencias de la Presidencia de la República, profesor e investigador de la Facultad de Derecho de la UNAM, entre otros.

Estudió la licenciatura y el doctorado en la Facultad de Derecho de la UNAM. Ha impartido cursos y conferencias en varias universidades de México, así como en las facultades de derecho de las universidades de Los Andes y Carabobo, de Venezuela; San Carlos, de Guatemala; Belgrano, de Buenos Aires; Católica, de Río de Janeiro; Salamanca, Sevilla, Alcalá de Henares y Valencia, de España.

Actualmente trabaja como investigador emérito en el Instituto de Investigaciones Jurídicas y del Sistema Nacional de Investigadores. Asimismo, su prioridad en derecho constitucional, derechos humanos y 
Este libro forma parte del acervo de la Biblioteca Jurídica Virtual del Instituto de Investigaciones Jurídicas de la UNAM

del recurso de amparo lo han llevado a ser designado presidente del Instituto Iberoamericano de Derecho Constitucional desde su fundación en 1974. Es miembro de los institutos Mexicano, Iberoamericano e Internacional de Derecho Procesal, del Instituto Internacional de Derechos Humanos de Estrasburgo, numerario de la Academia Internacional de Derecho Comparado, del Instituto de Derecho Agrario Internacional y Comparado, del Instituto Español de Derecho Procesal, y de la Academia Mexicana de Legislación y Jurisprudencia. También es miembro del Colegio Nacional desde 1974.

Por otra parte, algunos de los reconocimientos que ha recibido son, en 1963, el premio anual de la Academia de la Investigación Científica, y, en 1982, le otorgaron el Premio Nacional de Historia, Filosofía y Ciencias Sociales; el Premio UNESCO, 1986, de Enseñanza de los Derechos Humanos, en París, Francia, y la Presea Estado de México, José María Luis Mora; el Premio Universidad Nacional (1991), el Premio Nacional de Jurisprudencia (1994), Premio Juchimán de Plata en Derechos Humanos y la Paz (1997), la Medalla Belisario Domínguez (2002), y el Premio Internacional Justicia en el Mundo, conferido por la Unión Internacional de Magistrados (2004). Es doctor honoris causa por la Universidad Complutense de Madrid (2003), por la Universidad de Castilla La Mancha (2011) y por la Universidad de Sevilla.

Algunas de sus obras, claramente dedicadas a la investigación en Derecho son Ensayos sobre Metodología, Enseñanza e investigación Jurídicas; La protección procesal de los derechos humanos ante las jurisdicciones nacionales; Introducción a la justicia administrativa en el ordenamiento mexicano; Latinoamérica: Constitución, proceso y derechos humanos, y Derecho constitucional mexicano y comparado (en coautoría). 
Este libro forma parte del acervo de la Biblioteca Jurídica Virtual del Instituto de Investigaciones Jurídicas de la UNAM

\section{BIOGRAFÍA 18 \\ Sergio GARCÍA RAMírez}

Guadalajara, Jal., 1 de febrero de 1938

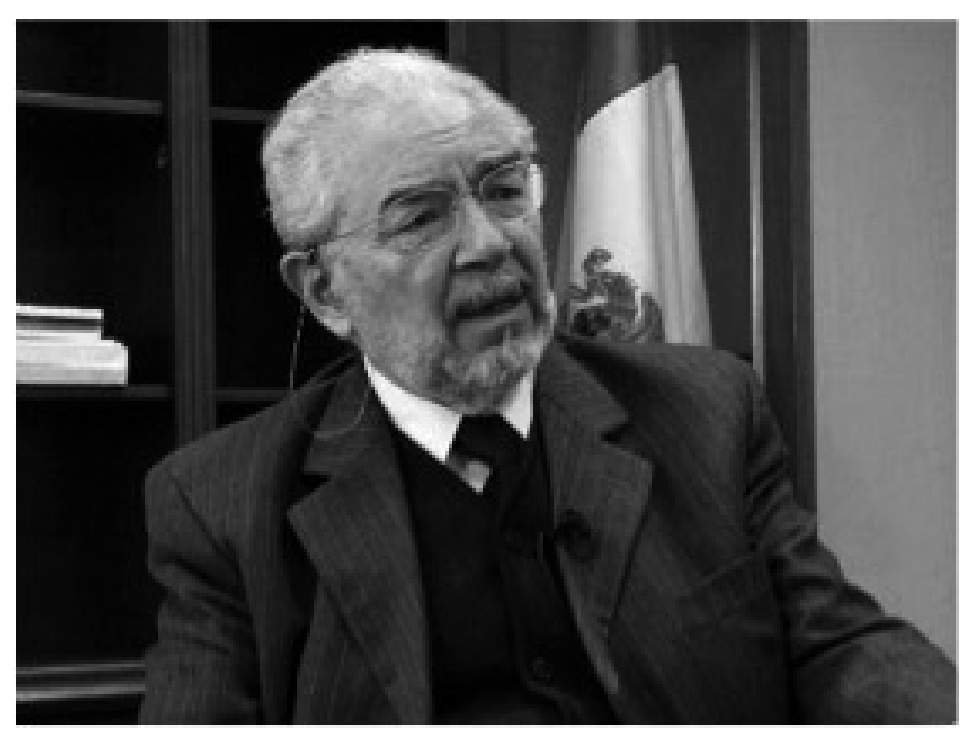

Político y abogado mexicano, jurista, académico y escritor. Ha ocupado diversos cargos públicos, como juez del Tribunal de Menores del Estado de México, procurador general de la República y del Distrito Federal, y ex juez y presidente de la Corte Interamericana de Derechos Humanos.

Licenciado en derecho por la Facultad de Derecho de la UNAM, en 1963, con mención honorífica, y doctor en derecho en la misma Facultad, en 1971, con mención magna cum laude (que por primera vez se otorgó en la División de Estudios Superiores de dicha Facultad).

Investigador de tiempo completo, en el Instituto de Investigaciones Jurídicas. Antiguo profesor titular de la Facultad de Derecho de la UNAM. Miembro del Sistema Nacional de Investigadores, como Investigador Nacional Emérito. Fue miembro de la Junta de Gobierno de la Universidad Nacional Autónoma de México y director de la Revista de la Facultad de Derecho de la UNAM. Miembro de la junta de gobierno del INACIPE. Presidente de la Academia Mexicana de Ciencias Penales.

En 1997 fue electo juez titular de la Corte Interamericana de Derechos Humanos por la Asamblea General de la Organización de los Estados Americanos, y reelecto en 2003 para otro periodo de seis años 
Este libro forma parte del acervo de la Biblioteca Jurídica Virtual del Instituto de Investigaciones Jurídicas de la UNAM

(2004-2010). En noviembre de 2004 fue elegido presidente de la señalada Corte, cargo que desempeñó hasta enero de 2008.

Además, ha ocupado otros cargos públicos, como juez del Tribunal para Menores del Estado de México; director de la cárcel preventiva de la Ciudad de México, procurador de justicia del Distrito Federal (19701972); subsecretario de la Industria Paraestatal (SEPAFIN, 1978-1981); secretario del trabajo; procurador general de la República, y secretario general del PRI (2000-2001).

Autor de más de cincuenta libros y numerosos artículos de revista, de investigación, docencia y divulgación, publicados en México y en el extranjero. La mayoría de sus publicaciones abordan temas jurídicos y criminológicos. Cuenta también con trabajos de otras materias: política y literaria, principalmente.

Entre sus obras jurídicas figuran: La ciudadanía de la juventud, La prisión, Curso de derecho procesal penal, Prontuario del proceso penal mexicano (en coautoría), Derecho penal, El sistema penal mexicano, Los personajes del cautiverio: prisiones, prisioneros y custodios, Manual de prisiones, Delitos en materia de estupefacientes y psicotrópicos, Cuestiones penales y criminológicas contemporáneas; Poder Judicial y ministerio público, Los derechos humanos y el derecho penal; Derecho social económico y la empresa pública en México, El nuevo procedimiento penal mexicano, La Corte Penal Internacional, Los derechos humanos y la jurisdicción interamericana, La Corte Interamericana de Derechos Humanos, y La reforma constitucional sobre derechos humanos. 2009-2011 (en coautoría), entre otros. 


\section{GRUPO 10}

Objetivos: Incrementar el vocabulario básico, y ampliarlo en la mente del estudiante, de manera que pueda entregarle competencias para desenvolverse de mejor forma en la aproximación y comprensión de textos.

Las soluciones respectivas, para mayor comprensión, que te permitirán comprobar tu avance, las podrás encontrar en el apartado correspondiente al final de este libro.

\section{Ejercicio léxico 1}

I. Observa bien las siguientes palabras:
1. Mixto
16. Materializar
2. Masas
17. Empresa
3. Natural
18. Aspiración
4. Recuperar
19. Efectivo
5. Plan
20. Estricto
6. Fortalecer
21. Riquezas
7. Subsuelo
22. Campesinos
8. Crédito
23. Redención
9. Nacionalización
24. Cardenismo
10. Agrícola
25. Vías
11. Economía
26. Capacidad
12. Operación
27. Capacitar
13. Sexenal
28. Distinto
14. Fertilizante
29. Nacionalista
15. Proyecto
30. Aspiración

II. Consulta en tu diccionario qué significan las palabras anteriores que ya observaste. 
Este libro forma parte del acervo de la Biblioteca Jurídica Virtual del Instituto de Investigaciones Jurídicas de la UNAM

III. De las palabras anteriores, selecciona la palabra o frase acorde al texto o al sentido expresado en el enunciado: ${ }^{10}$

1. Para asegurar lo anterior, se proponía la formación de cooperativas, incruento del crédito agrícola, introducción de maquinaria y fertilizantes, así como la construcción de obras de riego y de comunicación.

2. Debía lograrse la redención económica y social de los dotándolos no sólo de tierras y aguas, sino organizándolos y capacitándolos económicamente.

3. Para materializar la mixta, Cárdenas impulsa el primer plan sexenal.

4. Debían tomarse medidas para elevar la de compra de las grandes masas, con lo cual se perseguía el fortalecimiento del mercado interno.

5. México debía realizar una política nacionalista para proteger mejor sus naturales.

6. Con esta política pública, de claro perfil social y nacionalista, el inicia los proyectos que intentan materializar las aspiraciones originales de la Revolución de 1910.

7. Debía ejercerse una estricta en la operación de las distintas empresas extranjeras.

8. Debía hacerse efectivo el principio constitucionalista de nacionalización del , mediante la recuperación de los recursos naturales.

10 Lo anterior, asumiendo que puedes adecuar la mejor conjugación verbal y la relación entre género y número, para dar a la frase un sentido coherente. 
Este libro forma parte del acervo de la Biblioteca Jurídica Virtual del Instituto de Investigaciones Jurídicas de la UNAM www.juridicas.unam.mx

\section{Ejercicio léxico 2}

Marca con una "X" la palabra que mejor consideres para la definición dada.

1. Intención, proyecto.

Creencia ( )

Plan ( )

Señal ( )

2. Apoyo, abono, comprobación.

\begin{tabular}{|l|l|l|}
\hline Crédito ( ) & Especie ( ) & Remesa ( ) \\
\hline
\end{tabular}

3. Que sucede o se repite cada seis años.

\begin{tabular}{|l|l|l|}
\hline Sexteto ( ) & Sexenal ( ) & Seisañero ( ) \\
\hline
\end{tabular}

4. Unidad de organización dedicada a actividades industriales, mercantiles o de prestación de servicios con fines lucrativos.

\begin{tabular}{|l|l|l|}
\hline Cámara ( ) & Lucro ( ) & Empresa ( ) \\
\hline
\end{tabular}

5. Terreno que está debajo de la capa labrantía o laborable o, en general, debajo de una capa de tierra.

\begin{tabular}{l|l|l} 
Subterráneo ( ) & Subsuelo ( ) & Interior ( )
\end{tabular}

6. Formado por varios elementos que se mezclan para componer otro.

\begin{tabular}{l|l|l} 
Mixto ( ) & Diverso ( ) & Diferente ( )
\end{tabular}

7. Perteneciente o relativo a la agricultura o al agricultor.

\begin{tabular}{|l|l|l|}
\hline Campo ( ) & Agrícola ( ) & Urbano ( ) \\
\hline
\end{tabular}

8. Hacer que la tierra sea fértil o más fértil.

\begin{tabular}{|l|l|l|}
\hline Campo ( ) & Fertilizar ( ) & Urbano ( ) \\
\hline
\end{tabular}


Este libro forma parte del acervo de la Biblioteca Jurídica Virtual del Instituto de Investigaciones Jurídicas de la UNAM

9. Estrecho, ajustado enteramente a la necesidad o a la ley y que no admite interpretación.

\begin{tabular}{|l|l|l|}
\hline Estricto ( ) & Parcial ( ) & Relacionado ( ) \\
\hline
\end{tabular}

10. Abundancia de bienes y cosas preciosas.

\begin{tabular}{|l|l|l} 
Riqueza ( ) & Dinero ( ) & Potentado ( )
\end{tabular}

\section{Ejercicio léxico 3}

Anota la opción que consideres como mejor definición de las siguientes palabras:

\section{Recuperar ( )}

a. Retomar lo que es ajeno.

b. Asumir las fuerzas que se habían perdido.

c. Volver a tomar o adquirir lo que antes se tenía.

2. Economía ( )

a. Aplicación de soluciones monetarias a problemas caseros.

b. Ciencia que estudia los métodos más eficaces para satisfacer las necesidades humanas materiales, mediante el empleo de bienes escasos.

c. Administración de las cosas que nos brindan placer.

3. Distinto ( )

a. Que no es parecido, que tiene diferentes cualidades.

b. Ajeno a lo común de una cosa.

c. Relación ordenada de diferenciaciones puntuales.

4. Redención（ ）

a. Acto de expiación de los pecados cometidos.

b. Manera de lograr la inspiración espiritual.

c. Acción de librar una obligación o extinguirla. 
5. Nacionalista ( )

a. Que posee el sentimiento fervoroso de pertenencia a una nación y de identificación con su realidad y con su historia.

b. Que se relaciona con las festividades locales.

c. Que tiene un arraigo en un lugar determinado.

6. Efectivo ( )

a. Fracción de dinero.

b. Que no aparenta.

c. Real y verdadero.

7. Fortalecer ( )

a. Dar ánimo.

b. Hacer más fuerte o vigoroso.

c. Entregar ayuda. 
Este libro forma parte del acervo de la Biblioteca Jurídica Virtual del Instituto de Investigaciones Jurídicas de la UNAM

\section{Ejercicio léxico 4}

Haz una relación entre ambas columnas, trazando una línea entre el vocablo de la columna del lado izquierdo con la definición del lado derecho, que a tu juicio establezcan una relación correcta.

\begin{tabular}{|c|c|}
\hline Vocablo & Definición \\
\hline Aspiración & $\begin{array}{l}\text { 1. Perteneciente o relativo a la naturaleza o } \\
\text { conforme a la cualidad o propiedad de las } \\
\text { cosas. }\end{array}$ \\
\hline Campesino & $\begin{array}{l}\text { 2. Muchedumbre o conjunto numeroso de } \\
\text { personas. }\end{array}$ \\
\hline Capacidad & 3. Perteneciente o relativo al campo. \\
\hline Operación & 4. Cualidad de apto, o con talento, para algo. \\
\hline Capacitar & 5. Ejecución de algo. \\
\hline Natural & $\begin{array}{l}\text { 6. Hacer que pasen a manos de nacionales } \\
\text { de un país bienes o títulos de la deuda del } \\
\text { Estado o de empresas particulares que se ha- } \\
\text { llaban en poder de extranjeros. }\end{array}$ \\
\hline Proyecto & $\begin{array}{l}\text { 7. Acción y efecto de pretender o desear al- } \\
\text { gún empleo, dignidad u otra cosa. }\end{array}$ \\
\hline Masas & 8. Hacer a alguien apto, habilitarlo para algo. \\
\hline Nacionalizar & 9. Designio o pensamiento de ejecutar algo. \\
\hline
\end{tabular}


Este libro forma parte del acervo de la Biblioteca Jurídica Virtual del Instituto de Investigaciones Jurídicas de la UNAM www.juridicas.unam.mx

\section{Ejercicio léxico 5}

En las columnas siguientes anota, en el casillero correspondiente, el sinónimo (es decir, la palabra más parecida), así como el correspondiente antónimo (es decir, la palabra que signifique lo contrario), que más te parezca, del vocablo de la columna izquierda.

\begin{tabular}{|c|l|l|}
\hline Vocablo & Sinónimo & Antónimo \\
\hline Capacitar & & \\
\hline Recuperar & & \\
\hline Fortalecer & & \\
\hline Nacionalismo & & \\
\hline Efectivo & & \\
\hline Distinto & & \\
\hline Agrícola & & \\
\hline Aspirar & & \\
\hline Campesino & & \\
\hline Nacionalizar & & \\
\hline Subsuelo & & \\
\hline Estricto & & \\
\hline Riqueza & & \\
\hline Natural & & \\
\hline Capacidad & & \\
\hline Aspiración & & \\
\hline Redención & & \\
\hline Mixto & & \\
\hline
\end{tabular}


Este libro forma parte del acervo de la Biblioteca Jurídica Virtual del Instituto de Investigaciones Jurídicas de la UNAM www.juridicas.unam.mx

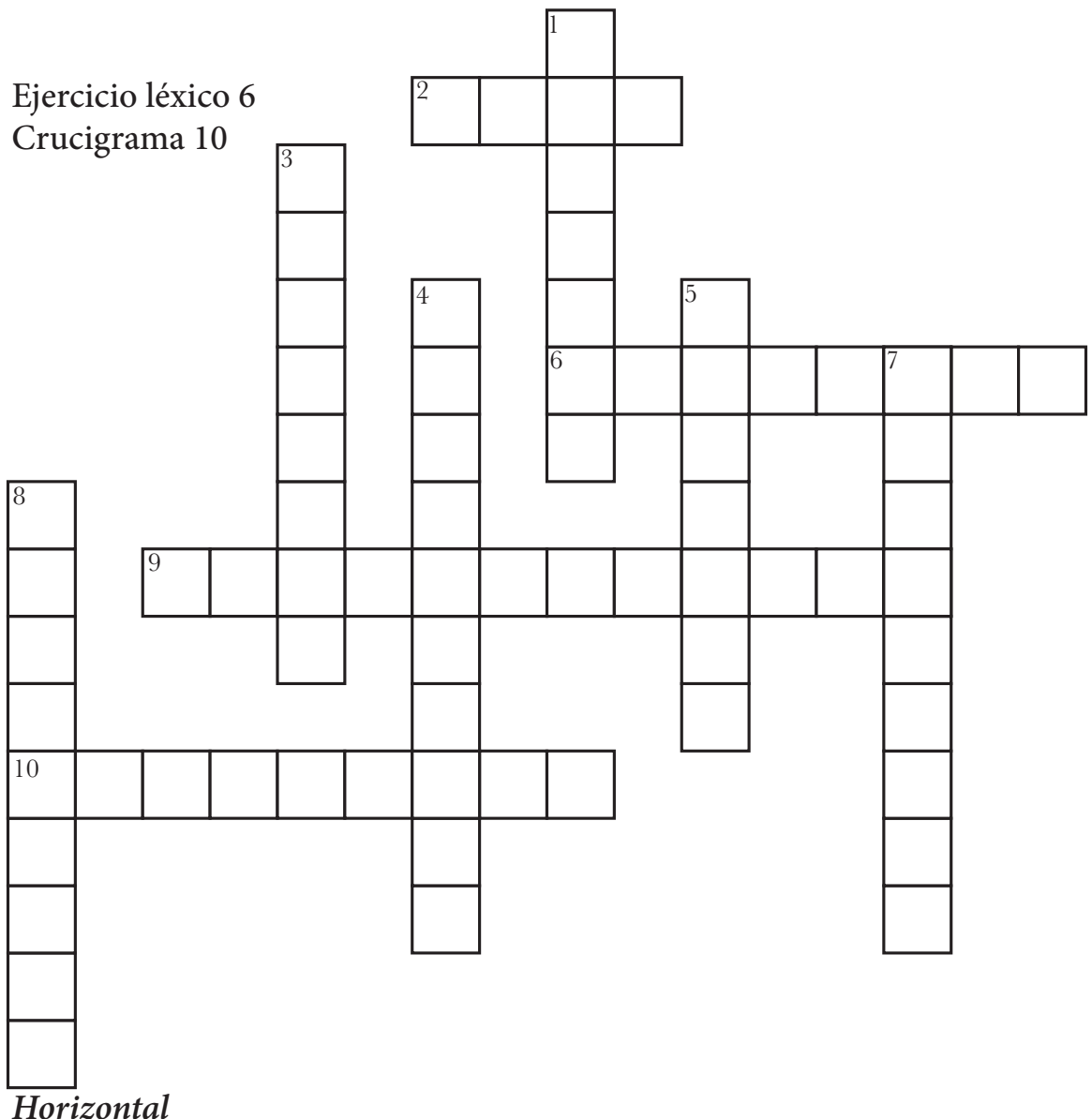

2. Intención, proyecto.

6. Perteneciente o relativo a la agricultura o al agricultor.

9. Dar naturaleza material y sensible a un proyecto, a una idea o a un sentimiento.

10. Dicho de una persona que vive y trabaja de forma habitual en el campo.

\section{Vertical}

1. Perteneciente o relativo a la naturaleza o conforme a la cualidad o propiedad de las cosas.

3. Estrecho, ajustado enteramente a la necesidad o a la ley y que no admite interpretación.

4. Acción y efecto de pretender o desear algún empleo, dignidad u otra cosa.

5. Apoyo, abono, comprobación.

7. Negociación o contrato sobre valores o mercaderías.

8. Cualidad de capaz. 
Este libro forma parte del acervo de la Biblioteca Jurídica Virtual del Instituto de Investigaciones Jurídicas de la UNAM

\section{BIOGRAFÍA 19 \\ Jorge CARPIZO MCGREgor}

Campeche, 2 de abril de 1944-Ciudad de México, 30 de marzo de 2012

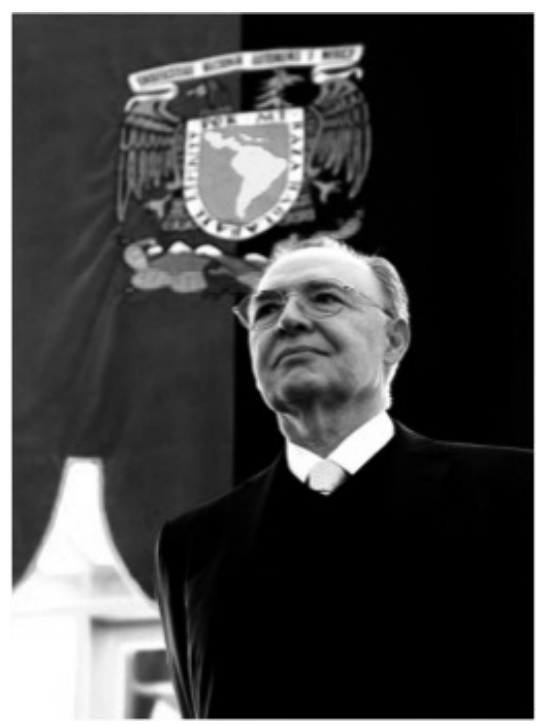

Abogado, jurista y político mexicano que ocupó destacados cargos públicos, entre ellos el de rector de la Universidad Nacional Autónoma de México (UNAM), presidente de la Comisión Nacional de los Derechos Humanos, procurador general de la República y secretario de Gobernación del gobierno mexicano.

Sus estudios de licenciatura los realizó en la Facultad de Derecho de la UNAM, entre 1963 y 1967. Entre 1969 y 1970 realizó la Maestría en Derecho en The London School Economics and Political Science de la Universidad de Londres. Entre 1970 y 1972 hizo los estudios de Doctorado en Derecho por la UNAM.

Se inició en la UNAM como subdirector general de la Dirección General de Asuntos Jurídicos, posteriormente abogado general. También en la UNAM fue rector (1985-1989), coordinador de Humanidades, director del Instituto de Investigaciones Jurídicas (1978-1984) y presidente de la Comisión Editorial.

Entre sus cargos públicos más destacados, fuera de la Universidad Nacional, destacan: ministro de la Suprema Corte de Justicia de la Na- 
Este libro forma parte del acervo de la Biblioteca Jurídica Virtual del Instituto de Investigaciones Jurídicas de la UNAM

ción (1989-1990), primer presidente de la Comisión Nacional de los Derechos Humanos (1990-1993), procurador general de la República (1993-1994), secretario de gobernación (1994-1995) y embajador de México en Francia (1995).

Entre sus textos más importantes: La Constitución de Querétaro (tesis de licenciatura, 1967); La Constitución Mexicana de 1917(1969, varias ediciones posteriores); Federalismo en Latinoamérica (1973); El presidencialismo mexicano, obra clave en la determinación constitucional del período del PRI en el poder, y traducido a varios idiomas (1978); Estudios constitucionales (1980); Derecho constitucional (1991); Derechos humanos y ombudsman (1993); Derecho a la información y derechos humanos (2000); El expediente Posadas a través de la lupa jurídica: Averno de impunidades (2004) y Derechos humanos, aborto y eutanasia (2010).

Escribió 87 artículos y 507 trabajos de menor extensión para revistas especializadas. Varias de sus obras han sido traducidas a otros idiomas: inglés, francés, alemán e italiano.

Al momento de su fallecimiento, era investigador emérito de la UNAM adscrito al Instituto de Investigaciones Jurídicas, investigador nacional nivel 3 del Sistema Nacional de Investigadores y presidente del Instituto Iberoamericano de Derecho Constitucional. 
Este libro forma parte del acervo de la Biblioteca Jurídica Virtual del Instituto de Investigaciones Jurídicas de la UNAM

\section{BIOGRAFÍA 20 \\ Eduardo Ferrer MaC-Gregor Poisot}

Tijuana, México, 18 de junio de 1968

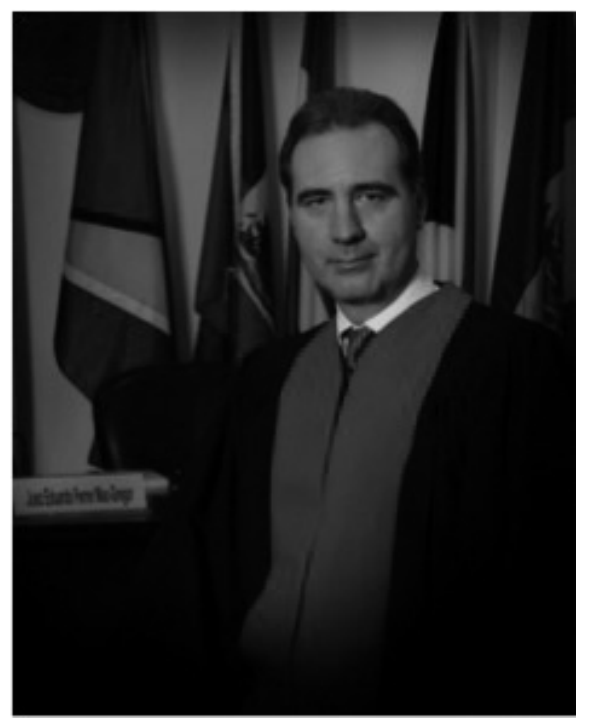

Jurista, académico y profesor mexicano, actual juez de la Corte Interamericana de Derechos Humanos.

Sus estudios superiores los inició en la Universidad Autónoma de Baja California (1987-1991), en donde se licenció en derecho, obteniendo el premio al "Mérito Escolar" (excelencia académica) y la medalla "Diario de México" como el mejor promedio de su generación (9.9). Es Doctor en Derecho por la Universidad de Navarra, España, con la tesis La acción constitucional de amparo en México y España. Estudio de derecho comparado, Cum Laude por unanimidad (1994-1997), texto que fue posteriormente editado y publicado por Porrúa. Tiene estudios de Especialización en Derechos Humanos en el Institut International des Droits de l'Homme, Estrasburgo, Francia (1997).

Ocupó diversos cargos en el Poder Judicial de la Federación, sobre todo en la Suprema Corte de Justicia de la Nación.

Juez ad hoc de la Corte Interamericana de Derechos Humanos (en el Caso Cabrera García y Montiel Flores vs. México, 2009-10), en 2012 fue electo juez titular de la Corte Interamericana de Derechos Humanos. 
Este libro forma parte del acervo de la Biblioteca Jurídica Virtual del Instituto de Investigaciones Jurídicas de la UNAM

Es investigador titular por oposición en el Instituto de Investigaciones Jurídicas de la UNAM, e investigador nivel III del Sistema Nacional de Investigadores del Consejo Nacional de Ciencia y Tecnología. Además, es profesor titular por oposición de la asignatura Derecho procesal constitucional en la Facultad de Derecho de la UNAM.

Entre sus libros, además, destacan: La protección orgánica de la Constitución (2011), El control difuso de convencionalidad (2012), El nuevo juicio de amparo. Guía de la reforma constitucional y la nueva Ley de Amparo (con Rubén Sánchez Gil, 2014), Derecho procesal de los derechos humanos (coordinación con Sonia Escalante, 2014) y Curso de derecho procesal constitucional (en coordinación con Juan Manuel Acuña, 2014).

Con fecha del 10. de enero de 2018, asume la Presidencia de la Corte Interamericana de Derechos Humanos el magistrado Eduardo Ferrer Mac-Gregor, completando con ello su brillante carrera de jurista distinguido. 


\section{EJERCICIOS LÉXICO-SINTÁCTICOS}

La comprensión de lectura, como las demás habilidades comunicativas, responde a un proceso activo, en el cual el lector reconstruye significados, a partir de lo escrito, así como mediante la activación de conocimientos y experiencias previas.

La lectura comprensiva supone al menos dos procesos: la decodificación (consistente en "decifrar" el código o lengua en la que está escrito el texto) y la reconstrucción de significados, que supone comprender unidades de distinto nivel (palabras, oraciones, párrafos) y relacionarlas entre sí y con conocimientos y experiencias previas del lector.

Objetivo: Se trata de articular e integrar al vocabulario básico y ampliado, visto anteriormente, con el objetivo de coadyuvar a la construcción de oraciones, frases y nociones conceptuales, organizadas lógicamente, según lo practicado en los Grupos de ejercicios ya revisados. Con ello, se facilita la construcción argumentativa de narrativas y discursos jurídicos.

Las soluciones respectivas, para mayor comprensión, que te permitirán comprobar tu avance, las podrás encontrar en el apartado correspondiente al final de este libro. 
Este libro forma parte del acervo de la Biblioteca Jurídica Virtual del Instituto de Investigaciones Jurídicas de la UNAM

\section{Adjetivos}

En los siguientes párrafos, completa los espacios en blanco a partir de los adjetivos que se te presentan.

\section{Ejemplo}

Adjetivos: Moral / Normativo / Humanos

Una de las definiciones, de fundamento establece un horizonte que asegura todos los derechos en las relaciones internacionales y en las sociedades.

Solución: Una de las definiciones [del concepto de seguridad humana], de fundamento normativo, establece un horizonte moral que asegura todos los derechos humanos en las relaciones internacionales y en las sociedades. ${ }^{11}$

\section{Ejercicios}

1. competente / determinados / unilateral / administrativo

El acto es la manifestación de la voluntad de un órgano administrativo , encaminada a crear, reconocer, modificar, transmitir, declarar o extinguir derechos u obligaciones, para ciertos particulares

2. público / colegiado / competente / esenciales

Debe ser expedido por órgano a través de un servidor $\mathrm{y}$, en caso de que dicho órgano fuere debe reunir las formalidades de la ley o decreto para emitirlo, las que son para que surta efectos.

3. manifestada / libremente / viciada / exenta

La voluntad no debe estar para poder hacer efectos en un contrato. El contrato es la relación de la intención de los contratantes, en la medida que estos la expresen y de vicios.

11 Sorj, Bernardo, "Seguridad, seguridad humana y América Latina", Sur, Revista Internacional de Derechos Humanos, Sao Paulo, núm. 3, año 2, 2005, p. 46. 
Este libro forma parte del acervo de la Biblioteca Jurídica Virtual del Instituto de Investigaciones Jurídicas de la UNAM

4. especiales/ inmediatas/ determinada/ particulares

El acto administrativo debe estar fundado y motivado, es decir, la autoridad administrativa debe citar de manera específica la ley exactamente aplicable al caso, así como expresar las circunstancias razones o causas que se hayan tenido en consideración para emitir el acto y la adecuación entre los motivos aducidos y las normas aplicables, emitidas por una autoridad

5. aplicable / administrativas / suprema / inconstitucional

Con respecto a la fundamentación, la Corte de Justicia de la Nación estableció que no es necesario que las autoridades citen la jurisprudencia al caso, aun cuando ésta declare una ley , ya que, de conformidad con la Constitución Política de los Estados Unidos Mexicanos, así como la Ley de Amparo, la jurisprudencia solamente obliga a los órganos jurisdiccionales.

6. fuerte / federal / administrativa / no autorizada

La infracción es una transgresión o violación a las normas administrativas y que amerita una sanción de la misma naturaleza. Como un ejemplo se puede citar la infracción a la Ley de Radio y Televisión, consistente en la emisión de los textos de anuncios o propaganda comerciales que requieran previamente la aprobación oficial.

\section{7. dominante/ general/ múltiples/ pública}

Son los efectos que puede producir un acto administrativo; sin embargo, de la teoría puede desprenderse, entre otras, una clasificación que atiende a los efectos en relación con los particulares y a los efectos respecto de la administración

\section{8. establecidos / obligada / permitidas / incompetente}

La autoridad, en atención a su competencia, está a observar los requisitos por las normas establecidas para el acto administrativo. Lo anterior responde al principio de legalidad, que se traduce en que las autoridades sólo están a hacer lo 
que la ley les permite. Así, por ejemplo, un acto administrativo será nulificado o anulado si lo realiza una autoridad

9. determinados / ejecutado / notarial / automática.

Existen actos administrativos que entrañan ejecución , es decir, con el hecho de que la autoridad cumpla requisitos para su emisión, el acto se considera como ocurre, por ejemplo, en el caso de un registro 
Este libro forma parte del acervo de la Biblioteca Jurídica Virtual del Instituto de Investigaciones Jurídicas de la UNAM

\section{Frases}

De la lista de frases que te mostramos a continuación, selecciona la que te parezca más precisa para completar los párrafos en sus espacios vacíos.

Ejemplo: de mañana / entre ambos pueblos / de relaciones diplomáticas / del establecimiento / entre México y la República Popular China.

El día celebraremos el 40 aniversario . No obstante, los contactos y la amistad datan de mucho tiempo atrás.

Solución: El día de mañana celebraremos el 40 aniversario del establecimiento de relaciones diplomáticas entre México y la República Popular China. No obstante, los contactos y la amistad entre ambos pueblos datan de mucho tiempo atrás.

\section{Ejercicios}

1. de la actividad / de la pensión / de la administración pública / del acto administrativo.

Respecto al órgano administrativo, los efectos consisten en la realización misma no En el ejemplo encomendada al órgaadministración será el pago de ésta. , el efecto para la

2. el Estado / último supuesto / que la obligación / de acuerdo con.

Frente a este incumplida, , para evitar quede la situación concreta, diversas acciones.

3. la formación / dentro del plazo / en el propio acto / a una condición. Cuando del acto administrativo esté sujeta o término suspensivo y éste no se realice señalado 
Este libro forma parte del acervo de la Biblioteca Jurídica Virtual del Instituto de Investigaciones Jurídicas de la UNAM

4. un derecho / de producir efectos jurídicos / para un particular / puede resultar.

El acto administrativo que se extingue deja , lo que dañoso que, en virtud del acto, hubiera adquirido

5. interesado / el acto / en exclusivo beneficio de éste / del interés público.

Renuncia del cuando hubiere sido dictado y su extinción no sea en perjuicio

6. extingue un acto / si la autoridad / recurrir a los tribunales / una reparación

La revocación procede sólo tiene facultades para determinarla; en tal caso, si una autoridad incompetente al revocarlo, el particular afectado puede administrativos o a los federales de amparo para solicitar

7. un fin específico / el conjunto de formalidades / determinan los requisitos/ sea válido

El procedimiento administrativo es y actos que, de manera directa o indirecta, nistrativo, para que éste que preceden al acto admiy cumpla

8. procedimientos de este tipo / de este procedimiento / de la materia / Federal de Procedimiento Administrativo

La regulación _ no está unificada. Depende __ de que se trate; así, por ejemplo, tanto la Ley como el Código Fiscal de la Federación prevén

9. esfera jurídica / acto administrativo / puede producir / dos supuestos Cuando el gación o les produce o impone a los particulares alguna oblise pueden presentar alguna afectación en su 
Este libro forma parte del acervo de la Biblioteca Jurídica Virtual del Instituto de Investigaciones Jurídicas de la UNAM www.juridicas.unam.mx

10. puede sustituir / el interés público / ley de la materia La ejecución directa se exija por revocación, cuando así lo de acuerdo con la 
Este libro forma parte del acervo de la Biblioteca Jurídica Virtual del Instituto de Investigaciones Jurídicas de la UNAM

\section{Adverbios y adjetivos}

A continuación, reconocerás algunas frases que utilizaste en los apartados anteriores de este capítulo. Con ellas, ahora agregarás alguno de los adverbios y/o adjetivos que corresponda de la siguiente lista.

Ejemplo:

Adverbios: acaso / ciertamente / entonces / predominante / sobremanera / socialmente / tan

En las últimas décadas, México ha aplicado a cabalidad las medidas económicas recomendadas por el Fondo Monetario Internacional y el Banco Mundial. A pesar de que se ha insistido hasta la saciedad en los supuestos beneficios, en nuestro país el crecimien-

to ha sido insuficiente y equívoco.

Las recomendaciones principales fueron la reducción del gasto en programas sociales, la liberación del mercado de bienes, la privatización de empresas públicas, la fijación de precios (eliminando subsidios y controles) y la liberación de las tasas de interés. Uno de los propósitos fundamentales de estas reformas fue reducir la intervención del Estado para que pasara de ser un Estado promotor a un Estado facilitador.

Solución: En las últimas décadas, México ha aplicado a cabalidad las medidas económicas recomendadas por el Fondo Monetario Internacional y el Banco Mundial. A pesar de que se ha insistido hasta la saciedad en los tan supuestos beneficios, en nuestro país el crecimiento ha sido ciertamente insuficiente y sobremanera equívoco. Las recomendaciones entonces principales fueron la reducción del gasto en programas sociales, la liberación del mercado de bienes, la privatización de empresas públicas, la fijación de precios eliminando subsidios y controles y la liberación de las tasas de interés. Uno de los propósitos acaso fundamentales de estas reformas fue reducir la intervención del Estado para que pasara de ser un Estado socialmente promotor a un Estado predominante facilitador. 
Este libro forma parte del acervo de la Biblioteca Jurídica Virtual del Instituto de Investigaciones Jurídicas de la UNAM

\section{Ejercicios}

1. como / pues / para / sus / más aun / profundamente

El reconocimiento ha sido defendido como una necesidad humana. , diversos autores consideran el reconocimiento colectivo una condición indispensable el ejercicio de los derechos individuales, da significado a las personas pertenecen a una cultura societal que le decisiones individuales.

2. propia / puede / autónomo / emergencia

Si se niega la existencia o validez de esa pertenencia, se afectar la capacidad de comportase como un agente . En las últimas décadas, América Latina ha sido testigo de lo que José Bengoa ha llamado la " indígena".

3. nueva / calidad / internacional / justamente

Se da una irrupción de diversos movimientos indígenas reclamando, en general, una relación con sus Estados, basada en el reconocimiento de los derechos colectivos que les corresponderían en su de pueblos pre-existentes al propio Estado. Estas reivindicaciones indígenas han sido acogidas en el seno de la comunidad traduciéndose primero, en el Convenio núm. 169 de la OIT de 1989.

4. más allá / autonomía / determinación / internacional / también / impacto

El punto culminante de recepción de la demanda indígena en la arena se dio en 2007, cuando la Asamblea General de Naciones Unidas adoptó la Declaración de Derechos de Pueblos Indígenas (DDPI). Este documento va que el mencionado Convenio, reconociendo directamente que los pueblos indígenas, como cualquier otro pueblo, tiene derecho a la libre expresada en el auto-gobierno en el seno de los Estados en que habitan con las consecuencias que ello conlleva. Por su parte, las reivindicaciones indígenas han tenido a nivel constitucional en América Latina, y también en otros países, como Canadá. ${ }^{12}$

12 De hecho, este último país, en su Ley Constitucional de 1982, reconoció la vi- 
Este libro forma parte del acervo de la Biblioteca Jurídica Virtual del Instituto de Investigaciones Jurídicas de la UNAM

5. sobre / les asiste / progresivo / dirigidos.

La Declaración de Derechos de Pueblos Indígenas reconoce derechos a los pueblos indígenas sus tierras y territorios, además de establecer mecanismos de participación política (consulta indígena), y reconocer el derecho que a ejercer un control sobre los programas de salud y educación a ellos, entre otras cosas.

6. incluido / siempre / valoran / implícitamente.

Diversas constituciones de la región, casi de asambleas constituyentes, han emanadas reconocen y la diversidad cultural de sus respectivos países, lo que incluye, al menos , a los pueblos indígenas.

7. multicultural / consagrar / precolonial / libre.

Frente a la alternativa , países como Ecuador y Bolivia han optado por el carácter plurinacional del Estado. Aunque la Constitución de Ecuador de 2008 es explícita al respecto, el paradigma en esta materia es la Constitución boliviana de 2006. Ésta reconoce la existencia derecho a la determinación. de los pueblos indígenas, y su

gencia de los derechos de los indígenas (aboriginal rights) y aquellos emanados de los tratados celebrados entre aquéllos y la Corona británica (treaty rights). 
Este libro forma parte del acervo de la Biblioteca Jurídica Virtual del Instituto de Investigaciones Jurídicas de la UNAM

\section{Verbos y adverbios}

Como en el apartado anterior, ahora trabajarás con adverbios, que agregarás a las oraciones con que ya te has familiarizado en secciones anteriores.

\section{Ejemplo:}

Adverbios: acusadamente / negativamente / paulatinamente / quizá / sobremanera.

El papel del Estado, central para esta reproducción, se veía quizá cada vez más minado porque su financiamiento era acusadamente deficitario, distorsionaba sobremanera los de por si débiles mercados financieros internos, y llevaba paulatinamente a un endeudamiento externo creciente, que, además, frente a la caída de los precios del petróleo en 1981, vio modificada negativamente su composición a favor de los créditos de corto plazo.

\section{Ejercicios}

1. expresamente / fuertemente / contextualmente / ampliamente el dualismo epistemológico surge, en el ámbito jurídico la obra de Hans Kelsen Teoría pura del derecho, texto que sentó las bases de lo que en la doctrina se conoce como positivismo jurídico, que ha marcado la forma de aproximación al estudio del derecho, aún en nuestros días, pese a la diversidad de autores e interpretaciones que sobre éste se han desarrollado desde principios del siglo XIX, dentro de la misma corriente y fuera de ella.

2. netamente / avalorativamente / valorativamente / claramente Hans Kelsen, desde una perspectiva dualista, objetiva -y por tanto - del derecho, en sentido neutro,

establece como objeto de estudio del derecho a la norma partiendo como hecho y no como valor, lo cual implica que no puedan emitirse juicios en relación con la norma, tales como justo, injusto, bueno, malo. 
Este libro forma parte del acervo de la Biblioteca Jurídica Virtual del Instituto de Investigaciones Jurídicas de la UNAM

3. definidamente/ inicialmente/ normativamente/ especialmente

Para delimitar el objeto de estudio de la ciencia Kelsen distinguió, a las ciencias morales, dentro de la cual se encuentra la ciencia normativa, de las ciencias naturales, causales o explicativas, a partir del término de "ley", que se aplica a ambas realidades con algunas diferencias. La ley natural se aplica a la explicación de hechos reales, es una proposición explicativa, proviene del plano del ser, donde todo está sujeto al principio de causalidad.

\section{4. formalmente/ específicamente/ autónomamente/ válidamente}

Kelsen también distinguió a la ley moral de la norma jurídica, la primera se encuentra en un intermedio entre la ley natural y la norma jurídica, dejando la contraposición entre ser y deber ser en segundo plano, causa de ello es que la moral actúa , es decir, son dictadas por el propio individuo para sí mismo o bien son aceptadas por el individuo cuando forman parte de un grupo, por eso sólo se asume o es obligatoria para aquellos que la acatan de hecho.

5. epistemológicamente/ largamente/ comprensivamente/ nítidamente

El positivismo jurídico crea un aislamiento porque se establece un dualismo que otro paradigma de la investigación social ha superado el constructivismo o interpretativismo, al señalar que no existe una separación entre el sujeto y objeto de estudio ya que estos se encuentran relacionados entre sí, otorgándole a la ciencia una tarea interpretativa de búsqueda de significado, cuyo objetivo se da y no tanto la explicación y búsqueda de leyes propias del positivismo científico.

\section{6. nítidamente / abiertamente / precisamente / aproximadamente}

Incluso pospositivistas científicos ya no defienden el dualismo como separación y ausencia de interferencia entre las dos realidades. Se tiene conciencia de los elementos de perturbación que introduce en el objeto de estudio el sujeto que lo estudia y de la reacción que se puede derivarse de ellos. La objetividad del conocimiento sigue siendo el criterio de referencia, pero sólo se puede lograr 
Este libro forma parte del acervo de la Biblioteca Jurídica Virtual del Instituto de Investigaciones Jurídicas de la UNAM www.juridicas.unam.mx

7. metodológicamente / directamente / cualitativamente / singularmente , porque considerar al derecho sólo como "norma", en un plano ideal, de abstracción, anula otras dimensiones como el hecho social que permitirían la aplicación de métodos sociales para aplicar cuantitativa y 
Este libro forma parte del acervo de la Biblioteca Jurídica Virtual del Instituto de Investigaciones Jurídicas de la UNAM

\section{Oraciones sustantivas}

\section{Oraciones sustantivas-sujeto}

Se definen a las oraciones subordinadas como aquellas "que están integradas dentro de otra oración",13 y depende de ésta. Es decir, estamos hablando de un conjunto estructurado de palabras que permite realizar la misma función que un sustantivo simple, aunque dependa de una oración principal. Con ello, su función también puede ser la de sujeto, complemento directo, indirecto, agente o de régimen proposicional.

Con estas premisas, puedes insertar las oraciones a través de las siguientes estrategias:

a. Usa conjunciones 'que' o 'quien', así como la estructura "el (la, los, las) que", y

b. Convierte al verbo de la oración secundaria en un infinitivo (terminación -ar, -er, -ir; por ejemplo, amar, comer, vivir), de forma que puedas agregar a la oración secundaria.

Lo anterior te ayuda a construir oraciones, que cumplan con una estructura esencial de lógica y concordancia.

El siguiente ejemplo te puede ayudar:

(...) que ellos no tienen.

Oración secundaria: tengo un par de datos.

Solución con a): Oración compuesta, "En la libreta tengo un par de datos que ellos no tienen".

Solución con b): oración compuesta, "Tengo un par de datos que ellos no tienen".

\section{Ejercicio}

1. a. (...) es inútil.

b. Oración secundaria: "se recuerdan las modificaciones de la técnica".

c. La técnica es psicoanalítica.

13 Munguía Zatarain, Irma et al., Gramática lengua española. Reglas y ejercicios, México, Larousse, 2015, p. 178. 
2. a. Los recursos genéticos.

$b$. exponentes tangibles de la biodiversidad.

c. en nuestro planeta.

3. a. La expansión tecnológica.

b. permitido una valorización de los recursos genéticos.

c. creciente demanda.

4. a. países que se encuentran en desarrollo.

b. países proveedores de recursos genéticos.

c. Son aquellos.

5. a. Los recursos genéticos.

b. para muchas naciones en vías de desarrollo.

c. constituyen una importante fuente económica. 
Este libro forma parte del acervo de la Biblioteca Jurídica Virtual del Instituto de Investigaciones Jurídicas de la UNAM

\title{
2. Oraciones sustantivas-complemento directo
}

El complemento directo se ha definido como aquella parte de la oración que "se refiere a la persona, animal o cosa que recibe directamente la acción del verbo". ${ }^{14}$

Con el objeto de cumplir esta función, debes agregar una oración secundaria a una oración principal, lo que te puede ser útil insertando la conjunción "que", 15 el verbo en infinitivo (terminaciones -ar, -er, -ir16), dos puntos con un estilo indirecto, 17 o algún nexo interrogativo indirecto; 18 del mismo modo, puede utilizarse el sintagma19 "lo que".20

Es necesario tomar en cuenta que, para incorporar la oración secundaria, es necesario adaptar el tiempo del verbo al de la oración principal con el objeto de darle concordancia y lógica.

\author{
Ejemplos: \\ Creeré ( ) \\ Oración secundaria: es necesario. \\ Oración compuesta: Creeré que es necesario.
}

1. Es obvio ( )

OS: Los países usuarios de recursos genéticos son los países desarrollados.

\section{Se señala (}

OS: el artículo 15 del Convenio sobre Diversidad Biológica es la principal normativa internacional que rige el acceso a los recursos genéticos.

14 Munguía Zatarain, Irma et al., Gramática lengua española. Reglas y ejercicios, cit., p. 158.

15 "Me cuentas qué fue lo ocurrido ayer".

16 V. gr., "Juan podrá asistir al paseo".

17 Por ejemplo, "Es verdad: todo lo dicho ratifica su declaración", que puede equivaler al estilo directo de "Es verdad que todo lo dicho ratifica su declaración".

18 Así, en oraciones como "Dile a Juan cómo hiciste tu tarea", "Es muy importante saber quién lo asesinó", "No me has contado cuándo regresas de tu paseo".

19 Se ha definido al sintagma como aquella "unidad conformada por una palabra que es la más importante y que funciona como núcleo; éste puede ir acompañado de complementos o modificadores, y juntos forman un bloque". Munguía Zatarain, Irma et al., Gramática lengua española. Reglas y ejercicios, cit., p. 141.

20 Por ejemplo, "No dejes para mañana lo que puedes hacer hoy". 
Este libro forma parte del acervo de la Biblioteca Jurídica Virtual del Instituto de Investigaciones Jurídicas de la UNAM www.juridicas.unam.mx

3. Se reconoce (

OS: existe la soberanía de los Estados sobre sus recursos naturales.

4. Se conceptúa ( ) OS: un recurso genético es todo aquel constituido por el ADN (material genético) y puede tener un valor real o potencial.

5. Se indica (

OS: una forma de vulnerar la propiedad de los recursos genéticos y el reparto justo de los beneficios comerciales es mediante la biopiratería. 
Este libro forma parte del acervo de la Biblioteca Jurídica Virtual del Instituto de Investigaciones Jurídicas de la UNAM

\section{Oraciones sustantivas-complemento indirecto}

Se define al complemento indirecto como "la persona, animal o cosa que recibe indirectamente la acción del verbo; es el beneficiado o perjudicado por la acción".21

La forma de comprobarse se da haciendo la pregunta "¿a quién?", agregando aquello que recibe el daño o beneficio del verbo. Así, por ejemplo: "Es necesario hacer una modificación legislativa, con el objeto de mejorar la reforma en curso"; en este caso, tras preguntarse ¿para qué es necesaria la modificación legislativa?, la respuesta es "para mejorar la reforma en curso".

\section{Ejemplo:}

a. Creo que las grandes pasiones.

b. Oración secundaria: de vivir una vida simple y honesta.

c. Son sólo un sustito a la imposibilidad. Oración compuesta: Creo que las grandes pasiones son sólo un sustito a la imposibilidad de vivir una vida simple y honesta.

\section{Ejercicios}

1. a. La tesis, como trabajo intelectual

b. Forma de investigación

c. Proceso sistemático de ejercicios analíticos y sintéticos que se dan entre un sujeto y un objeto en cuya relación se busca alcanzar un producto científico nuevo o diferente.

2. a. La curiosidad.

b. Inquietud que surge en el estudiante.

c. Predispone para fijar en su mente en algún atributo, característica o institución de un objeto determinado.

21 Munguía Zatarain, Irma et al., Gramática lengua española. Reglas y ejercicios, cit., p. 162. 
Este libro forma parte del acervo de la Biblioteca Jurídica Virtual del Instituto de Investigaciones Jurídicas de la UNAM

3. a. La observación

b. Otra etapa de la investigación

c. Supone una revisión general de la bibliografía sobre el objeto de la curiosidad a disposición del estudiante y las discusiones preliminares con maestros especializados en el tema.

4. a. La abstracción

b. Etapa clave de toda tesis o investigación

c. El estudiante o el investigador proyecta senderos posibles, variables a verificar, pistas de acercamiento, que serán la base de toda investigación o tesis, y sus posibles productos o metas científicas.

5. a. La comprobación

b. Etapa en que el estudiante debe saber recolectar la información pertinente

c. Validar las conjeturas que se planteó en relación con el objeto, materia de su investigación o tesis. 
Este libro forma parte del acervo de la Biblioteca Jurídica Virtual del Instituto de Investigaciones Jurídicas de la UNAM

\section{Oraciones sustantivas-agente}

Se ha definido al complemento agente como aquel que "aparece solamente en las oraciones en voz pasiva y designa al agente de la acción verbal".22

Se expresa, por regla general, antecedido por las preposiciones 'de' o "por'. Por ejemplo: "será considerada" como perífrasis de "considerarán", en "Estas pruebas serán consideradas por las partes en el juicio" / "Las partes del juicio considerarán las pruebas".

Así, las oraciones secundarias pueden ser consideradas como sustantivos:

"Estas pruebas serán consideradas por las partes en el juicio".

"Estas pruebas serán consideradas por los fiscales".

\section{Ejemplo}

a. Su familia, dice.

b. Oración secundaria: se compone de santos y pecadores.

c. Como cualquiera que se respete.

Oración compuesta: Su familia, dice, como cualquiera que se respete, se compone de santos y pecadores.

1. a. Hay una estrecha vinculación.

b. El desarrollo y la tecnología.

c. La relación de ambos.

2. a. La carencia de recursos financieros, aunada a la urgencia de resolver necesidades básicas de la población.

b. Postergar o hasta a abandonar la investigación y el desarrollo tecnológicos.

c. El resultado de la carencia y urgencia

22 Munguía Zatarain, Irma et al., Gramática Lengua Española. Reglas y ejercicios, cit., p. 170. 
3. a. México es un país en desarrollo.

b. Enormes carencias todavía no resueltas.

c. México tiene.

4. a. Los países industrializados.

b. Sumas crecientes a la investigación tecnológica, convencidos de que se trata de una inversión redituable.

c. Los países industrializados dan.

5. a. Existe una estrecha vinculación entre el desarrollo y la tecnología.

$b$. Ésta constituye un prerrequisito para alcanzar aquél.

c. La vinculación se da. 
Este libro forma parte del acervo de la Biblioteca Jurídica Virtual del Instituto de Investigaciones Jurídicas de la UNAM www.juridicas.unam.mx

\section{LECTURAS}

\section{FRAGMENTOS DE LOS TEXTOS BASE PARA LA ELABORACIÓN DE LOS EJERCICIOS}


Este libro forma parte del acervo de la Biblioteca Jurídica Virtual del Instituto de Investigaciones Jurídicas de la UNAM

\section{EL DEREGHO EN EL ÁMBITO DE LAS GIENGIAS SOGIALES *}

El Derecho como integrante del universo de las ciencias sociales ha seguido en parte los marcos referenciales genéricos que describimos precedentemente.

\section{EL POSITIVISMO Y EL NORMATIVISMO JURÍDICO}

En este contexto de dualismo epistemológico surge, en el ámbito jurídico la obra de Hans Kelsen Teoría pura del derecho, texto que sentó las bases de lo que en la doctrina se conoce como positivismo jurídico, que ha marcado la forma de aproximación al estudio del derecho, aún en nuestros días, pese a la diversidad de autores e interpretaciones que sobre éste se han desarrollado desde principios del siglo XIX, dentro de la misma corriente y fuera de ella. ${ }^{1}$

Hans Kelsen, desde una perspectiva dualista, objetiva y por tanto avalorativa del derecho, en sentido netamente neutro, establece como objeto de estudio del derecho a la norma partiendo como hecho y no como valor, lo cual implica que no puedan emitirse juicios de valor en relación con la norma, tales como justo, injusto, bueno, malo.

¿Cómo logra objetivizar el comportamiento humano en la norma?, ¿cómo construye al derecho inserto en este dualismo epistemológico?

Para delimitar el objeto de estudio de la ciencia normativa, Kelsen en principio distinguió a las ciencias morales, dentro de la cual se encuentra la ciencia normativa, de las ciencias naturales, causales o explicativas, a partir del término de "ley", que se aplica a ambas realidades con algunas diferencias. La ley natural se aplica a la explicación de hechos reales, es una proposición explicativa, proviene del plano del ser, donde todo está sujeto al principio de causalidad.

Texto seleccionado de Witker, Jorge, "Las ciencias sociales y el derecho", Boletín Mexicano de Derecho Comparado, nueva serie, año XLVIII, núm. 142, enero-abril de 2015, pp. 345-352.

1 Corbetta, P., Metodología y técnicas de investigación social, Madrid, McGraw Hill, 2007, p. 14. 
Este libro forma parte del acervo de la Biblioteca Jurídica Virtual del Instituto de Investigaciones Jurídicas de la UNAM

Las leyes morales (jurídicas, lógicas, gramaticales, estéticas) conocidas también con el nombre de normas son proposiciones que prescriben una conducta, exigen que algo sea o no sea, establecen que debe ser y lo que no debe ser, proponen lo que debería ser, formulan deberes; no aplican la ley de la causalidad, mostrando las causas de lo que sucede, sino que proponen lo que debería suceder. ${ }^{2}$

Se encuentran en un plano de idealidad. ${ }^{3}$ Así que la primera distinción se realiza con base en el mundo del ser (ley natural) y el deber ser (ley moral o norma).

En segundo lugar, distinguió a la ley moral de la norma jurídica, la primera se encuentra en un punto intermedio entre la ley natural y la norma jurídica, dejando la contraposición formal entre ser y deber ser en segundo plano, causa de ello es que la moral es autónoma, es decir, son dictadas por el propio individuo para sí mismo o bien son aceptadas por el individuo cuando forman parte de un grupo, por eso sólo tiene validez o es obligatoria para aquellos que la acatan de hecho. En cambio, las normas jurídicas no son autónomas, las leyes no se las dan a sí mismos los propios individuos, el derecho es heterónomo, viene de un poder externo, la voluntad del Estado, ${ }^{4}$ es válido para todos los individuos, aunque éstos no quieran o no acepten las normas.

En el ámbito del Derecho, la legislación se crea y se aplica al margen de la voluntad de los individuos a los que afecte: el deber ser jurídico, la validez de las leyes, es totalmente independiente del ser, o sea, de los deseos y otros movimientos psíquicos de los individuos. La forma (deber ser) es independiente del contenido, de la materia de las normas y de los destinatarios de ellas (el ser). ${ }^{5}$

Así Kelsen, en su obra Los problemas capitales, en donde sienta las bases de la teoría pura, considera a la norma como expresión de la vo-

2 López Hernández, José, Introducción histórica a la filosofía del Derecho contemporánea, España, Universidad de Murcia, 2005, p. 65.

3 Dice Kelsen que: "mientras las leyes naturales consideran el acaecer de que son testimonio como un acaecer real y efectivo, contemplando en su realidad, los hechos que forman el contenido de las normas sólo interesan a éstas desde el punto de vista específico de la idealidad". Kelsen, Hans, Problemas capitales del derecho y del Estado, México, Porrúa, 1987, p. XLV.

4 Voluntad del Estado vista como una construcción jurídica con vistas a la imputación, y no como un acto síquico.

5 López Hernández, José, Introducción histórica..., cit., p. 67. 
Este libro forma parte del acervo de la Biblioteca Jurídica Virtual del Instituto de Investigaciones Jurídicas de la UNAM

luntad del Estado, voluntad que es una construcción jurídica con vista a la imputación, que se expresa en un juicio hipotético bajo la siguiente fórmula: "Bajo tales o cuales circunstancias (es decir, ante una determinada conducta de los hombres), el Estado quiere que sucedan tales o cuales actos, tales o cuales consecuencias de la conducta antijurídica (penas o medidas ejecutivas)".

Noción de norma que en la teoría pura modifica, como consecuencia de una relativización de la separación radical antes expuesta entre el mundo del ser y del deber ser. Al señalar que tanto en las ciencias naturales como en el derecho se producen actos humanos y también se atribuyen significados a éstos.

En este sentido, en el mundo del derecho tenemos hechos, a los cuales se les considera jurídicos, es decir lo primero es la identificación de un hecho que ocurre en el tiempo y espacio y lo segundo es la significación jurídica que se le da a ese hecho, acciones complementarias entre sí.

El significado o sentido subjetivo de un acto humano es aquel que le atribuye el sujeto que lo realiza, el sentido objetivo del acto es el que le atribuye el Derecho. En este sentido la norma es la que dota de sentido objetivo a los actos humanos, funcionando como un esquema de explicación de la realidad jurídica, en el cual se ordena, permite o autoriza un comportamiento humano.

Por lo tanto, en el Kelsen de Los problemas capitales, como en el Kelsen de la Teoría pura del derecho, la norma se configura como un objeto independiente del sujeto, de cómo éste la vive, de cuál es su sentimiento o su conciencia del deber, sin importar el hecho síquico. Construyendo epistemológicamente un dualismo.

Considerando lo anterior, de forma general partiendo del pensamiento de Kelsen, podemos señalar que, "el positivismo jurídico surge como consecuencia del esfuerzo por convertir al derecho en una auténtica ciencia, que posea los mismos caracteres de las ciencias físico-matemáticas, naturales y sociales", 6 entre ellos la neutralidad valorativa, es decir la rigurosa exclusión de juicio de valor (toma de posición frene a la realidad) del horizonte científico, quien debe formular exclusivamente juicios de hecho (conocimiento acerca de la realidad), obteniendo con ello un conocimiento puramente objetivo de la realidad. "Por tanto

6 Bobbio, Norberto, El positivismo jurídico. Lecciones de filosofía del derecho reunidas por el doctor Nello Mora, trad. de Rafael de Asís y Andrea Greppi, Madrid, Debate, 1998, p. 145. 
Este libro forma parte del acervo de la Biblioteca Jurídica Virtual del Instituto de Investigaciones Jurídicas de la UNAM

el positivismo jurídico asume una actitud científica frente al derecho porque, como decía Austin, estudia el derecho tal como es y no como debiera ser. El positivismo jurídico consiste pues, en el estudio del derecho como hecho y no como valor".7

García Máynez, recuperando el pensamiento de Bobbio en su obra Positivismo jurídico, realismo sociológico y iusnaturalismo, reafirma al positivismo como una forma de abocarse al estudio del derecho que presupone una rigurosa distinción entre el "Derecho real o existente" y el "Derecho ideal", entre el Derecho como hecho y como valor, entre el "Derecho que es" y el "que debiera ser".

Por tanto, esta corriente del positivismo jurídico, creada a la luz de positivismo científico y del siglo XIX y principios del siglo XX, ha propiciado un aislamiento del derecho del resto de las ciencias sociales en el ámbito epistemológico y metodológico.

Epistemológicamente, porque se establece un dualismo que otro paradigma de la investigación social ha superado, el constructivismo o interpretativismo, al señalar que no existe una separación entre el sujeto y objeto de estudio ya que estos se encuentran relacionados entre sí, otorgándole a la ciencia una tarea interpretativa de búsqueda de significado, cuyo objetivo es la comprensión y no tanto la explicación y búsqueda de leyes propias del positivismo científico. Incluso pospositivistas científicos ya no defienden el dualismo como separación y ausencia de interferencia entre las dos realidades. Se tiene conciencia de los elementos de perturbación que introduce en el objeto de estudio el sujeto que lo estudia y de la reacción que se puede derivar de ellos. La objetividad del conocimiento sigue siendo el criterio de referencia, pero sólo se puede lograr de forma aproximada.

Metodológicamente, porque considerar al derecho sólo como "norma", en un plano ideal, de abstracción, anula otras dimensiones como el hecho social que permitirían la aplicación de métodos sociales cuantitativos (encuesta, análisis de datos cuantitativos es decir estadista) y cualitativos (etnografía, grupos focales, análisis de conversaciones, estudio de casos).

Por tanto, dentro del derecho se hace necesaria promover otra visión epistemológica más abierta que permita el acercamiento con las ciencias sociales y propicie por tanto la interdisciplinariedad, actualizando al derecho científicamente para enfrentar problemas y realizar investigaciones de frontera que resuelvan temas complejos como seguridad

7 Ibidem, p. 146. 
Este libro forma parte del acervo de la Biblioteca Jurídica Virtual del Instituto de Investigaciones Jurídicas de la UNAM

pública, clonación, regulación de ADN, maternidad subrogada, medio ambiente, educación en derechos humanos, costumbres contraria a derechos humanos, etcétera.

\section{El REALISMO JURÍDICO ${ }^{8}$}

Puede definirse al sociologismo o realismo jurídico como la concepción del derecho en que prevalecen los elementos conductuales entre los normativos. Se clasifican en dos grandes ramas: el realismo estadounidense y el realismo europeo; este último incluyendo al realismo escandinavo, que presenta un mayor desarrollo metodológico. Se aludirá a algunos pensadores representativos del primero y a Alf Ross como representativo del segundo.

Dentro del realismo de Estados Unidos, para Oliver Wendel Holmes el objeto de la jurisprudencia es predecir en especial lo que los tribunales harán en el futuro:

Los individuos desean saber en qué circunstancias y hasta qué punto correrán el riesgo de ir contra de lo que es mucho más fuerte para ellos, por lo que se proponen la tarea de discurrir cuando ese peligro ha de ser temido. El objeto de nuestro estudio es entonces la predicción de la interferencia de las fuerzas públicas a través del instrumento de los tribunales, entiendo por derecho las profecías acerca de lo que los tribunales harán realmente, y nada más... Los derechos y deberes primarios con que la jurisprudencia se ocupa no son otra cosa que una profecía. Lo que se llama deber jurídico no es sino la predicción de lo que, si un hombre hace u omite ciertas cosas, tendrá que sufrir en una o en otra forma, en virtud de una sentencia del tribunal; pudiendo decirse lo propio de un derecho subjetivo. La obligación de celebrar un contrato de acuerdo con el common law, implica la predicción de que quien no lo cumpla tendrá que pagar los consiguientes daños y perjuicios, y nada más.

\section{Y continúa Holmes:}

Si queréis conocer el Derecho y nada más, mirad el problema con los ojos del mal hombre, a quien solo le importan las consecuencias materiales que gracias a ese conocimiento puede predecir; no con los del buen hombre que encuentra razones para su conducta dentro o fuera del derecho en los mandamientos de su conciencia. Tomad por ejemplo la pregunta fun-

8 Witker, Jorge y Larios, Rogelio, Metodología jurídica, México, Mc Graw Hill, 1997, pp. 148-53. 
Este libro forma parte del acervo de la Biblioteca Jurídica Virtual del Instituto de Investigaciones Jurídicas de la UNAM

damental ¿qué es el Derecho? Encontrareis que ciertos autores os dicen que es algo distinto de los que deciden los tribunales de Massachusetts o de Inglaterra, que es un sistema de la razón, que es deducción a partir de principios de ética o axiomas universalmente aceptados, o cosa parecida que puede o no coincidir con las sentencias judiciales. Pero si aceptamos el punto de vista de nuestro amigo el mal hombre, veremos que este le importa un bledo los axiomas o deducciones, pero en cambio le interesa saber qué es lo que en efecto han de resolver probablemente los tribunales de Massachusetts o de Inglaterra. Yo opino de manera bastante parecida. Entiendo por derecho las profecías acerca de que los tribunales harán en concreto, nada más ni nada menos.

Dentro del mismo realismo, Roscoe Pound, quien se inspira en Holmes, afirma que la investigación sociológica en el campo del derecho debe realizarse con un análisis de los factores preceptivos: reglas, principios, doctrinas; y de los intereses individuales, públicos y sociales. Según Pound, la generación anterior de juristas se contentaba con ocuparse de la justicia abstracta de las normas en abstracto, pero el trabajo de la nueva generación debe caracterizarse por el estudio de los efectos sociales concretos de institutos y doctrinas jurídicas, y de los medios para hacer operativas a las normas jurídicas; el estudio sociológico como actividad preparatoria de la promulgación de las leyes; el estudio de la metodología jurídica; elaboración de una historia sociológica del derecho, y reconocer la importancia de la solución razonable y equitativa en los casos particulares.

Pound remplaza el racionalismo de la ciencia jurídica por el empirismo y pragmatismo, y niega la existencia de principios jurídicos eternos e inmutables. El derecho es fluido y cambia cuando cambian las condiciones sociales a las que debe su origen. Lo importante no es la naturaleza, sino el propósito del derecho, el cual es un instrumento de la civilización para mejorar el orden social y económico, que no se ocupa primordialmente de derechos, sino de intereses, aspiraciones y pretensiones. Un derecho es solamente el medio para la satisfacción de los intereses; se ha exagerado mucho su importancia en el pasado. Puesto que no es posible dar satisfacción a todos, el principio debe ser satisfacer tantas pretensiones como sea posible. En la medida que estas pretensiones e intereses se contraponen mutuamente, la función del derecho es armonizarlos y reconciliarlos. Así, el orden jurídico surge como un sistema de ingeniería social para eliminar la fricción en el goce de los bienes. La justicia puede lograrse con o sin el derecho; con el de- 
Este libro forma parte del acervo de la Biblioteca Jurídica Virtual del Instituto de Investigaciones Jurídicas de la UNAM

recho significa una administración de justicia impersonal, igual y cierta, que pueda ser asegurada mediante principios decisorios de aplicación general. La justicia sin derecho es administrada según la voluntad de un individuo con gran libertad discrecional, que no está obligado a observar reglas fijas generales. La historia muestra una continua oscilación entre la discreción amplia y la regla detallada y estricta.

Por su parte, el realismo europeo, en su especie de realismo escandinavo, es representado por Alf Ross junto con Hagestrom, Olivecrona, Lundstedt y otros.

En oposición a la concepción normativista, en especial la Kelseniana, para Ross, en su primera época, el objeto de la ciencia jurídica es la conducta humana, entendida como fenómeno psicosocial —que es la aportación del realismo escandinavo-, pero sin aceptar la idea del realismo norteamericano, de que el derecho se reduce a hechos sociales. Rechaza la distinción entre ciencias del ser y ciencias del deber ser, porque desde una perspectiva empirista moderna esa distinción no tiene cabida. La ciencia del derecho es una ciencia social empírica que tiene órdenes jurídicos determinados como objeto de conocimiento. En época posterior, replantea que el derecho consiste en fenómenos y normas, y la ciencia del derecho, en sentido estricto, se ocupa de las normas. Pero propone un concepto de norma que tiene las ventajas de las entidades empíricas verificables, de las que carecen los significados ideales, sin que se produzca una reducción de las normas a los hechos.

Para Ross, la coacción estatal no es una parte necesaria del derecho en el sentido de que cada regla deba contenerla, pero si es indispensable que un sistema, para ser jurídico, tenga que basarse en alguna parte en la coacción.

Ross indica que el estudio del derecho se divide en dos ramas: del derecho en acción, de los fenómenos jurídicos se ocupará la sociología jurídica; de las directivas o normas se ocupará la ciencia jurídica, la cual descubre el significado ideal que funciona como esquema de interpretación para los fenómenos. Ambas disciplinas no pueden separarse y sus límites no son claros, porque su diferencia es de enfoque y de interés. 
Este libro forma parte del acervo de la Biblioteca Jurídica Virtual del Instituto de Investigaciones Jurídicas de la UNAM

\section{¿ES EL DERECHO UNA CIENCIA?*}

El debate sobre si el derecho es ciencia o no proviene del siglo XIX. En 1847, el jurista alemán Von Kirchmann pronunció una conferencia que llevaba el titulo de "La falta de valor de la jurisprudencia como ciencia", en la que negó rotundamente que lo que hacen los juristas pueda ser llamado ciencia. Los argumentos de Kirchmann son los siguientes: es imposible que se pueda construir ciencia respecto de un objeto que carece de fijeza y permanencia, "tres palabras rectificadoras del legislador convierten bibliotecas enteras en basura"; a consecuencia de ello es imposible aprehender el objeto; no se pueden aplicar métodos similares a los de las ciencias naturales, tales como la observación, la verificación y la experimentación; es un conocimiento que no progresa en la misma medida que las ciencias naturales, y los resultados del derecho también carecen de utilidad porque son variables y poco certeros. En conclusión, la variabilidad del objeto, la ausencia de progreso, la falta de certeza y de utilidad, impiden que el derecho sea ciencia.

Los argumentos de Von Kirchmann pueden ser desmontados, así sobre el problema de la variabilidad del objeto, se puede decir que el carácter de científico de un conocimiento no reside exclusivamente en el objeto sino en el conocimiento mismo. En cuanto a la afirmación sobre el escaso progreso del derecho, ésta se puede desmentir fácilmente a la luz del desarrollo dogmático en el derecho de las últimas décadas, por ejemplo, la aparición de nuevas ramas del derecho, nuevos modelos de aproximación al estudio del derecho, nuevos y variados enfoques metodológicos y epistemológicos, etcétera. Sobre la falta de certeza, se puede indicar que la indeterminación que pueda existir en la dogmática jurídica no siempre conduce a la duda absoluta ni tampoco puede calificarse de inútil, pues de la deliberación y discusión de argumentos entre los dogmáticos pueden encontrarse soluciones, si no sólidas al menos plausibles o aceptables para los prácticos del derecho. El dere-

Texto seleccionado de Cárdenas Gracia, Jaime, Introducción al estudio del derecho, México, UNAM, 2009, pp. 44 y 45. 
Este libro forma parte del acervo de la Biblioteca Jurídica Virtual del Instituto de Investigaciones Jurídicas de la UNAM

cho no es un conocimiento inútil porque permite perfeccionar su objeto de estudio, el que cumple en la sociedad múltiples funciones sociales: estructurar la convivencia social, premiar o castigar conductas, promover el cambio social, etcétera.

El profesor Atienza, sin embargo, le da la razón a Von Kirchmann en un punto y considera que el asunto está mal planteado y que:

La auténtica raíz del problema es la falta de prestigio social de los juristas y de la labor teórica que desarrollan, carencia que se pretende superar usufructuando el rótulo de científico. Nos encontramos, pues, con un nuevo caso de "definición persuasiva", como lo prueba el hecho de que la polémica ha quedado circunscrita a los juristas de países de derecho continental, y no se plantea en los del common law (ni se planteó tampoco, al menos como un problema importante, en la jurisprudencia romana), donde los juristas gozan de un prestigio indiscutido. En otras palabras, Von Kirchmann tenía razón —y la sigue teniendo—al sostener que la jurisprudencia no es una ciencia... la jurisprudencia es una técnica. 


\section{JURISDICCIÓN ${ }^{*}$}

\section{CONCEPTO}

Etimológicamente, la palabra jurisdicción deriva de dos raíces latinas. En primer término, iurisdictio, -onis, que significa "poder o autoridad que tiene alguien para gobernar y poner en ejecución las leyes o para aplicarlas en juicio". Otro precedente latino se encuentra en las voces latinas jus, derecho, y dicere, proclamar, declarar, decir. De acuerdo con esto último, jurisdicción significa decir el derecho.

Estas definiciones etimológicas no se apartan mucho de lo que, en materia procesal, quiere decir jurisdicción. El concepto a seguir en este ámbito es el siguiente: es la facultad que tiene el Estado para dirimir litigios de trascendencia jurídica, a través de alguno de sus órganos o por medio de árbitros, mediante la aplicación de normas jurídicas e individualizadas.

Ciertamente, el Estado cuenta, entre su cúmulo de atribuciones, con la de instalar órganos - precisamente llamados jurisdiccionales- que se encargan de impartir justicia entre los gobernados. Esos órganos, por regla general, son públicos y pertenecen al Poder Judicial de la Federación, a los poderes judiciales locales, o bien, al Poder Ejecutivo, como en el caso del Tribunal Federal de Justicia Fiscal y Administrativa. No obstante, existe también la posibilidad de dirimir controversias a través del arbitraje; éste constituye un medio no judicial de solución de conflictos en virtud del cual, las partes, de común acuerdo, se someten a la decisión de un árbitro, el cual emite un laudo, no una sentencia. Cabe señalar que los arbitrajes en materia laboral constituyen un caso especial, ya que las juntas de conciliación y arbitraje, aun cuando formalmente no son tribunales, cuentan con plena jurisdicción para emitir sus laudos y para hacerlos cumplir incluso coactivamente.

Texto seleccionado de Manual del justiciable. Elementos de teoría general del proceso, México, Suprema Corte de Justicia de la Nación, 2005, pp. 51-55. 
Este libro forma parte del acervo de la Biblioteca Jurídica Virtual del Instituto de Investigaciones Jurídicas de la UNAM

\section{ClasificACión}

Puede clasificarse a la jurisdicción, entre otros, de acuerdo a los siguientes criterios:

1. Voluntaria y contenciosa. Esta clasificación se basa en la existencia o inexistencia de una controversia. La jurisdicción voluntaria tiene lugar cuando no hay una controversia a resolver, al contrario de lo que ocurre con la contenciosa, donde necesariamente debe haberla.

2. Federal, local y concurrente. Está en función del nivel de gobierno al que pertenezcan los órganos jurisdiccionales. Así, la jurisdicción federal es la que corresponde a los juzgados y tribunales de la Federación, la local es la que ejercen los juzgados y tribunales estatales, así como de la Ciudad de México, y la concurrente supone la intervención, en la misma especie de asuntos, de órganos del Poder Judicial de la Federación y de la entidad federativa del territorio de que se trate.

3. Propia y delegada. La jurisdicción propia —o "retenida" — la concede la propia ley a los órganos jurisdiccionales, a través de disposiciones en las que se establece exactamente cuál es su jurisdicción; en cambio, la jurisdicción delegada entraña que un órgano con jurisdicción propia delegue parte de ésta en otro órgano.

4. Judicial y arbitral. La primera es la que corresponde a los juzgadores de los poderes judiciales de la Federación, de los estados y del Distrito Federal; en cuanto a la arbitral, la tienen los integrantes de órganos — públicos o privados — que desempeñan labores de arbitraje.

5. Ordinaria, especial y excepcional. La ordinaria es aquella a la que se atribuye el conocimiento de asuntos no reservados a una jurisdicción especial, que es la que tiene lugar en atención a las cualidades de una persona que sólo se puede ver involucrada en un tipo específico de asuntos; por ejemplo, un militar. Por último, la jurisdicción excepcional se relaciona con lo dispuesto por el artículo 13 de la Constitución Política de los Estados Unidos Mexicanos, que prevé la improcedencia de procesos sustanciados ante tribunales especiales. La creación de un tribunal especial para que conozca de un solo asunto, daría lugar a esta especie de jurisdicción. 
Este libro forma parte del acervo de la Biblioteca Jurídica Virtual del Instituto de Investigaciones Jurídicas de la UNAM www.juridicas.unam.mx

6. Constitucional. Es la que corresponde a los órganos especializados en la resolución de asuntos derivados de la interpretación y aplicación de los preceptos constitucionales; en México, la jurisdicción constitucional en sentido estricto le corresponde a la Suprema Corte de Justicia de la Nación. 
Este libro forma parte del acervo de la Biblioteca Jurídica Virtual del Instituto de Investigaciones Jurídicas de la UNAM

\title{
DEL ESTADO LIBERAL AL ESTADO SOCIAL Y DEMOCRÁTICO DE DERECHO*
}

\begin{abstract}
El Estado moderno nace durante la llamada Baja Edad Media, bajo la premisa de los elementos esenciales que, con los respectivos vaivenes, se mantienen hasta hoy: "territorio", "soberanía", "población". Esta noción de concentración del poder en manos del rey, respecto de la población ubicada en un territorio determinado, se da como reacción a la atomización del poder político que había supuesto el carácter socioeconómico del feudalismo, así como beneficiado por la circunstancia histórica del fin de las Cruzadas.
\end{abstract}

Característica de esta primera etapa del Estado moderno sería el poder absoluto del monarca, que tendría reacciones, ya manifestadas primigeniamente en la insular Inglaterra desde la Carta Magna de 1215, daría lugar en el siglo XVIII al proceso de la Ilustración, cuyo resultado político plasma las ideas de Montesquieu y Rousseau en las Revoluciones estadounidense de 1776 y francesa de 1789. De esta última, destacan la Declaración de Derechos del Hombre y del Ciudadano y la Constitución Política de 1789, y del primer documento citado se extrae el núcleo estructural del constitucionalismo contemporáneo, en su artículo 16: "Toda sociedad en que no esté establecida la garantía de los derechos, ni determinada la separación de poderes, carece de Constitución".

El Estado de derecho, en cuanto a sus bases fundamentales y filosóficas, se encuentra principalmente en las obras de Kant y de Humboldt. Básicamente, consiste actualmente en la:

Sujeción de la actividad estatal a la Constitución y a las normas aprobadas conforme a los procedimientos que ella establezca, que garantizan el cumplimiento responsable y controlado de los órganos del poder; el ejercicio de la autoridad conforme a disposiciones reconocidas y no retroactivas en tér-

Texto seleccionado de Witker, Jorge, Juicios orales y derechos humanos, México, UNAM, 2016, pp. 30-34. 
Este libro forma parte del acervo de la Biblioteca Jurídica Virtual del Instituto de Investigaciones Jurídicas de la UNAM

minos perjudiciales, y la observancia de los derechos individuales, sociales, culturales y políticos.

Normalmente, se adjudica al jurista alemán Robert von Möhl quien acuñó hacia 1829 la expresión Staatsrechts, que significa "Estado de derecho", por oposición a Machtstaat o "Estado de fuerza", o Estado de la monarquía absoluta, y a Polizeistaat o Estado de Policía; en el Estado de Fuerza, el "rex facit legem", mientras que en el Estado de derecho, "lex facit regem". Por su parte, sería Otto Bähr quien publicó en el año 1864 un libro con este título, partiendo de la idea de que el concepto del Estado de derecho no significa que éste reglamente, mediante preceptos, la vida que en él se desarrolla, ni que limite sus fines a la realización del derecho, sino que tal Estado eleva el derecho a condición fundamental de su existencia. El concepto de Estado de derecho — como ya he mencionado- supone básicamente que el Estado se somete a la ley que él mismo impone a través de su imperio; ley que es obligatoria para todos, gobernantes y gobernados, en igualdad de condiciones, contrariamente a lo que ocurría en la monarquía absoluta, donde el monarca era legibus solutus. Se trata de respuesta del liberalismo de la Ilustración, en oposición al ancien règime anterior a la Revolución Francesa de 1789.

Pero, el Estado (liberal) de derecho sólo permitía entregar y respetar, por parte del Estado, derechos y libertades civiles y políticas, sin respetar necesariamente las condiciones de vida de los habitantes/ciudadanos de cada país. Los movimientos sociales de Europa en la segunda mitad del siglo XIX, la llamada "cuestión social" de fines del siglo XIX/ inicios del siglo XX, la Revolución mexicana de 1910, la Segunda República Española de 1931 y la Revolución rusa de 1917, Ilevaron a la palestra la necesidad de que el Estado también debía ocuparse de los llamados derechos económicos, sociales y culturales (DESC, en la terminología pedagógica de los derechos humanos), pues, ¿cómo puede concebirse suficiente el poder votar, elegir y ser elegido, pensar, reunirse, manifestarse, si no se tiene una vivienda digna, una educación digna, un sistema de salud digno, un trabajo digno?, ¿puede concretarse real y plenamente el derecho a la vida, si no están garantizados aquellos otros derechos? Así, la Constitución Política mexicana de 1917, la Declaración de los Derechos del Pueblo Trabajador y Explotado de Rusia y la Constitución de Weimar de 1918, y la Constitución de la Segunda República Española de 1931, abrieron el camino para el reconocimiento por el Estado de dichos derechos, sin dejar de respetar los derechos 
Este libro forma parte del acervo de la Biblioteca Jurídica Virtual del Instituto de Investigaciones Jurídicas de la UNAM

civiles y políticos, convirtiéndose el Estado (liberal) de derecho en un "Estado social de derecho".

Ya a fines del siglo pasado, sobre todo tras la evidencia del desastre que el llamado "Consenso de Washington" y la consecuente aplicación de políticas económicas neoliberales en la región, vino la pregunta necesaria: ¿es suficiente que el Estado me permita elegir periódicamente sus autoridades, consagre en sus textos fundamentales derechos económicos, sociales y culturales, cuando en la práctica las decisiones cardinales sean tomadas sin considerar la participación activa de sus ciudadanos? Por ello, se concibe una nueva etapa de democratización del Estado, donde las decisiones sean tomadas en forma "participativa" y no sólo "representativa", como lo presenta la doctrina constitucional clásica, a través del llamado "Estado democrático y social de derecho". Ejemplos claros son los textos constitucionales de casos de Alemania, Italia, Francia, Portugal, Suiza, Polonia y España, además de los textos vigentes de Colombia, Brasil, Venezuela, Ecuador y Bolivia, en nuestro continente.

En fin, y después de las experiencias extremas del siglo XX, la actual concepción del Estado se percibe como de amplio respeto de los derechos humanos en su plenitud, en virtud de lo que el concepto de democracia es inclusivo en todos sus niveles, y donde el principio de supremacía constitucional (y, por tal, el de soberanía nacional) cede ante el sistema jurídico internacional, sobre todo cuando este último amplíe el ámbito de protección de los derechos humanos, dando real claridad al principio de progresividad establecido en los diferentes instrumentos internacionales en materia de derechos humanos (es decir, que cada vez se profundicen y consoliden más).

El entendimiento del Estado democrático y social de derecho es un reforzamiento del reconocimiento de los derechos civiles y políticos, pero es también un reconocimiento a nivel teleológico, por parte del Estado, de los derechos económicos, sociales y culturales. El Estado democrático y social de derecho es un Estado (sobre todo) democráti$\mathrm{co}$, en que la democracia es entendida en dos sentidos armónicamente interrelacionados: democracia política como método de designación de los gobernantes y participación activa de los gobernados, y democracia social como la realización del principio de igualdad en la sociedad.

Como consecuencia, el Estado asume un rol esencial en la consolidación de los derechos económicos, sociales y culturales, al entenderse la importancia de dicho rol en un mundo neoliberalmente globalizado. 
Este libro forma parte del acervo de la Biblioteca Jurídica Virtual del Instituto de Investigaciones Jurídicas de la UNAM

\section{EL GONTROL DE GONVENGIONALIDAD}

\section{INTRODUCCIÓN Y DEFINICIONES}

Dentro de los contenidos de la reforma constitucional de 2011 en materia de derechos humanos, uno de los que más destaca en la interpretación del juez y de toda autoridad jurisdiccional (y no sólo judicial) ha sido la del control de convencionalidad.

Efectivamente, en aras del desarrollo de una mejor forma de garantizar los derechos humanos contenidos en el catálogo constitucional (e internacional), dice relación con este mecanismo de relativamente reciente data (su inclusión en el sistema interamericano de derechos humanos no data más allá de tres lustros)

Hay que aclarar que la doctrina ha variado en relación con su definición. Para el argentino Víctor Bazán, éste:

Consiste en verificar la adecuación de las normas jurídicas internas que aplican en casos concretos a la Convención Americana sobre Derechos Humanos... y a los estándares interpretativos forjados por la Corte Interamericana de Derechos Humanos... ${ }^{1}$

Por su parte, para la académica mexicana Roselia Bustillo Marín, se trata de un

mecanismo que se ejerce para verificar que una ley, reglamento o acto de las autoridades del Estado, se ajustan a las normas, los principios y obligaciones de la Convención Americana de Derechos Humanos principalmente, en la que funda la competencia contenciosa de la Corte IDH².

* Texto seleccionado de Witker, Jorge, Derechos de las personas extranjeras, México, UNAM, 2016, pp.

1 Bazán, Víctor, "El control de convencionalidad: incógnitas, desafíos y perspectivas", en Bazán, Víctor y Nash, Claudio (eds.), Justicia constitucional y derechos fundamentales. El control de convencionalidad 2011, Bogotá, Centro de Derechos Humanos de la Facultad de Derecho de la Universidad de Chile-Konrad Adenauer Stiftung, 2012, pp. 17 y 18.

2 Bustillo Marín, Roselia, El control de convencionalidad. La idea del bloque de 
Este libro forma parte del acervo de la Biblioteca Jurídica Virtual del Instituto de Investigaciones Jurídicas de la UNAM

La Corte IDH ha definido a esta figura como "una institución que se utiliza para aplicar el derecho internacional", sobre todo en cuanto "el derecho internacional de los derechos humanos, y específicamente la Convención Americana y sus fuentes, incluyendo la jurisprudencia" de dicho órgano ${ }^{3}$. Por tal, se debe entender de que existe una obligación internacional a cargo de todas las autoridades de los Estados parte de la $\mathrm{CADH}$, respecto a interpretar toda norma jurídica nacional (Constitución, ley, decreto, reglamento, jurisprudencia, etcétera) de conformidad con la misma CADH y, en general, con el llamado corpus iuris interamericano; si llega a existir una manifiesta incompatibilidad entre la norma interna y el referido corpus iuris interamericano, es obligación de las respectivas autoridades estatales el de abstenerse de aplicar la norma nacional, con el objeto de evitar la violación de los derechos humanos protegidos internacionalmente. Así, estas autoridades estatales han de ejercer de oficio el control de convencionalidad, actuando siempre en el ámbito de sus respectivas competencias, así como tomando en cuenta las debidas regulaciones procesales establecidas en su legislación interna.

\section{Desarrollo histórico}

A un destacado jurista mexicano debemos el nacimiento de la figura del control de convencionalidad. Precisamente, fue Sergio García Ramírez, quien, en su calidad de juez de la Corte IDH, emitió un voto concurrente en el Caso Myrna Mack Chang vs. Guatemala, ${ }^{4}$ ahí, García Ramírez señala que:

No es posible seccionar internacionalmente al Estado, obligar ante la Corte sólo a uno o algunos de sus órganos, entregar a éstos la representación del Estado en el juicio — sin que esa representación repercuta sobre el Estado en su conjunto- y sustraer a otros de este régimen convencional de responsabilidad, dejando sus actuaciones fuera del 'control de convencionalidad' que trae consigo la jurisdicción de la Corte Internacional. ${ }^{5}$

constitucionalidad y su relación con el control de constitucionalidad en materia electoral, México, Tribunal Electoral del Poder Judicial de la Federación, 2013, p. 6.

3 Ferrer Mac-Gregor, Eduardo et al. (coords.), Diccionario de derecho procesal constitucional y convencional, cit., t. I, A-F, p. 233.

4 Caso Myrna Mack Chang vs. Guatemala, fondo, reparaciones y costas, sentencia del 25 de noviembre de 2003, San José, Corte IDH, 2003.

5 Caso Myrna Mack Chang vs. Guatemala, cit., párr. 27 del voto concurrente. 
Este libro forma parte del acervo de la Biblioteca Jurídica Virtual del Instituto de Investigaciones Jurídicas de la UNAM

El propio García Ramírez reiterarará dicho criterio (también mediante voto concurrente) en el Caso Tibi vs. Ecuador, ${ }^{6}$ al sostener que la tarea de la Corte IDH

se asemeja a la que realizan los tribunales constitucionales. Éstos examinan los actos impugnados — disposiciones de alcance general— a la luz de las normas, los principios y los valores de las leyes fundamentales. La Corte Interamericana, por su parte, analiza los actos que llegan a su conocimiento en relación con normas, principios y valores de los tratados en los que funda su competencia contenciosa. Dicho de otra manera, si los tribunales constitucionales controlan la 'constitucionalidad', el tribunal internacional de derechos humanos resuelve acerca de la 'convencionalidad' de esos actos. A través del control de constitucionalidad, los órganos internos procuran conformar la actividad del poder público —y, eventualmente, de otros agentes sociales - al orden que entraña el Estado de derecho en una sociedad democrática. El tribunal interamericano, por su parte, pretende conformar esa actividad al orden internacional acogido en la Convención fundadora de la jurisdicción interamericana y aceptado por los Estados parte en ejercicio de su soberanía. ${ }^{7}$

Tal doctrina fue reafirmada por la Corte IDH en el Caso Almonacid Arellano y otros vs. Chile, en 2006,8 a propósito del Decreto Ley NúM. 2191 de 1978, y la "justificación" que hasta entonces asumía el Estado chileno para evadir sus responsabilidades internacionales. ${ }^{9}$ Con base en su propia jurisprudencia en materia de justicia transicional, la Corte IDH declaró la nulidad ab initio del referido Decreto Ley, indicando que

en casos donde el Poder Legislativo falle en su tarea de suprimir leyes contrarias al Pacto de San José, el Poder Judicial permanece obligado a respetar y garantizar los derechos protegidos por la Convención y, por lo tanto, debe realizar un control de convencionalidad, de forma tal que los jueces velen porque los efectos de las disposiciones de la Convención Americana

6 Caso Tibi vs. Ecuador, excepciones preliminares, fondo, reparaciones y costas, sentencia del 7 de septiembre de 2004, San José, Corte IDH, 2004.

7 Caso Tibi vs. Ecuador, cit., párr. 3 del voto concurrente.

8 Caso Almonacid Arellano y otros vs. Chile, fondo, reparaciones y costas, sentencia del 26 de septiembre de 2006, San José, Corte IDH, 2006, párr. 124.

9 Decreto Ley núm. 2.191, que Concede amnistía general, bajo las circunstancias que indica, por los delitos que señala, publicado en el Diario Oficial de la República de Chile, núm. 30.042, del 19 de abril de 1978. 
Este libro forma parte del acervo de la Biblioteca Jurídica Virtual del Instituto de Investigaciones Jurídicas de la UNAM

no se vean mermados por la aplicación de leyes contrarias a su objeto y fin. ${ }^{10}$

Se trata de una línea que es coherente con lo que establece cuando indica que

La Corte es consciente que los jueces y tribunales internos están sujetos al imperio de la ley y, por ello, están obligados a aplicar las disposiciones vigentes en el ordenamiento jurídico. Pero cuando un Estado ha ratificado un tratado internacional como la Convención Americana, sus jueces, como parte del aparato del Estado, también están sometidos a ella, lo que obliga a velar por que los efectos de las disposiciones de la Convención no se vean mermados por la aplicación de leyes contrarias a su objeto y fin, y que desde un inicio carecen de efectos jurídicos. En otras palabras, el Poder Judicial debe ejercer una especie de "control de convencionalidad" entre las normas jurídicas internas que aplican en los casos concretos y la Convención Americana sobre Derechos Humanos. En esa tarea, el Poder Judicial debe tener en cuenta no solamente el tratado, sino también la interpretación que del mismo ha hecho la Corte Interamericana, intérprete último de la Convención Americana. ${ }^{11}$

Se trata de un precedente que se ha reiterado (incluso precisando sustancialmente diversos aspectos conceptuales), como Caso Trabajadores Cesados del Congreso (Aguado Alfaro y otros) vs. Perú (2006),12 Caso Heliodoro Portugal vs. Panamá (2008), 13 Radilla Pacheco vs. México (2009), 14 Caso Cabrera García y Montiel Flores vs. México (2010),15

10 Ferrer Mac-Gregor, Eduardo et al. (coords.), Diccionario de derecho procesal constitucional y convencional, cit., t. I, A-F, p. 234.

11 Caso Almonacid Arellano y otros vs. Chile, op. cit., párr. 124.

12 Caso Trabajadores Cesados del Congreso (Aguado Alfaro y otros) vs. Perú, fondo, reparaciones y costas, sentencia del 24 de noviembre de 2006, San José, Corte IDH, 2006, párr. 128.

13 Caso Heliodoro Portugal vs. Panamá, fondo, reparaciones y costas, sentencia del 12 de agosto de 2008, San José, Corte Interamericana de Derechos Humanos, 2008, párr. 180.

14 Caso Radilla Pacheco vs. México, excepciones preliminares, fondo, reparaciones y costas, sentencia del 23 de noviembre de 2009, San José, Corte IDH, 2009, párr. 339.

15 Caso Cabrera García y Montiel Flores vs. México, excepción preliminar, fondo, reparaciones y costas, sentencia del 26 de noviembre de 2010, San José, Corte IDH, 2010, párr. 225. 
Este libro forma parte del acervo de la Biblioteca Jurídica Virtual del Instituto de Investigaciones Jurídicas de la UNAM

y Caso Gelman vs. Uruguay (2011),16 así como la supervisión de cumplimiento de esta última sentencia (2013). ${ }^{17}$

Aquí es importante indicar quiénes tienen la obligación de aplicar este control. Reproduciendo al argentino Víctor Bazán, el mexicano Miguel Carbonell identifica cuatro etapas de la jurisprudencia: 18

- Sólo el Poder Judicial (Caso Almonacid Arellano vs. Chile);

- Todos los órganos del Poder Judicial (Caso Trabajadores Cesados del Congreso vs. Perú);

- Todos los jueces y órganos vinculados a la administración de justicia, en todos los niveles (Caso Cabrera García Montiel Flores vs. México); y, actualmente,

- En cualquier autoridad pública, y no sólo del poder judicial (Caso Gelman vs. Uruguay).

16 Caso Gelman vs. Uruguay, fondo y reparaciones, sentencia del 24 de febrero de 2011, San José, Corte IDH, 2011.

17 Caso Gelman vs. Uruguay, supervisión de cumplimiento de sentencia, 20 de marzo de 2013, San José, Corte IDH, 2013.

18 Carbonell Sánchez, Miguel, Introducción general al control de convencionalidad, México, Porrúa-UNAM, Instituto de Investigaciones Jurídicas, 2014, pp. 14 y 15. 
Este libro forma parte del acervo de la Biblioteca Jurídica Virtual del Instituto de Investigaciones Jurídicas de la UNAM

\section{EL ACTO ADMINISTRATIVO}

\section{I. ¿QUÉ ES UN ACTO ADMINISTRATIVO?}

Es la manifestación unilateral de la voluntad de un órgano administrativo competente, encaminada a crear, reconocer, modificar, transmitir, declarar o extinguir derechos u obligaciones.

Como ejemplos de actos administrativos se pueden mencionar los permisos, las licencias, las autorizaciones, las clausuras, las certificaciones, las expropiaciones, los registros, etcétera.

\section{II. ¿QUÉ ELEMENTOS DEBE REUNIR UN ACTO ADMINISTRATIVO?}

Según la doctrina y la Ley Federal de Procedimiento Administrativo, los elementos que debe reunir un acto administrativo son:

1. Sujeto. Debe ser expedido por órgano competente a través de un servidor público y, en caso de que dicho órgano fuere colegiado, debe reunir las formalidades de la ley o decreto para emitirlo.

2. Voluntad. Debe ser expedido libre de error respecto a la identificación del expediente, documentos o nombre completo de las personas, y sin que medie dolo o violencia en su emisión.

3. Objeto. Debe tener por objeto uno que pueda ser materia del acto; determinado o determinable; preciso en cuanto a las circunstancias de tiempo y lugar, y previsto por la ley.

4. Motivo. El acto administrativo debe estar fundado y motivado, es decir, la autoridad administrativa debe citar de manera específica la ley exactamente aplicable al caso, así como expresar las circunstancias especiales, razones particulares o causas inmediatas que se hayan tenido en consideración para emitir el acto y la adecuación entre los motivos aducidos y las normas aplicables. Cabe señalar que, con respecto a la fundamentación, la Suprema Corte

* Texto seleccionado de Manual del justiciable. Materia administrativa, México, Suprema Corte de Justicia de la Nación, 2005, pp. 21-28. 
Este libro forma parte del acervo de la Biblioteca Jurídica Virtual del Instituto de Investigaciones Jurídicas de la UNAM

de Justicia de la Nación estableció que no es necesario que las autoridades administrativas citen la jurisprudencia aplicable al caso, aun cuando ésta declare la inconstitucionalidad de una ley, ya que, de conformidad con la Constitución Política de los Estados Unidos Mexicanos, así como la Ley de Amparo, la jurisprudencia solamente obliga a los órganos jurisdiccionales.

5. Fin. El acto administrativo debe cumplir con la finalidad del interés público, regulado por las normas en que se concreta, sin que puedan perseguirse otros fines distintos.

6. Forma. Debe constar por escrito y con la firma autógrafa de la autoridad que lo expida, salvo en aquellos casos en que la ley autorice otra forma de expedición.

\section{III. ¿QUÉ EFECTOS TIENE UN ACTO ADMINISTRATIVO?}

Son múltiples los efectos que puede producir un acto administrativo; sin embargo, de la teoría puede desprenderse, entre otras, una clasificación general que atiende a los efectos en relación con los particulares y a los efectos respecto de la administración pública.

En relación con los particulares, los efectos del acto administrativo son la creación, modificación, transmisión, declaración o extinción de derechos y obligaciones. Como ejemplo puede mencionarse el pago de una pensión a un jubilado. El efecto para el particular será la determinación de su monto, pues ello implica la creación o determinación de un derecho a favor de éste.

Respecto al órgano administrativo, los efectos del acto administrativo consisten en la realización misma de la actividad encomendada al órgano de la administración pública. En el ejemplo de la pensión, el efecto para la administración será el pago de ésta.

Debe señalarse que la autoridad, en atención a su competencia, está obligada a observar los requisitos que las normas establecen para el acto administrativo. Lo anterior responde al principio de legalidad, que se traduce en que las autoridades sólo pueden hacer lo que la ley les permite. Así, por ejemplo, un acto administrativo será nulificado o anulado si lo realiza una autoridad incompetente.

\section{IV. ¿Cómo SE EJECUTA Un ACTO ADMINISTRATIVO?}

Existen actos administrativos que entrañan ejecución automática, es decir, con el hecho de que la autoridad cumpla determinados requisi- 
Este libro forma parte del acervo de la Biblioteca Jurídica Virtual del Instituto de Investigaciones Jurídicas de la UNAM

tos para su emisión, el acto se considera ejecutado, como ocurre, por ejemplo, en el caso de un registro.

Sin embargo, cuando el acto administrativo impone a los particulares alguna obligación o les produce o puede producir alguna afectación en su esfera jurídica, se pueden presentar dos supuestos:

1. Que el acto se obedezca voluntariamente por el particular;

2. Que no se obedezca voluntariamente.

Frente a este último supuesto, para evitar que la obligación quede incumplida, el Estado puede llevar a cabo, de acuerdo con la situación concreta, las siguientes acciones:

1. La ejecución directa, con lo que sustituye al particular en el cumplimiento de la obligación; por ejemplo: una clausura.

2. La imposición de una sanción, para compeler al particular al cumplimiento; por ejemplo: la imposición de una multa.

3. La coacción física, que se ejecuta en la persona del particular; por ejemplo: la aplicación forzosa de una medida sanitaria cuando se presenta una epidemia.

\section{V. ¿CÓMO PUEDE EXTINGUIRSE UN ACTO ADMINISTRATIVO?}

El acto administrativo se extingue de pleno derecho, por las siguientes causas:

1. Cumplimiento de su finalidad.

2. Prescripción o caducidad.

3. Cuando la formación del acto administrativo esté sujeta a una condición o término suspensivo y éste no se realice dentro del plazo señalado en el propio acto.

4. Acaecimiento de una condición resolutoria.

5. Renuncia del interesado, cuando el acto hubiere sido dictado en exclusivo beneficio de éste y su extinción no sea en perjuicio del interés público.

6. Por revocación, cuando así lo exija el interés público, de acuerdo con la ley de la materia.

El acto administrativo que se extingue deja de producir efectos jurídicos, lo que puede resultar dañoso para un particular que, en virtud del 
Este libro forma parte del acervo de la Biblioteca Jurídica Virtual del Instituto de Investigaciones Jurídicas de la UNAM

acto, hubiera adquirido un derecho. La revocación, por ejemplo, procede sólo si la autoridad tiene facultades para determinarla; en tal caso, si una autoridad incompetente extingue un acto al revocarlo, el particular afectado puede recurrir a los tribunales administrativos o a los federales de amparo para solicitar una reparación.

\section{VI. ¿QUÉ ES EL PROCEDIMIENTO ADMINISTRATIVO?}

Es el conjunto de formalidades y actos que, de manera directa o indirecta, determinan los requisitos que preceden al acto administrativo, para que éste sea válido y cumpla un fin específico.

La regulación de este procedimiento no está unificada. Depende de la materia de que se trate; así, por ejemplo, tanto la Ley Federal de Procedimiento Administrativo como el Código Fiscal de la Federación prevén procedimientos de este tipo.

\section{VII. ¿QUÉ SON LAS INFRACCIONES ADMINISTRATIVAS?}

La infracción administrativa es una transgresión o violación a las normas administrativas y que amerita una sanción de la misma naturaleza. Como un ejemplo se puede citar la infracción a la Ley Federal de Radio y Televisión, consistente en la emisión no autorizada de los textos de anuncios o propaganda comerciales que requieran previamente la aprobación oficial. 
Este libro forma parte del acervo de la Biblioteca Jurídica Virtual del Instituto de Investigaciones Jurídicas de la UNAM

\section{LOS PUEBLOS INDÍGENAS EN EL CONSTITUCIONALISMO LATINOAMERICANO CONTEMPORÁNEO ${ }^{1}$}

El reconocimiento ha sido defendido como una necesidad profundamente humana. Más aun, diversos autores consideran el reconocimiento colectivo como una condición indispensable para el ejercicio de los derechos individuales, pues las personas pertenecen a una cultura societal que le da significado a sus decisiones individuales. Si se niega la existencia o validez de esa pertenencia, se puede afectar la propia capacidad de comportase como un agente autónomo. En las últimas décadas, América Latina ha sido testigo de lo que José Bengoa ha llamado la "emergencia indígena". Se trata de la irrupción de diversos movimientos indígenas reclamando, en general, una nueva relación con sus Estados, basada justamente en el reconocimiento de los derechos colectivos que les corresponderían en su calidad de pueblos pre-existentes al propio Estado. Estas reivindicaciones indígenas han sido acogidas en el seno de la comunidad internacional, traduciéndose primero, en el Convenio núm. 169 de la OlT de 1989.

Este instrumento reconoce derechos a los pueblos indígenas sobre sus tierras y territorios, además de establecer mecanismos de participación política (consulta indígena), y reconocer el derecho que les asiste a ejercer un control progresivo sobre los programas de salud y educación dirigidos a ellos, entre otras cosas. El punto culminante de esta recepción de la demanda indígena en la arena internacional se dio en 2007, cuando la Asamblea General de Naciones Unidas, con la participación de Chile, adoptó la Declaración de Derechos de Pueblos Indígenas (DDPI). Este documento va más allá que el mencionado Convenio, reconociendo directamente que los pueblos indígenas, como cualquier otro pueblo, tiene derecho a la libre determinación, expresada en el auto-gobierno en el seno de los Estados en que habitan (autonomía), con las consecuencias que ello conlleva. Por su parte, las reivindica-

1 Texto seleccionado de Meza-Lopehandía G., Matías, Pueblos indígenas y Constitución, Quito, Corte Constitucional del Ecuador, 2008, pp. 37-45. 
Este libro forma parte del acervo de la Biblioteca Jurídica Virtual del Instituto de Investigaciones Jurídicas de la UNAM

ciones indígenas también han tenido impacto a nivel constitucional en América Latina, y también en otros países, como Canadá. ${ }^{2}$

Diversas constituciones de la región, casi siempre emanadas de asambleas constituyentes, han incluido disposiciones que reconocen y valoran la diversidad cultural de sus respectivos países, lo que incluye, al menos implícitamente, a los pueblos indígenas. Así, por ejemplo, Brasil, en su Constitución de 1988 establece el deber del Estado de proteger "las manifestaciones de las culturales populares, indígenas y afro-brasileñas" (artículo 215), y les reconoce derechos territoriales (cap. VIII). En Colombia, la Constitución de 1991 "reconoce y protege la diversidad étnica y cultural de la Nación colombiana" (artículo 7), sin perjuicio de otras disposiciones que siguen de cerca lo establecido en el Convenio 169 de la OIT. ${ }^{3}$ Por su parte, la Constitución argentina de 1994 ordena al Congreso "[r]econocer la preexistencia étnica y cultural de los pueblos indígenas argentinos" (artículo 75.17). También Guyana, Paraguay, Perú y Venezuela cuentan con disposiciones, e incluso capítulos completos, que reconocen a los pueblos indígenas y les asignan derechos colectivos. Frente a la alternativa multicultural, países como Ecuador y Bolivia han optado por consagrar el carácter plurinacional del Estado. Aunque la Constitución de Ecuador (2008) es explícita al respecto (artículo 1), el paradigma en esta materia es la Constitución boliviana de 2006. Ésta reconoce la existencia precolonial de los pueblos indígenas, y su derecho a la libre determinación (artículos 2 y 3). A partir de esto, la Constitución reconoce la democracia comunitaria como medio de generación de autoridades (artículo 11.II.3), la proporcionalidad de la representación indígena en el parlamento (artículo 146.IV), establece un Tribunal Constitucional integrado con criterios de proporcionalidad (artículo 196.I), y en general, incluye las instituciones indígenas en la estructura general del Estado (artículo 30.II.5), entre otros aspectos distintivos. En Sudamérica, sólo Chile, Uruguay y Surinam, carecen de reconocimiento explícito a los pueblos indígenas, pese a que los tres países cuentan con dicha población. ${ }^{4}$ Es más, en el más

2 De hecho, este último país, en su Ley Constitucional de 1982, reconoció la vigencia de los derechos de los indígenas (aboriginal rights) y aquellos emanados de los tratados celebrados entre aquéllos y la Corona británica (treaty rights).

3 Entre ellas, reserva escaños en el Senado a los representantes indígenas (artículo 171), reconoce la jurisdicción especial indígena (artículo 246), y establece los territorios indígenas como partes de la organización territorial del Estado (artículo 286).

4 Generalmente se afirma que en Uruguay no existe población indígena. Sin embargo, de acuerdo a las estadísticas oficiales, el $4 \%$ de la población declara tener as- 
Este libro forma parte del acervo de la Biblioteca Jurídica Virtual del Instituto de Investigaciones Jurídicas de la UNAM www.juridicas.unam.mx

amplio contexto constitucional latinoamericano (que incluye Centro y Norteamérica), el reconocimiento es la regla general.

cendencia indígena (INE Uruguay, 2010). Es importante tener presente que el principal elemento de identificación indígena en el derecho internacional es la autoidentificación individual y colectiva, sin perjuicio del elemento objetivo (descender de las poblaciones originarias) (cfr. artículo 1 Convenio 169 OIT). 
Este libro forma parte del acervo de la Biblioteca Jurídica Virtual del Instituto de Investigaciones Jurídicas de la UNAM

\section{RECURSOS GENÉTICOS Y BIOPIRATERÍA ${ }^{*}$}

\section{RECURSOS GENÉTICOS, SU IMPORTANCIA Y PROTECCIÓN, BIOPIRATERÍA}

De acuerdo a Teresa Agüero, investigadora de ODEPA:

los recursos genéticos, exponentes tangibles de la biodiversidad presente en nuestro planeta, adquieren cada día mayor importancia y utilidad, principalmente por el fuerte desarrollo de la investigación biotecnológica, por el uso por parte de la industria farmacéutica, por la actividad de la industria de semillas, que busca la obtención de nuevas variedades vegetales, y por la fitomedicina. Tienen un rol clave en el desarrollo agrícola y forestal, por su contribución para enfrentar los desafíos ambientales, como son la desertificación, la adaptación al cambio climático, el estrés hídrico, la aparición de nuevas plagas y enfermedades, entre otros. Esta expansión tecnológica ha permitido una valorización de los recursos genéticos y, consecuentemente, una creciente demanda. ${ }^{1}$

En general, los países proveedores de recursos genéticos corresponden a los países que se encuentran en desarrollo; en cambio, los países usuarios de estos recursos genéticos son los poseedores de las tecnologías, que fundamentalmente son los países desarrollados. De esta manera, los recursos genéticos pueden constituir una importante fuente económica para muchas naciones en vías de desarrollo. Estos recursos están vinculados, en muchas ocasiones, con el conocimiento tradicional de las comunidades indígenas y locales y por consiguiente constituyen un patrimonio natural e intelectual invalorable desde el punto de vista social, económico, cultural y ecológico que se constituye en un poderoso estímulo para que los países en desarrollo... legislen sobre la protección y el acceso a sus recursos genéticos. ${ }^{2}$ Por su parte,

\footnotetext{
* Texto seleccionado de Hafner, Annette y Williams, Guido, Recursos genéticos y biopiratería: casos y sanciones en legislación comparada, Valparaíso, Biblioteca del Congreso Nacional de Chile, 2015, pp. 2-4.

1 Disponible en: http://www.odepa.gov.cl/odepaweb/publicaciones/doc/2283.pdf (fecha de consulta: enero de 2015).

2 Pérez Salóm, J. "El derecho internacional y el Estatuto de los Recursos Genéti-
} 
Este libro forma parte del acervo de la Biblioteca Jurídica Virtual del Instituto de Investigaciones Jurídicas de la UNAM

el artículo 15 del Convenio sobre Diversidad Biológica, ${ }^{3}$ es actualmente la principal normativa internacional que rige el acceso a los recursos genéticos. Este artículo trata los términos y condiciones para el acceso a los recursos genéticos y la participación en los beneficios generados por su utilización. Además, reconoce la soberanía de los Estados sobre sus recursos naturales y estipula que el acceso a dichos recursos será sometido al consentimiento previo de la Parte Contratante que proporciona tales recursos. Cabe señalar que el mismo Convenio sobre Diversidad Biológica, en su artículo 2, describe recursos genéticos como el material genético de valor real o potencial, siendo este último considerado como todo material de origen vegetal, animal, microbiana o de otro tipo que contenga unidades funcionales de la herencia. A la luz de los conceptos referidos, un recurso genético es todo aquel que, estando constituido por el ADN (material genético), pueda tener un valor real o potencial. De acuerdo a Rodríguez Bertoldi, la característica central del artículo 15 es que:

El acceso a un determinado recurso genético está vinculado a contraprestaciones anteriormente inexistentes que afectan especialmente a la Parte usuaria de un recurso genético, entre las que destacan:

- la transferencia de tecnologías, incluidas las biotecnologías,

- la distribución justa y equitativa de los beneficios provenientes de cualquier modalidad de utilización,

- la realización de investigaciones científicas con la participación del proveedor y

- la adopción de medidas legislativas, administrativas o de política que faciliten la distribución de los beneficios derivados de la utilización comercial o de otra naturaleza. ${ }^{4}$

La misma autora menciona que:

la finalidad de este artículo es promover el intercambio de recursos genéticos y, con ello, el desarrollo económico de los países poseedores mediante un reparto justo y equitativo de los beneficios comerciales, tecnológicos y/o

cos", Anuario de Derecho Internacional, Pamplona, vol. XIII, 1997, p. 373.

3 Adoptada en la Conferencia de las Naciones Unidas sobre el Medio Ambiente y Desarrollo, celebrada en Río de Janeiro en 1992 y que entró en vigor el 29 de diciembre de 1993.

4 Disponible en: http://www.reei.org/reei\%2011/M.Rodrigues(reei11).pdf(fecha de consulta: enero de 2015). 
Este libro forma parte del acervo de la Biblioteca Jurídica Virtual del Instituto de Investigaciones Jurídicas de la UNAM

científicos obtenidos a partir del recurso explotado. Por otra parte, estos beneficios pueden cumplir una función ambiental, ya que en muchos casos serán empleados en la conservación de la biodiversidad. ${ }^{5}$

Una forma de vulnerar la propiedad de los recursos genéticos y el reparto justo de los beneficios comerciales mencionado es mediante la biopiratería. Al respecto, Vandana Shiva ${ }^{6}$ señala que biopiratería es el: "Uso injustificado de los sistemas de propiedad intelectual, con el objeto de asegurar la legitimidad de la apropiación exclusiva y en esta misma dirección, del control sobre múltiples recursos, productos y procesos biológicos, que se relacionan, fundamentalmente, con la diversidad biológica".

5 Idem.

6 Ramírez, Hugo, Biopiratería: notas en torno a sus significados jurídicos, Ponencia al Instituto de Investigaciones Jurídicas de la UNAM. Disponible en: http://www. juridicas.unam.mx/sisjur/saldyder/pdf/5-239s.pdf, cit. por Shiva, Vandana, Protec or plunder? Understanding Intelectual Property Rights, Londres, Zed Book, 2001, p. 49. 
Este libro forma parte del acervo de la Biblioteca Jurídica Virtual del Instituto de Investigaciones Jurídicas de la UNAM

\section{DERECHOS ECONÓMICOS, SOCIALES Y CULTURALES ${ }^{*}$}

\section{DEFINICIÓN DE LOS DERECHOS ECONÓMICOS, SOCIALES Y CULTURALES}

Según la Oficina del Alto Comisionado de las Naciones Unidas para los

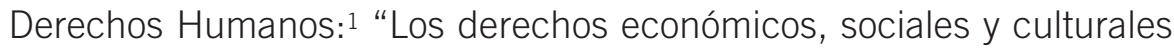
son los derechos humanos relacionados con el lugar de trabajo, la seguridad social, la vida en familia, la participación en la vida cultural y el acceso a la vivienda, la alimentación, el agua, la atención de la salud y la educación".

No hay una definición única de lo que cada uno de los derechos mencionados implica, ya que depende de la legislación nacional de cada país, y/o de los convenios y otros instrumentos internacionales vigentes.

No obstante, la Oficina presenta una lista básica de los DESC. Ésta se resume de la siguiente manera: ${ }^{2}$

- Derechos de los trabajadores:

- Prohibición del trabajo forzado.

- Derecho de aceptar o rechazar un trabajo.

- Salario equitativo y justo.

- Limitación de las horas de trabajo y suficiente tiempo libre.

- Seguridad e higiene en el lugar de trabajo.

- Afiliación a sindicatos, derecho de huelga.

- El derecho a la seguridad social y a la protección social:

- No denegación de manera arbitraria o no razonable.

- Derecho a la igualdad en el disfrute de la adecuada protección.

* Texto seleccionado de Hafner, Annette, La protección de los derechos económicos, sociales y culturales en la Constitución. Derecho comparado, Santiago de Chile, Biblioteca del Congreso Nacional de Chile, 2014, pp. 2 y 3.

1 Oficina del Alto Comisionado de las Naciones Unidas para los Derechos Humanos. Folleto informativo "Preguntas frecuentes sobre los Derechos Económicos, Sociales y Culturales. Disponible en: http://www.ohchr.org/Documents/Issues/ESCR/FAQ\%20 on\%20ESCR-sp.pdf (fecha de consulta: junio de 2014).

2 Idem. 
Este libro forma parte del acervo de la Biblioteca Jurídica Virtual del Instituto de Investigaciones Jurídicas de la UNAM

- La protección de la familia y la asistencia a ésta:

- Contraer matrimonio mediante libre consentimiento.

- Protección de la maternidad y paternidad.

- Protección de los hijos de la explotación económica y social.

- El derecho a un nivel de vida adecuado:

- Derecho a la alimentación y protección contra el hambre.

- Derecho a una vivienda adecuada, agua y vestido.

- El derecho a la salud, que incluye el derecho:

- Accesión a las instalaciones, los bienes y los servicios relacionados con la salud.

- Condiciones ambientales y laborales saludables.

- Protección contra enfermedades epidémicas.

- Protección de la salud sexual y reproductiva.

- El derecho a la educación:

- Enseñanza primaria gratuita y obligatoria.

- Enseñanza superior accesible y progresivamente gratuita.

- Derecho de los padres de escoger la escuela de los hijos.

- Los derechos culturales:

- Participación en la vida cultural.

- Derecho a compartir los adelantos científicos y beneficiarse de ellos.

- Derecho a la protección de los intereses morales y materiales de autor.

\section{MARCO LEGAL INTERNACIONAL}

El fundamento de la codificación supranacional los derechos económicos, sociales y culturales (DESC) es la Declaración Universal de los Derechos Humanos de 1948. Esta ha sido complementada, en 1966, por el Pacto Internacional sobre los DESC. En 2008, se estableció un Protocolo adicional facultativo respecto de los DESC.

El Pacto Internacional sobre los DESC 3 contiene derechos, obligaciones, compromisos y normas materiales en materia de los DESC. En particular, establece los siguientes derechos:

- Derecho al trabajo (en condiciones justas y favorables).

- Derecho a la protección social.

3 Pacto disponible en: http://www2.ohchr.org/spanish/law/cescr.htm (fecha de consulta: junio de 2014). 
Este libro forma parte del acervo de la Biblioteca Jurídica Virtual del Instituto de Investigaciones Jurídicas de la UNAM

- Derecho a un nivel de vida adecuado.

- Derecho al más alto nivel posible de salud física y mental.

- Derecho a la educación.

- Derecho a la participar en la vida cultural.

- Derecho a gozar de los beneficios del progreso científico.

El Protocolo adicional facultativo ${ }^{4}$, por su parte, atribuye nuevas competencias al Comité de los DESC ${ }^{5}$, para recibir y examinar comunicaciones (que se explican a continuación) conforme a lo dispuesto en el Protocolo. Asimismo, se establecen dos mecanismos nuevos para la mejor protección de los DESC:

- Los individuos, grupos de personas u organizaciones que los representan pueden presentar "comunicaciones" al Comité por violaciones de los derechos económicos, sociales y culturales enunciados en el Pacto. El Comité hace las investigaciones necesarias y emite un dictamen, junto con recomendaciones.

- El Comité puede hacer investigaciones en los Estados partes, en caso de que reciba información fidedigna que da cuenta de violaciones graves o sistemáticas de los derechos económicos, sociales y culturales enunciados en el Pacto.

4 Protocolo disponible en: http://www2.ohchr.org/spanish/law/docs/A.RES.63.117_ sp.pdf (fecha de consulta: junio de 2014).

5 El Comité de los DESC ha sido establecido en 1985 para asumir las funciones de monitoreo otorgadas al Consejo Económico y Social de las Naciones Unidas en el Pacto sobre los DESC. Más información disponible en: http://www.ohchr.org/EN/HRBodies/ CESCR/Pages/CESCRIndex.aspx (fecha de consulta: junio de 2014). 
Este libro forma parte del acervo de la Biblioteca Jurídica Virtual del Instituto de Investigaciones Jurídicas de la UNAM

\section{CÁRDENAS Y EL INICIO DE LA ECONOMÍA MIXTA (PLAN SEXENAL) $^{*}$}

Con esta política pública, de claro perfil social y nacionalista, el cardenismo inicia los proyectos que intentan materializar las aspiraciones originales de la Revolución de 1910, cuyas bases jurídicas se han analizado en los capítulos precedentes.

Para materializar la economía mixta, Cárdenas impulsa el primer plan sexenal que, por su importancia, pasamos brevemente a resumir: ${ }^{1}$

a. Que México debía realizar una política nacionalista para proteger mejor sus riquezas naturales.

b. Debía hacerse efectivo el principio constitucionalista de nacionalización del subsuelo, mediante la recuperación de los recursos naturales.

c. Debía ejercerse una estricta vigilancia en la operación de las distintas empresas extranjeras.

d. Debía promoverse el desarrollo de la minería, el petróleo, la industria, la agricultura, etcétera, con recursos nacionales, creándose cuerpos técnicos para promover la exploración de los yacimientos minerales y petrolíferos, aumentando las reservas nacionales en función del desarrollo industrial, regulando la operación de la industria existente por medio de la creación de consejos de planificación industrial, etcétera.

e. Debían suprimirse las formas de intermediación comercial que deforman el mercado y desvían de los renglones productivos el excedente económico, dilapidándolo. Con ello, se debía procurar la eliminación de las formas negativas de concentración de capitales.

Texto seleccionado de Witker Velásquez, Jorge, El constitucionalismo económico de la carta de Querétaro 1917-2017, México, LXIII Legislatura de la H. Cámara de Diputados, 2016, t. II, pp. 85-87.

1 Cabrera Guerrero, Héctor, Estructura económica y política de la historia de México, México, Guajardo, 1978, p. 77. 
Este libro forma parte del acervo de la Biblioteca Jurídica Virtual del Instituto de Investigaciones Jurídicas de la UNAM

f. Debían tomarse medidas para elevar la capacidad de compra de las grandes masas, con lo cual se perseguía el fortalecimiento del mercado interno.

g. Debía lograrse la redención económica y social de los campesinos, dotándolos no sólo de tierras y aguas, sino organizándolos y capacitándolos económicamente. Para asegurar lo anterior, se proponía la formación de cooperativas, incremento del crédito agrícola, introducción de maquinaria y fertilizantes, así como la construcción de obras de riego y vías de comunicación.

h. Finalmente, debía impulsarse la educación, mereciendo preferencia la educación rural, indicándose los porcentajes para tal fin, que eran de un 15\% en 1934 a un 20\% en 1939.

Mediante este instrumento, con el cual se inicia la planeación económica en México, y que Cárdenas lo implementó a través de un órgano consultivo ad-hoc llamado Comité Asesor Especial, para su seguimiento y evaluación, culminando con una oficina técnica responsable, inscrita en la Secretaría de Gobernación. 
Este libro forma parte del acervo de la Biblioteca Jurídica Virtual del Instituto de Investigaciones Jurídicas de la UNAM

\section{LA INVESTIGACIÓN JURÍDICA. ELEMENTOS PRELIMINARES}

La tesis, como trabajo intelectual, es una forma de investigación, esto es, un proceso sistemático de ejercicios analíticos y sintéticos que se dan entre un sujeto (inquisidor, investigador o postulante) y un objeto (material o espiritual) en cuya relación se busca alcanzar un producto científico nuevo o diferente.

Para comprender la tarea de hacer una tesis jurídica debemos detenernos brevemente en los pasos que sigue toda investigación científica, que son: curiosidad, observación, abstracción, comprobación y tesis o producto científico.

Estos pasos operan entre los dos elementos que se presentan dialécticamente. El sujeto (yo o el estudiante-investigador) y el objeto, esto es, en nuestro caso, el derecho como ciencia social normativa que regula conductas individuales y sociales y que se nos presenta como institución jurídica, de relación jurídica, idea o concepto jurídico-social, hecho social con efectos jurídicos relevantes, etcétera.

Veamos cómo se articulan los pasos señalados:

\section{a. La curiosidad}

Es el primer momento en la relación sujeto-objeto y opera en el área cognoscitiva del sujeto cuando entra en contacto con los diversos objetos jurídicos del conocimiento. La curiosidad es una inquietud que surge en el estudiante y que lo predispone para fijar su mente en algún atributo, característica o institución de un objeto determinado. La curiosidad es consecuencia de varios factores, generalmente derivados del medio sociocultural del estudiante y del contacto positivo y orientador de maestros que naturalmente transmiten entusiasmo y creatividad en los grupos.

Texto seleccionado de Witker Velásquez, Jorge, La investigación jurídica. Bases para la tesis de grado en derecho, 3a. ed., México, Publilex, 2016, pp. 29-31. 
Este libro forma parte del acervo de la Biblioteca Jurídica Virtual del Instituto de Investigaciones Jurídicas de la UNAM

\section{b. La observación}

Es la etapa siguiente y supone una revisión general de la bibliografía sobre el objeto de la curiosidad a disposición del estudiante y las discusiones preliminares con maestros especializados en el tema, con lo cual vamos, lentamente, sometiendo a nuestra conciencia el objeto posible, siempre que se inscriba en campos temáticos que nos gusten. Se trata de fijar la mente en algo y "verlo" (observarlo) detenidamente.

\section{c. La abstracción}

Es la etapa clave de toda tesis o investigación, pues en ella el estudiante o el investigador, conocedor de los principales aspectos del objeto observado, comienza a dialogar en voz alta, a plantearse interrogantes, es decir, a proyectar senderos posibles, variables a verificar, pistas de acercamiento, que serán la base de toda investigación o tesis, y sus posibles productos o metas científicas. Es el inicio de la problematización temática. En esta etapa, el tutor de la tesis debe jugar un papel sustancial, pues su experiencia y conocimiento en el tema serán la mejor ayuda del estudiante que se inicia en la dura tarea de saber elaborar próximamente las hipótesis, pues de ellas depende el resultado final de la investigación.

\section{d. La comprobación}

Este cuarto paso o etapa, denominada por algunos como la parte artesanal de la tesis, supone el comprobar o descartar los elementos o variables contemplados en la o las hipótesis de trabajo. Aquí vamos de lleno a trabajar con las técnicas de investigación (documental o de campo), opción que estará determinada por la composición y estructura de la hipótesis o preguntas que nos hemos hecho en la etapa anterior. En esta etapa, el estudiante debe saber recolectar la información pertinente para validar las conjeturas que se planteó en relación al objeto, materia de su investigación o tesis. 
Este libro forma parte del acervo de la Biblioteca Jurídica Virtual del Instituto de Investigaciones Jurídicas de la UNAM

\section{PROBLEMAS DE TRANSFERENCIA DE TECNOLOGÍA E INVERSIÓN EXTRANJERA*}

\section{LA TECNOLOGÍA}

Los países industrializados destinan sumas crecientes a la investigación tecnológica, convencidos de que se trata de una inversión redituable, y efectivamente lo es, dado que es la base de la productividad, además de que el proceso de traspaso tecnológico, tal como se verifica actualmente, ha hecho de la tecnología una mercancía que se vende a altos precios en un mercado monopolizado por sus propietarios.

Hay una estrecha vinculación entre el desarrollo y la tecnología, ya que ésta constituye un prerrequisito para alcanzar aquél; pero también el desarrollo es indispensable para que pueda darse el progreso tecnológico. Esta suerte de "círculo virtuoso" acontece en la realidad en los países desarrollados, mientras que en el mundo en desarrollo se convierte en un "círculo vicioso" que no es fácil de romper.

En efecto, la carencia de recursos financieros, aunada a la urgencia de resolver necesidades básicas de la población, conduce a postergar o hasta a abandonar la investigación y el desarrollo tecnológicos, lo que a su vez trae como consecuencia la "pobreza" tecnológica que se observa en casi todos los países no industrializados.

México es un país en desarrollo con enormes carencias todavía no resueltas y con una población mayoritariamente marginada de los beneficios del progreso, y al igual que en las demás naciones que componen ese heterogéneo grupo, es el Estado el que fundamentalmente enfrenta el gasto en estas actividades, obviamente de manera incompleta y además generalmente ineficiente.

La crisis financiera que se desencadenó a partir de 1995 ha traído como consecuencia que el Estado mexicano destine cada vez menos recursos financieros a este renglón fundamental, por lo que la brecha

Texto seleccionado de Witker Velásquez, Jorge, Introducción al derecho económico, 12a. ed., México, Publilex, 2016, pp. 210 y 211. 
Este libro forma parte del acervo de la Biblioteca Jurídica Virtual del Instituto de Investigaciones Jurídicas de la UNAM

tecnológica que separa a México de los países industrializados se ha venido ensanchando.

No obstante, para enfrentar la crisis se adoptó un nuevo modelo de desarrollo que pone el acento en la apertura comercial y la interrelación con otras economías, tratando de provocar en el aparato productivo una actitud más propicia a generar exportaciones.

La apertura comercial es un reto para los empresarios, pero constituye también una oportunidad para la modernización del aparato productivo. Mejorar los procesos productivos significa introducir tecnologías de "punta", mejorar la planta es obtener nuevos y más modernos equipos tecnológicamente avanzados y no descartar la automatización. Todo esto implica la necesidad de alcanzar una adecuada importación tecnológica y una rápida asimilación de lo importado, aunada a la realización de actividades propias de investigación que propicien innovaciones en procesos y productos.

Por su parte, el gobierno debe apoyar los esfuerzos del sector productivo mediante el fortalecimiento de la infraestructura científica y tecnológica, y propiciar el desarrollo de la tecnología en las instituciones de investigación con acciones que faciliten y promuevan la vinculación entre ambos.

El progreso tecnológico se manifiesta en la elevación del monto de los bienes y servicios que el aparato productivo pone a disposición de los consumidores, es decir, en el incremento de los volúmenes de producción; pero su impacto no es sólo cuantitativo sino también cualitativo, ya que la tecnología permite acceder a la productividad y provoca cambios importantes en los hábitos de consumo y en el modo de vida de las personas.

Nadie puede dudar que el desarrollo de la ciencia y la tecnología se alimenta constantemente de los frutos de la capacidad inventiva del ser humano, máxime si se reconoce que la tecnología es dinámica por naturaleza, y en esa constante evolución la propiedad intelectual funge como el motor que propicia su aceleramiento. 
Este libro forma parte del acervo de la Biblioteca Jurídica Virtual del Instituto de Investigaciones Jurídicas de la UNAM

\section{LA JUSTICIA COMO SERVICIO PÚBLICO*}

La justicia es uno de los valores superiores de nuestro ordenamiento jurídico; su realización es un objetivo fundamental de nuestro Estado constitucional democrático, que tiene a su cargo — como una de sus tareas fundamentales- dirimir controversias jurídicas, con la justicia como fin.

El acceso a la justicia es el derecho fundamental que tiene toda persona para acudir y promover la actividad de los órganos encargados de prestar el servicio público de impartición de justicia, con la finalidad de obtener la tutela jurídica de sus intereses mediante una resolución pronta, completa e imparcial.

Este acceso a la justicia se instaura sobre la base de que este es un servicio público, que encuentra fundamento en instrumentos internacionales como el Pacto de Derechos Civiles y Políticos, artículo segundo; la Declaración Universal de los Derechos Humanos, artículo 10; así como el artículo 13 del Convenio Europeo para la Protección de los Derechos Humanos.

En el contexto de nuestro Estado social de derecho, la función de la justicia debe estar acorde con sus ejes rectores. La idea de justicia debe partir de una concepción instrumental y no finalista; concebir la administración de justicia no como un fin en sí mismo sino como un medio para conseguir determinados fines sociales ${ }^{1}$, fines que son funciones cardinales del Estado, encaminadas a garantizar una calidad de vida digna para los ciudadanos. Esta labor es encomendada a funcionarios públicos, jueces y magistrados, quienes deciden sobre la vida y libertad de aquellos, frente a la exigencia de una correcta prestación del servi-

Texto seleccionado de Witker Velásquez, Jorge, "Justicia y cambio cultural en la formación judicial en México”, Judicatus, Monterrey, 2a. época, año 1, núm. 2, 2009, pp. 4-7.

1 Toharia, J. J., citado por Tajadura Tejada, Javier, Reflexiones en torno a la configuración de la justicia como servicio público, XXIII Jornadas de Estudio de la Abogacía General del Estado, Madrid, 2001. 
Este libro forma parte del acervo de la Biblioteca Jurídica Virtual del Instituto de Investigaciones Jurídicas de la UNAM

cio público correspondiente. Los responsables deben ser funcionarios altamente especializados, pues tienen a su cargo un servicio público que responde a una demanda social en términos formales (conforme a derecho) y materiales (pronta, expedita y eficaz) de los ciudadanos.

La idea de justicia puede ser concebida como una organización de una determinada expresión potestativa de la autoridad estatal, que nos refiere, en específico, al Poder Judicial. ${ }^{2}$ Los jueces y magistrados, como funcionarios públicos, están ligados al Estado por una innegable relación de servicio público. De esta manera, se convierten en los exponentes máximos de justicia como servicio público y, al igual que ella, requieren de una mayor legitimidad. ${ }^{3}$ Ante la sociedad, el Poder Judicial está comprometido a obtener una legitimación de origen y de ejercicio, una síntesis entre lo normativo y lo fáctico, entre la legalidad y la eficacia. ${ }^{4}$

El grado de legitimación del Poder Judicial está dado por la percepción de sus usuarios. Una imagen total de satisfacción es imposible, porque el derecho siempre asistirá a una de las partes y difícilmente se contará con el beneplácito de todos los contendientes. Aunado a ello, el Poder Judicial tiene gran dificultad en comunicar y valorizar su acción usando cínicamente argumentos jurídicos que, en ocasiones, no resultan acordes para el sentido común e idea generalizada acerca de lo que es o no justo. Es por ello que para una mayor legitimación del Poder Judicial debe concentrarse en la legitimidad de su actuar, que en el contexto actual reside en una adecuada formación judicial y modernización en la impartición de justicia, traducidas en decisiones fundamentales congruentes con el orden jurídico y el contexto social. La satisfacción de los usuarios de la justicia se encuentra en el seno de un cambio de paradigmas del modelo tradicional, que hoy ha sido altamente cuestionado por la opinión pública.

El Poder Judicial no es un fin en sí mismo; como servicio público persigue satisfacer las demandas de los ciudadanos, atendiendo las funciones tradicionales de la gobernanza, que son mantener la paz social y resolver las controversias que se susciten entre los miembros del conglomerado político. Actualmente, el papel del Poder Judicial tiene

2 Idem.

3 La idea de justicia implica la legitimación y limitación de las autoridades-poderes públicos.

4 Canales Aliende, José Manuel, "El servicio público de la justicia: actualidad y perspectivas", Política y Sociedad, Madrid, núm. 20, 1995, pp. 63-70. 
competencia y capacidad para garantizar los principios fundamentales de la democracia, influye de manera determinante en la implementación y ejecución de las políticas públicas, interactúa con agentes de otros poderes en un contexto jurídico-político y se encuentra permanentemente en la mira de la opinión pública. 


\section{SOLUCIONES}

\section{Grupo 1 \\ Ejercicio léxico 1}

1. Desarrollo

10. Dogmática

2. Solución

11. Argumentos

3. Jurisprudencia

12. Convivencia

4. Métodos

13. Conferencia

5. Conocimiento

14. Razón

6. Técnica

15. Científico

7. Progreso

16. Plausibles

8. Consecuencia

17. Circunscrita

9. Enfoques

18. Variabilidad

Ejercicio léxico 2

1. Listo

2. Técnica

3. Conocimiento

4. Lectura

5. Afinidad
6. Jurisprudencia
7. Interés
8. Consecuencia
9. Conferencia
10. Progreso

Ejercicio léxico 3

1. $b$

2. $c$

3. $b$

4. a

5. a

6. c

7. $\mathrm{c}$

8. $b$

\section{Ejercicio léxico 4}

Razón (5)

Perspectiva (6)

Argumento (8)

Literatura (2)

Filosofía (7)
Durar (3)

Certeza (9)

Desarrollo (4)

Abandonar (1) 
Este libro forma parte del acervo de la Biblioteca Jurídica Virtual del Instituto de Investigaciones Jurídicas de la UNAM

\section{Ejercicio léxico 6}

Crucigrama 1

\section{Vertical}

1. Escuela

2. Progreso

6. Facilidad
1. Vaivenes

2. Imperio

3. Sociedad

4. Condición
5. Poder

6. Sujeción

7. Estado

8. Designación

Ejercicio léxico 2

1. Conocimiento

2. Condición

3. Unívoco

4. Jurista

5. Fundamental

6. Vaivén

7. Estructura

8. Poder

9. Potestad

10. Nación

\section{Ejercicio léxico 3}

1. $b$

5. c

2. $c$

6. a

3. a

4. $b$

\section{Ejercicio léxico 4}

Cómplice (7)

Poder (4)

Persuasión (1)

Fundamental (2)

Democracia (9)
Ética (5)

Primigenio (3)

Vaivén (6)

Progresivo (8) 
Este libro forma parte del acervo de la Biblioteca Jurídica Virtual del Instituto de Investigaciones Jurídicas de la UNAM

\section{Ejercicio léxico 6}

Crucigrama 2

\section{Horizontal \\ 4. Estado \\ 6. Democracia \\ 7. Imperio \\ 8. Vaivén \\ 9. Sujeción}

\section{Vertical}

1. Unívoco.

2. Persuasión

3. Poder

5. Designación

\section{Grupo 3 \\ Ejercicio léxico 1}

1. Jurisdicción

5. Arbitraje

2. Solución

6. Materia

3. Tribunales

7. Federación

4. Gobernados

8. Voluntaria

\section{Ejercicio 2}
1. Decisión
2. Jurisdicción
3. Arbitraje
4. Término
5. Precedente
6. Acuerdo
7. Coacción

\section{Ejercicio léxico 3}
1. $\mathrm{C}$
2. $a$
3. $\mathrm{c}$
4. $b$

5. a

6. c

7. $b$

\section{Ejercicio léxico 4}

Instalar (3)

Cúmulo (6)

Militar (9)

Laudo (8)

Materia (7)
Controversia (1)

Entidad (4)

Local (2)

Resolver (5) 
Este libro forma parte del acervo de la Biblioteca Jurídica Virtual del Instituto de Investigaciones Jurídicas de la UNAM

\section{Ejercicio léxico 6}

Crucigrama 3

\author{
Horizontal \\ 1. Último \\ 6. Militar \\ 8. Controversia \\ 9. Atención \\ 10. Solución
}

1. Investigaciones

2. Sociales

3. Codificación

4. Reproductiva

\author{
Vertical \\ 2. Tribunales \\ 3. Jurisdicción \\ 4. Coactivo \\ 5. Laudo \\ 7. Federación
}

\section{Grupo 4 \\ Ejercicio léxico 1}
1. Enseñanza
2. Acertar
3. ONU
4. Oficina
5. Vida

5. Implica

6. Naciones Unidas

7. Individuos

\section{Ejercicio léxico 2}
2. $\mathrm{c}$
3. a
4. c

1. $a$
6. Acceder
7. Comisionado
8. Superior
9. Trabajo
10. Vestido

Ejercicio léxico 3
5. a
6. c
7. $b$

\section{Ejercicio léxico 4}

Implicar (4)

Comunicar (1)

Investigación (8)

Codificación (9)

Convenio (7)
Reproducir (5)

Condición (2)

Mencionar (6)

Relacionar (3) 
Este libro forma parte del acervo de la Biblioteca Jurídica Virtual del Instituto de Investigaciones Jurídicas de la UNAM

\section{Ejercicio léxico 6}

Crucigrama 4

\section{Horizontal \\ 3. Compartir \\ 4. Acierto \\ 7. Vestido \\ 8. Acceso \\ 9. Beneficio \\ 10. Legislación}

\section{Vertical}

1. Superior

2. Codificación

5. Trabajo

6. Prohibición
1. Validez

2. Deber

3. Ley

4. Moral

\section{Grupo 5}

Ejercicio léxico 1
1. a
2. $b$
3. $b$
4. c
5. Conducta
6. Pura
7. Expresión
8. Autónoma

Ejercicio léxico 2

Ejercicio léxico 3
1. a
2. $b$
3. a
4. c
5. b

6. a

7. c

8. $b$

9. b

10. a

\section{Ejercicio léxico 4}

Sujeto (5)

Instrumento (1)

Ley (8)

Normativa (2)

Teoría (6)
Deber (7)

Moral (9)

Expresión (4)

Conducta (3) 
Este libro forma parte del acervo de la Biblioteca Jurídica Virtual del Instituto de Investigaciones Jurídicas de la UNAM

\section{Ejercicio léxico 6}

Crucigrama

\section{Horizontal \\ 3. Neutro \\ 7. Diversidad \\ 10. Alcanzar}
Vertical
1. Base
2. Normativa
4. Obligación
5. Orden
6. Deber
8. Conducta
9. Validez

\section{Grupo 6}

Ejercicio léxico 1
1. Frontera
2. Virtud
3. Análisis
4. Individuos
5. Epistemológica
6. Predicción
7. Cumpla
8. Realismo
9. Concepción

Ejercicio léxico 2
1. Decir
2. Sentido
3. Concepción
4. Maternidad
5. Elemento
6. Escandinavo
7. Metodología
8. Predecir
9. Individuo
10. Virtud

\section{Ejercicio léxico 3}
1. $b$
6. $b$
2. $a$
7. $a$
3. $\mathrm{c}$
8. $b$
4. $b$
9. a
5. c
10. c 
Este libro forma parte del acervo de la Biblioteca Jurídica Virtual del Instituto de Investigaciones Jurídicas de la UNAM

\section{Ejercicio léxico 4}

Entender (4)

Realismo (7)

Alcanzar (9)

Omitir (1)

Futuro (6)
Realizar (8)

Universal (2)

Importar (3)

Complejo (5)

\section{Ejercicio léxico 6}

\section{Crucigrama 6}

\section{Horizontal}

2. Complejo

4. Fuerte

5. Universal

7. Elemento

9. Sentido

10. Predecir

\section{Vertical}

1. Frontera

3. Virtud

6. Entender

8. Omitir

\section{Grupo 7}

Ejercicio léxico 1
1. Juntas
2. Ejecución
3. Apartan
4. Raíces

5. Impartir

6. General

7. Litigios

\section{Ejercicio léxico 2}
1. Etimología
2. Litigio
3. Regla
4. Raíz
5. Juicio
6. Apartar
7. Ejecución
8. General
9. Atribuir
10. Caso

Ejercicio léxico 3
1. $b$
5. a
2. $a$
6. c
3. $c$
7. $b$
4. $b$ 
Este libro forma parte del acervo de la Biblioteca Jurídica Virtual del Instituto de Investigaciones Jurídicas de la UNAM

\section{Ejercicio léxico 4}

Derivar (3)

Gobernar (6)

Medio (9)

Fiscal (2)

Conciliación (8)

\author{
Dirimir (7) \\ Impartir (1) \\ Hacer (5) \\ Proclamar (4)
}

Ejercicio léxico 6

Crucigrama 7

\section{Horizontal \\ 2. Hacer \\ 4. Juicio \\ 5. Atribución \\ 7. Fiscal \\ 8. Contar \\ 10. Dirimir}

\section{Vertical}

1. General

3. Litigio

6. Impartir

9. Formal

\section{Grupo 8}

Ejercicio léxico 1
1. Excepcional
2. Constitucional
3. Judicial
4. Ordinaria
5. Propia
6. Contenciosa
7. Territorio

Ejercicio léxico 2

1. Específico

2. Proceso

3. Gestión

4. Especie

5. Disposición
6. Ejercicio
7. Corresponder
8. Visión
9. Cualidad
10. Disponer

Ejercicio léxico 3
1. $b$

2. $b$

3. $a$

4. c
5. a

6. b

7. $a$ 
Este libro forma parte del acervo de la Biblioteca Jurídica Virtual del Instituto de Investigaciones Jurídicas de la UNAM

\section{Ejercicio léxico 4}

Reservado (5)

Asunto (8)

Judicial (2)

Constitucional (9)

Existencia (7)
Precepto (3)

Involucrar (1)

Excepcional (4)

Rural (6)

\section{Ejercicio léxico 6}

Crucigrama 8

Horizontal

1. Excepcional

3. Gestión

7. Propia

8. Judicial

10. Ordinaria

\section{Vertical}

2. Constitucional

4. Especie

5. Tratar

6. Precepto

9. Visión

\section{Grupo 9}

Ejercicio léxico 1

1. Reforma

5. Internacional

2. Académica

6. De oficio

3. Abstenerse

7. Representación

\section{Ejercicio léxico 2}
1. Sustraer
2. Reforma
3. Juez
4. Catálogo
5. Destacar
6. Régimen
7. Ajustar
8. Doctrina
9. Data
10. Estándar

\section{Ejercicio léxico 3}
1. $b$
5. b
2. $c$
6. c
3. $b$
7. a
4. a 
Este libro forma parte del acervo de la Biblioteca Jurídica Virtual del Instituto de Investigaciones Jurídicas de la UNAM

\section{Ejercicio léxico 4}

Adaptar (3)

Reglamento (4)

Representación (8)

Interpretar (9)

Actuar (6)
Competencia (7)

Repercutir (5)

Mecanismo (2)

Adecuar (1)

\section{Ejercicio léxico 6}

Crucigrama 9

\section{Horizontal \\ 3. Juez \\ 5. Doctrina \\ 6. Interpretar \\ 7. Adaptar \\ 9. Proteger}

1. Vías

2. Campesinos

3. Economía

4. Capacidad

\section{Vertical}

1. Destacar

2. Repercutir

4. Estándar

8. Reforma

10. Régimen

\section{Grupo 10 \\ Ejercicio léxico 1}

5. Riquezas

6. Cardenismo

7. Vigilancia

8. Subsuelo

\section{Ejercicio léxico 2}
1. Plan
2. Crédito
3. Sexenal
4. Empresa
5. Subsuelo

6. Mixto

7. Agrícola

8. Fertilizar

9. Estricto

10. Riqueza

\section{Ejercicio léxico 3}
1. c
5. a
2. $b$
6. c
3. a
7. $b$
4. c 
Este libro forma parte del acervo de la Biblioteca Jurídica Virtual del Instituto de Investigaciones Jurídicas de la UNAM

\section{Ejercicio léxico 4}

Aspiración (7)

Campesino (3)

Capacidad (4)

Operación (5)

Capacitar (8)
Natural (1)

Proyecto (9)

Masa (2)

Nacionalizar (6)

Ejercicio léxico 6

Crucigrama 10
Horizontal
2. Plan
6. Agrícola
9. Materializar.
10. Campesino

\author{
Vertical \\ 1. Natural \\ 3. Estricto \\ 4. Aspiración \\ 5. Crédito \\ 7. Operación \\ 8. Capacidad
}

\section{Ejercicios léxico-sintácticos}

\section{Adjetivos}

1. El acto administrativo es la manifestación unilateral de la voluntad de un órgano administrativo competente, encaminada a crear, reconocer, modificar, transmitir, declarar o extinguir derechos u obligaciones, para ciertos particulares determinados.

2. Debe ser expedido por órgano competente a través de un servidor público y, en caso de que dicho órgano fuere colegiado, debe reunir las formalidades de la ley o decreto para emitirlo, las que son esenciales para que surta efectos.

3. La voluntad no debe estar viciada para poder hacer efectos en un contrato. El contrato es la relación manifestada de la intención de los contratantes, en la medida que estos la expresen libremente y exenta de vicios.

4. El acto administrativo debe estar fundado y motivado, es decir, la autoridad administrativa debe citar de manera específica la ley exactamente aplicable al caso, así como expresar las circunstancias especia$\underline{\text { les, }}$, razones particulares o causas inmediatas que se hayan tenido en consideración para emitir el acto y la adecuación entre los motivos aducidos y las normas aplicables, emitidas por una autoridad determinada. 
Este libro forma parte del acervo de la Biblioteca Jurídica Virtual del Instituto de Investigaciones Jurídicas de la UNAM

5. Con respecto a la fundamentación, la Suprema Corte de Justicia de la Nación estableció que no es necesario que las autoridades administrativas citen la jurisprudencia aplicable al caso, aun cuando ésta declare una ley inconstitucional, ya que, de conformidad con la Constitución Política de los Estados Unidos Mexicanos, así como la Ley de Amparo, la jurisprudencia solamente obliga a los órganos jurisdiccionales.

6. La infracción administrativa es una transgresión o violación a las normas administrativas y que amerita una fuerte sanción de la misma naturaleza. Como un ejemplo se puede citar la infracción a la Ley Federal de Radio y Televisión, consistente en la emisión no autorizada de los textos de anuncios o propaganda comerciales que requieran previamente la aprobación oficial.

7. Son múltiples los efectos que puede producir un acto administrativo; sin embargo, de la teoría dominante puede desprenderse, entre otras, una clasificación general que atiende a los efectos en relación con los particulares y a los efectos respecto de la administración pública.

8. La autoridad, en atención a su competencia, está obligada a observar los requisitos establecidos por las normas establecen para el acto administrativo. Lo anterior responde al principio de legalidad, que se traduce en que las autoridades sólo están permitidas a hacer lo que la ley les permite. Así, por ejemplo, un acto administrativo será nulificado o anulado si lo realiza una autoridad incompetente.

9. Existen actos administrativos que entrañan ejecución automática, es decir, con el hecho de que la autoridad cumpla determinados requisitos para su emisión, el acto se considera ejecutado, como ocurre, por ejemplo, en el caso de un registro notarial.

\section{Frases}

1. Respecto al órgano administrativo, los efectos del acto administrativo consisten en la realización misma de la actividad encomendada al órgano de la administración pública. En el ejemplo de la pensión, el efecto para la administración será el pago de ésta.

2. Frente a este último supuesto, para evitar que la obligación quede incumplida, el Estado puede llevar a cabo, de acuerdo con la situación concreta, diversas acciones.

3. Cuando la formación del acto administrativo esté sujeta a una condición o término suspensivo y éste no se realice dentro del plazo señalado en el propio acto. 
Este libro forma parte del acervo de la Biblioteca Jurídica Virtual del Instituto de Investigaciones Jurídicas de la UNAM

4. El acto administrativo que se extingue deja de producir efectos jurídicos, lo que puede resultar dañoso para un particular que, en virtud del acto, hubiera adquirido un derecho.

5. Renuncia del interesado, cuando el acto hubiere sido dictado en exclusivo beneficio de éste y su extinción no sea en perjuicio del interés público.

6. La revocación procede sólo si la autoridad tiene facultades para determinarla; en tal caso, si una autoridad incompetente extingue un acto) al revocarlo, el particular afectado puede recurrir a los tribunales administrativos o a los federales de amparo para solicitar una reparación.

7. El procedimiento administrativo es el conjunto de formalidades y actos que, de manera directa o indirecta, determinan los requisitos que preceden al acto administrativo, para que éste sea válido y cumpla un fin específico.

8. La regulación de este procedimiento no está unificada. Depende de la materia de que se trate; así, por ejemplo, tanto la Ley Federal de Procedimiento Administrativo como el Código Fiscal de la Federación prevén procedimientos de este tipo.

9. Cuando el acto administrativo impone a los particulares alguna obligación o les produce o puede producir alguna afectación en su esfera jurídica, se pueden presentar dos supuestos.

10. La ejecución directa se puede sustituir por revocación, cuando así lo exija(el interés público, de acuerdo con la ley de la materia.

\section{Adverbios y adjetivos}

1. El reconocimiento ha sido defendido como una necesidad profundamente humana. Más aun, diversos autores consideran el reconocimiento colectivo (como) una condición indispensable para el ejercicio de los derechos individuales, pues las personas pertenecen a una cultura societal que le da significado a sus decisiones individuales.

2. Si se niega la existencia o validez de esa pertenencia, se puede afectar la propia capacidad de comportase como un agente autónomo. En las últimas décadas, América Latina ha sido testigo de lo que José Bengoa ha llamado la "emergencia indígena".

3. Se da una irrupción de diversos movimientos indígenas reclamando, en general, una nueva relación con sus Estados, basada justamente en el reconocimiento de los derechos colectivos que les corresponderían en su calidad de pueblos pre-existentes al propio Estado. Estas reivin- 
Este libro forma parte del acervo de la Biblioteca Jurídica Virtual del Instituto de Investigaciones Jurídicas de la UNAM

dicaciones indígenas han sido acogidas en el seno de la comunidad (internacional), traduciéndose primero, en el Convenio N. ${ }^{\circ} 169$ de la OlT de 1989.

4. El punto culminante de recepción de la demanda indígena en la arena internacional se dio en 2007, cuando la Asamblea General de Naciones Unidas adoptó la Declaración de Derechos de Pueblos Indígenas (DDPI). Este documento va más allá que el mencionado Convenio, reconociendo directamente que los pueblos indígenas, como cualquier otro pueblo, tiene derecho a la libre determinación, expresada en el auto-gobierno en el seno de los Estados en que habitan autonomía, con las consecuencias que ello conlleva. Por su parte, las reivindicaciones indígenas también han tenido impacto a nivel constitucional en América Latina, y también en otros países, como Canadá. ${ }^{5}$

5. La Declaración de Derechos de Pueblos Indígenas reconoce derechos a los pueblos indígenas sobre sus tierras y territorios, además de establecer mecanismos de participación política (consulta indígena), y reconocer el derecho que les asiste a ejercer un control progresivo sobre los programas de salud y educación dirigidos a ellos, entre otras cosas.

6. Diversas constituciones de la región, casi siempre emanadas de asambleas constituyentes, han incluido disposiciones que reconocen y valoran la diversidad cultural de sus respectivos países, lo que incluye, al menos implícitamente, a los pueblos indígenas.

7. Frente a la alternativa multicultural, países como Ecuador y Bolivia han optado por consagrar el carácter plurinacional del Estado. Aunque la Constitución de Ecuador de 2008 es explícita al respecto, el paradigma en esta materia es la Constitución boliviana de 2006. Ésta reconoce la existencia precolonial de los pueblos indígenas, y su derecho a la libre determinación.

\section{Verbos y adverbios}

1. Contextualmente, el dualismo epistemológico surge, en el ámbito jurídico la obra de Hans Kelsen Teoría pura del derecho, texto que sentó expresamente las bases de lo que en la doctrina se conoce como positivismo jurídico, que ha marcado fuertemente la forma de aproximación

5 De hecho, este último país, en su Ley Constitucional de 1982, reconoció la vigencia de los derechos de los indígenas (aboriginal rights) y aquellos emanados de los tratados celebrados entre aquéllos y la Corona británica (treaty rights). 
Este libro forma parte del acervo de la Biblioteca Jurídica Virtual del Instituto de Investigaciones Jurídicas de la UNAM

al estudio del derecho, aún en nuestros días, pese a la diversidad de autores e interpretaciones que sobre éste se han desarrollado ampliamente desde principios del siglo XIX, dentro de la misma corriente y fuera de ella.

2. Hans Kelsen, desde una perspectiva dualista, objetiva -y por tanto avalorativamente- del derecho, en sentido netamente neutro, establece como objeto de estudio del derecho a la norma partiendo como hecho y no como valor, lo cual implica claramente que no puedan emitirse juicios valorativamente en relación con la norma, tales como justo, injusto, bueno, malo.

3. Para delimitar el objeto de estudio de la ciencia normativamente, Kelsen distinguió, inicialmente, a las ciencias morales, dentro de la cual se encuentra la ciencia normativa, de las ciencias naturales, causales o explicativas, especialmente a partir del término de "ley", que se aplica a ambas realidades con algunas diferencias. La ley natural se aplica a la explicación de hechos reales, es una proposición explicativa, proviene del plano del ser, donde todo está definidamente sujeto al principio de causalidad.

4. Kelsen también distinguió específicamente a la ley moral de la norma jurídica, la primera se encuentra en un intermedio entre la ley natural y la norma jurídica, dejando formalmente la contraposición entre ser y deber ser en segundo plano, causa de ello es que la moral actúa autónomamente, es decir, son dictadas por el propio individuo para sí mismo o bien son aceptadas por el individuo cuando forman parte de un grupo, por eso sólo se asume válidamente o es obligatoria para aquellos que la acatan de hecho.

5. El positivismo jurídico crea un aislamiento epistemológicamente, porque se establece un dualismo que otro paradigma de la investigación social ha superado largamente, el constructivismo o interpretativismo, al señalar que no existe una separación entre el sujeto y objeto de estudio ya que estos se encuentran relacionados entre sí, otorgándole nítidamente a la ciencia una tarea interpretativa de búsqueda de significado, cuyo objetivo se da comprensivamente y no tanto la explicación y búsqueda de leyes propias del positivismo científico.

6. Incluso pospositivistas científicos ya no defienden (abiertamente) el dualismo como separación y ausencia de interferencia entre las dos realidades. Se tiene precisamente conciencia de los elementos de perturbación que introduce en el objeto de estudio el sujeto que lo estudia y de la reacción que se puede derivarse nítidamente de ellos. La objeti- 
Este libro forma parte del acervo de la Biblioteca Jurídica Virtual del Instituto de Investigaciones Jurídicas de la UNAM

vidad del conocimiento sigue siendo el criterio de referencia, pero sólo se puede lograr aproximadamente.

7. Metodológicamente, porque considerar al derecho sólo como "norma", en un plano ideal, de abstracción, anula directamente otras dimensiones como el hecho social que permitirían singularmente la aplicación de métodos sociales para aplicar cuantitativa y cualitativamente.

\section{Oraciones sustantivas}

\section{Oraciones sustantivas-sujeto}

1. La técnica es psicoanalítica. Es decir, es inútil si no se recuerdan las modificaciones de la técnica.

2. Los recursos genéticos son exponentes tangibles de la biodiversidad presente en nuestro planeta.

3. La expansión tecnológica ha permitido una valorización de los recursos genéticos y una creciente demanda.

4. Los países proveedores de recursos genéticos son los países que se encuentran en desarrollo.

5. Los recursos genéticos constituyen una importante fuente económica para muchas naciones en vías de desarrollo.

\section{Oraciones sustantivas-complemento directo}

1. Es obvio que los países usuarios de recursos genéticos son los países desarrollados.

2. Se señala que el artículo 15 del Convenio sobre Diversidad Biológica es la principal normativa internacional que rige el acceso a los recursos genéticos.

3. Se reconoce que existe la soberanía de los Estados sobre sus recursos naturales.

4. Se conceptúa que un recurso genético es todo aquel constituido por el ADN (material genético) y puede tener un valor real o potencial.

5. Se indica que una forma de vulnerar la propiedad de los recursos genéticos y el reparto justo de los beneficios comerciales es mediante la biopiratería. 
Este libro forma parte del acervo de la Biblioteca Jurídica Virtual del Instituto de Investigaciones Jurídicas de la UNAM

\section{Oraciones sustantivas-complemento indirecto}

1. La tesis, como trabajo intelectual, es una forma de investigación, esto es, un proceso sistemático de ejercicios analíticos y sintéticos que se dan entre un sujeto y un objeto en cuya relación se busca alcanzar un producto científico nuevo o diferente.

2. La curiosidad es una inquietud que surge en el estudiante y que lo predispone para fijar su mente en algún atributo, característica o institución de un objeto determinado.

3. La observación es otra etapa de la investigación y supone una revisión general de la bibliografía sobre el objeto de la curiosidad a disposición del estudiante y las discusiones preliminares con maestros especializados en el tema.

4. La abstracción es la etapa clave de toda tesis o investigación, y en ella el estudiante o el investigador proyecta senderos posibles, variables a verificar, pistas de acercamiento, que serán la base de toda investigación o tesis, y sus posibles productos o metas científicas.

5. La comprobación es la etapa en que el estudiante debe saber recolectar la información pertinente para validar las conjeturas que se planteó en relación con el objeto, materia de su investigación o tesis.

\section{Oraciones sustantivas-agente}

1. Oración compuesta: Hay una estrecha vinculación entre el desarrollo y la tecnología, ya que ésta constituye un prerrequisito para alcanzar aquél.

2. Oración compuesta: La carencia de recursos financieros, aunada a la urgencia de resolver necesidades básicas de la población, lleva a postergar o hasta a abandonar la investigación y el desarrollo tecnológicos.

3. Oración compuesta: México es un país en desarrollo con enormes carencias todavía no resueltas.

4. Oración compuesta: Los países industrializados otorgan sumas crecientes a la investigación tecnológica.

5. Oración compuesta: Existe una estrecha vinculación entre el desarrollo y la tecnología, ya que ésta constituye un prerrequisito para alcanzar aquél. 
Este libro forma parte del acervo de la Biblioteca Jurídica Virtual del Instituto de Investigaciones Jurídicas de la UNAM

\section{BIBLIOGRAFÍA}

ÁlvareZ, Graciela, "La enseñanza del discurso jurídico oral y escrito en la carrera de la abogacía", Academia, Revista sobre Enseñanza del Derecho, Buenos Aires, año 6, núm. 11, 2008.

ARriAga CAmpos, Ricardo, Comprensión y Redacción de textos de economía, México, Facultad de Economía de la UNAM, 2013.

BazermnA, Charles, "Why Activity Sistems are Literacy Genres Part of?", Readerly, Writerly Texts, Essays in Literary, Composition, and Pedagogical Theory, vol. 10, núm. 1 y 2, 2003.

Bernardo, José, Estrategias de aprendizaje. Para aprender más y mejor, Madrid, Ediciones RIALP.

BoBBIo, Norberto, El positivismo jurídico. Lecciones de filosofía del derecho reunidas por el doctor Nello Mora, Madrid, Debate, 1998.

CÁRdENAS GRACIA, Jaime, Introducción al estudio del derecho, México, UNAM, 2009.

CARLINo, Paula, Escribir, leer y aprender en la Universidad. Una introducción a la alfabetización académica, Buenos Aires, Fondo de Cultura Económica, 2012.

CARlino, Paula, "Alfabetización académica diez años después", Revista Mexicana de Investigación Educativa, vol. 18, núm. 57, 2013.

CorbetTA, P., Metodología y técnicas de investigación social, Madrid, McGraw Hill, 2007.

Elgueta, María Francisca (ed.), Actas Primer Congreso Nacional de Pedagogía Universitaria y Didáctica del Derecho, Santiago de Chile, Facultad de Derecho de la Universidad de Chile, 2012.

ELGUETA, Francisca y PALMA, Eric, La investigación en ciencias sociales y jurídicas, Santiago de Chile, Facultad de Derecho de la Universidad de Chile, 2010.

HABERMAS, Jürgen, Teoría de la acción comunicativa: complementos y estudios previos, Buenos Aires, Cátedra, 1997.

HAFNER, Annette, La protección de los derechos económicos, sociales y culturales en la Constitución. Derecho comparado, Santiago de Chile, Biblioteca del Congreso Nacional de Chile, 2014. 
Este libro forma parte del acervo de la Biblioteca Jurídica Virtual del Instituto de Investigaciones Jurídicas de la UNAM

Kelsen, Hans, Problemas capitales del derecho y del Estado, México, Porrúa, 1987.

LÓPEZ HERNÁNDEZ, José, Introducción histórica a la filosofía del derecho contemporánea, España, Universidad de Murcia, 2005.

Manual del Justiciable. Elementos de teoría general del proceso, México, Suprema Corte de Justicia de la Nación, 2005.

Manual del Justiciable. Materia administrativa, México, Suprema Corte de Justicia de la Nación, 2005.

MARTIN, J. R. y RoSE, David, "Interacting with text. The role of dialogue in learning to read and write", Foreign Studies Journal, Beijing, 2007.

Montolío, Estrella, "La situación del discurso jurídico escrito español. Estado de la cuestión y algunas propuestas de mejora", en Hacia la modernización del discurso jurídico, Barcelona, Ediciones y Publicaciones de la Universidad de Barcelona, 2011.

Moreno, Mariano, "Sobre la libertad de escribir", Academia, Revista sobre enseñanza del derecho, Buenos Aires, año 5, núm. 9, 2007.

Munguía ZatARAin, Irma et al., Gramática lengua española. Reglas y ejercicios, México, Larousse, 2015.

NAVARRO, Federico, "Trayectorias de formación en lectura y escritura disciplinar en carreras universitarias de humanidades. Diagnóstico y propuesta institucional", Revista Mexicana de Investigación Educativa, vol. 18, núm. 58, 2013.

PARODI, Giovanni (ed.), Alfabetización académica y profesional en el siglo XXI: leer y escribir desde las disciplinas, Santiago de Chile, Grupo Editorial Planeta, 2010.

PARoDI, Giovanni, Géneros académicos y géneros profesionales. Accesos discursivos para saber y hacer, Valparaíso, Ediciones Universitarias de la Pontificia Universidad Católica de Valparaíso, 2008.

PÉREZ Perdomo, Rogelio, "Educación jurídica, abogados y globalización en América Latina", 2014, disponible en: http://www.sistemasjudi ciales.org/content/jud/archivos/notaarchivo/428.pdf.

VALADÉs, Diego, La lengua del derecho y el derecho de la lengua. Discurso de ingreso a la Academia Mexicana de la Lengua, México, UNAM-Academia Mexicana de la Lengua, 2010.

WITKER VELÁSquEZ, Jorge, Derechos de las personas extranjeras, MéxiCO, INHERM-UNAM, 2016.

WITKER VELÁSQUEZ, Jorge, El constitucionalismo económico de la carta de Querétaro 1917-2017, México, LXIII Legislatura de la H. Cámara de Diputados, 2016, t. II. 
WiTKER VelÁsquez, Jorge, Introducción al derecho económico, 12a. ed., México, Publilex, 2016.

WitKER VELÁSQUEZ, Jorge, Juicios orales y derechos humanos, México, UNAM, 2016.

WITKER VELÁSQUEZ, Jorge, La investigación jurídica. Bases para la tesis de grado en derecho, 3a. ed., México, Publilex, 2016.

WITKER VELÁSQUEZ, Jorge y LARIOS, Rogelio, Metodología jurídica, México, McGraw Hill, 1997. 
Competencia lectoras y narrativas para el derecho, editado por el Instituto de Investigaciones Jurídicas de la UNAM, se terminó de imprimir el 25 de abril de 2018 en los talleres de Cromo Editores, S. A. de C. V., Miravalle 703, colonia Portales, delegación Benito Juárez, 03570 Ciudad de México, tel. 5674 2137. Se utilizó tipo Trade Gothic LT Std de 11 y 9 puntos. En esta edición se empleó papel cream book de 70 × 95 de 60 gramos para los interiores y cartulina couché de 250 gramos para los forros. Consta de 500 ejemplares (impresion offset). 
